\author{
Universidade de São Paulo \\ Instituto de Física
}

\title{
Estudo do Magnetismo de Filmes Finos Multicamadas Baseados em Ligas Níquel-Cobre e Antiferromagnetos de Anisotropia Cúbica
}

\author{
Francisco José Garanhani
}

Orientador: Prof. Dr. Daniel Reinaldo Cornejo

Dissertação apresentada ao Instituto de Física para a obtenção do título de Mestre em Ciências

Banca examinadora:

Prof. Dr. Daniel Reinaldo Cornejo (Orientador - IF - USP)

Prof. Dr. Rafael Sá de Freitas (IF - USP)

Prof $^{\mathrm{a}}$. Dr ${ }^{\mathrm{a}}$. Vitória Maria Tupinambá de Souza Barthem (IF - UFRJ)

São Paulo 


\section{FICHA CATALOGRÁFICA}

Preparada pelo Serviço de Biblioteca e Informação do Instituto de Física da Universidade de São Paulo

Garanhani, Francisco José

Estudo do magnetismo de filmes finos multicamadas baseados em ligas níquel-cobre e antiferromagnetos de anisotropia cúbica. São Paulo, 2015.

Dissertação (Mestrado) - Universidade de São Paulo. Instituto de Física. Depto. de Física dos Materiais e Mecânica.

Orientador: Prof. Dr. Daniel Reinaldo Cornejo

Área de Concentração: Laboratório de Materiais Magneticos.

Unitermos: 1. Magnetismo; 2. Filmes finos; 3. Nanociência. 
Onde houver erro, que eu leve a verdade.

atribuído a São Francisco de Assis 
$\mathcal{A}$ todas as minhas professoras e meus professores que sempre me apoiaram e reconheceram meu potencial, desde a primeira série do ensino fundamental até as mais diversas disciplinas do ensino médio, graduação e pós-graduação. 


\section{Agradecimentos}

Ao meu orientador, prof. dr. Daniel Reinaldo Cornejo, pela chance concedida na iniciação científica e paciência com meu aprendizado durante esses últimos anos.

Ao meu falecido pai, Raul, que me proporcionou o privilégio de poder me preocupar apenas com meus estudos e carreira acadêmica.

Ao meu amigo Vinícius, pelo companheirismo dentro e fora do DFMT.

Aos meus bons colegas Gerson, Karel e Fernanda, pelos vários conselhos úteis e momentos de descontração.

Aos técnicos do LMM, principalmente Renato e Sérgio, pelos consistentes tutoriais e suporte com os equipamentos.

Aos técnicos da criogenia, principalmente Vagner, pela prontidão na transferência de He para o SQUID.

Aos outros professores e colegas do LMM, pela boa convivência.

Aos meus amigos, íntimos ou não, virtuais ou presenciais, que se dispuseram a ouvir sobre meus problemas, a tentar me compreender e a me ajudar de diversas formas.

Aos meus outros colegas de graduação do IFUSP, por me fazer enxergar um mundo mais amplo, dentro e fora da Física.

À CNPq pela bolsa concedida, à CAPES pela bolsa de monitoria. 


\section{Resumo}

Neste trabalho foram estudadas as propriedades magnéticas e características estruturais de filmes finos bicamadas e multicamadas formados com $\mathrm{Ni}_{x} \mathrm{Cu}_{1-x}$ (ferromagneto, $50 \leq x \leq 90$ e níquel puro), NiO, FeMn e IrMn (antiferromagnetos). Ligas de níquel-cobre podem ser classificadas como fracamente ferromagnéticas. Ferromagnetismo fraco gera efeitos únicos em propriedades de transporte eletrônico, junções com supercondutores e sistemas de exchange bias. Sendo uma solução sólida extremamente simples, diversas propriedades do $\mathrm{NiCu}$ dependem linearmente da estequiometria da liga.

Os filmes finos foram depositados via magnetron sputtering em substratos monocristalinos de $\mathrm{Si}(100)$ a temperatura ambiente. A estrutura cristalina foi caracterizada por difração de raios-X e a morfologia foi analisada por retroespalhamento Rutherford.

Propriedades magnéticas foram medidas com um SQUID a temperaturas entre $5 \mathrm{~K}$ e $300 \mathrm{~K}$ (curvas ZFC/FC e de magnetização a diferentes temperaturas) e com um VSM a temperatura ambiente (curvas de magnetização em diferentes ângulos no plano do filme). As amostras com $\mathrm{Ni}_{x} \mathrm{Cu}_{1-x}$ mais ricas em cobre apresentam os maiores campos coercivo e de exchange bias a baixas temperaturas, mas os menores em altas temperaturas, geralmente respeitando as temperaturas de bloqueio indicadas nas curvas ZFC/FC.

$\mathrm{O}$ acoplamento na interface das bicamadas $\mathrm{NiO} / \mathrm{Ni}_{x} \mathrm{Cu}_{1-x}$ foi muito reduzido em temperaturas mais altas, não sendo observada anisotropia unidirecional nas medidas a temperatura ambiente. As constantes de interação $\mathrm{J}_{\text {int }}$ foram calculadas para as bicamadas $\mathrm{Ni}_{x} \mathrm{Cu}_{1-x} / \mathrm{FeMn}$ e $\mathrm{Ni}_{x} \mathrm{Cu}_{1-x} / \mathrm{IrMn}$ a $5 \mathrm{~K}$ e temperatura ambiente. O sistema $\mathrm{Ni} / \mathrm{IrMn}$ apresentou o maior valor dessa constante em ambas as temperaturas, diminuindo muito com o acréscimo de cobre na camada $\mathrm{Ni}_{x} \mathrm{Cu}_{1-x}$. O sistema $\mathrm{Ni}_{90} \mathrm{Cu}_{10} / \mathrm{FeMn}$ apresentou os maiores valores em ambas as temperaturas (excluindo o de níquel puro), comparável até com $\mathrm{Ni} / \mathrm{IrMn}$ no caso de $5 \mathrm{~K}$. Esse comportamento pode ser explicado por uma maior afinidade entre as estruturas do $\mathrm{FeMn}$ e $\mathrm{Ni}_{x} \mathrm{Cu}_{1-x}$ na direção [111], o que favorece a formação da face (111) no FeMn, mais consistentemente do que no IrMn.

Nenhuma das multicamadas estudadas se comportou como uma válvula de spin, mas foi observado um aumento na coercividade e supressão do exchange bias, provavelmente por causa de acoplamento entre as camadas ferromagnéticas. 


\section{Abstract}

In this work, a study of magnetic properties and structural characteristics of bilayered and multilayered thin films was carried out. These films were made with $\mathrm{Ni}_{x} \mathrm{Cu}_{1-x}$ (ferromagnet, $50 \leq x \leq 90$ and pure nickel) and $\mathrm{NiO}$, FeMn or IrMn as antiferromagnets. Nickel-copper alloys may be classified as weakly ferromagnetic. Weak ferromagnetism generates unique effects in electron transport, junctions with superconductors and exchange bias systems. Being an extremely simple solid solution, many properties of the $\mathrm{NiCu}$ alloy have a linear dependence with its stoichiometry.

The thin films were deposited via magnetron sputtering on Si (100) monocrystalline substracts at room temperature. The crystalline structure was characterized by X-ray diffraction, while the morphology was analyzed by Rutherford back-scattering.

Magnetic properties were measured by SQUID at temperatures between $5 \mathrm{~K}$ and $300 \mathrm{~K}$ (ZFC/FC curves and magnetization curves at different temperatures) and by VSM at room temperature (magnetization curves at varying angles at the film plan). The samples with copper-richer $\mathrm{Ni}_{x} \mathrm{Cu}_{1-x}$ showed the largest coercive and exchange bias fields in lower temperatures, but the lowest ones in higher temperatures, usually following the blocking temperatures denoted by the $\mathrm{ZFC} / \mathrm{FC}$ curves.

The interfacial coupling in $\mathrm{NiO} / \mathrm{Ni}_{x} \mathrm{Cu}_{1-x}$ was very weak in higher temperatures, not showing unidirectional anisotropy at room temperature. The $\mathrm{J}_{\text {int }}$ exchange interaction constants were calculated for the $\mathrm{Ni}_{x} \mathrm{Cu}_{1-x} /$ FeMn and $\mathrm{Ni}_{x} \mathrm{Cu}_{1-x} / \mathrm{IrMn}$ bilayers at $5 \mathrm{~K}$ and room temperature. $\mathrm{Ni} / \mathrm{IrMn}$ had the largest values at both temperatures, heavily decreasing with the copper content in the $\mathrm{Ni}_{x} \mathrm{Cu}_{1-x}$ layer. $\mathrm{Ni}_{90} \mathrm{Cu}_{10} / \mathrm{FeMn}$ showed the largest values at both temperatures (except for the pure $\mathrm{Ni}$ sample), even reaching the values of $\mathrm{Ni} / \mathrm{IrMn}$ at $5 \mathrm{~K}$. This behavior may be explaned by a greater matching between the FeMn and $\mathrm{Ni}_{x} \mathrm{Cu}_{1-x}$ crystalline structures on the [111] direction, which favors the formation of the (111) FeMn face more consistently than the corresponding IrMn face.

All the studied multilayers showed no spin valve behavior, but an increased coercivity and supressed exchange bias were observed, probably because of coupling between the ferromagnetic layers. 


\section{Lista de Figuras}

1.1 Lei de Moore para semicondutores (curva DRAM) e o análogo para mídias de gravação magnética (curva HDD). [1] . . . . . . . . . . . . . . . . . .

1.2 Curvas de magnetização típicas para um diamagneto (a) e um paramagneto (b). Note que a curva sigmoidal do paramagneto atinge um limite de magnetização (o material é saturado quando todos os momentos atômicos estão alinhados paralelamente), enquanto, a princípio, não há limite para a indução magnética no diamagneto. . . . . . . . . . . . . . . . . . . .

1.3 Curvas de magnetização típicas para um ferromagneto (a) e antiferromagneto (b). A linha mais clara em (a) é uma curva de magnetização inicial, partindo de um estado desmagnetizado. A curva vermelha em (b) reflete o caso de campo magnético aplicado na direção da magnetização das subredes: a rede favorecida em cada região se comporta como um ferromagneto. A curva azul em (b) reflete o caso mais geral, onde o campo aplicado perturba o equilíbrio das redes, lembrando a curva de um paramagneto. .

1.4 Curva de magnetização típica de um sistema com interface FM/AFM. $\mathrm{H}_{E B}$ é o campo de exchange bias. O contato também gera uma aumento da coercividade do ferromagneto. $\mathrm{H}$ é positivo quando paralelo ao campo da anisotropía unidirecional induzida. . . . . . . . . . . . . . .

1.6 Diagrama de fase da liga FeMn. [15]. . . . . . . . . . . . . . . . . 10

1.7 Configuração de spin 3Q: os spins da célula unitária apontam para o centro do tetraedro descrito pelas posições dos átomos - ou seja, para as direções

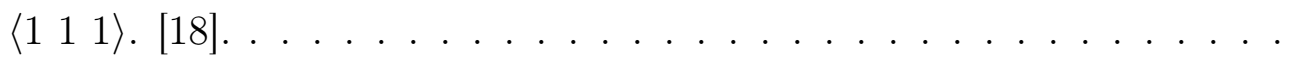

1.8 Possíveis planos atômicos do modelo $\left\langle\begin{array}{lll}1 & 1 & 1\end{array}\right\rangle$. [22] . . . . . . . . . . . 
1.9 Estrutura cristalina de um AFM tipo II. Para o NiO, as esferas menores cinzentas representam íons de oxigênio enquanto as esferas maiores representam íons de níquel (uma cor para cada orientação de spin, a direção das setas não representando a direção real dos momentos magnéticos). A deformação romboédrica é denotada com o ângulo $\alpha \neq 90^{\circ}\left(\alpha=90,1^{\circ}\right)$. [30]. 13

1.10 Diminuição da fração de regiões acopladas paralelamente ao eixo fácil. Valores de $H_{E B}$ cada vez menores são obtidos em medidas com campo aplicado na direção do eixo fácil após cada acréscimo na temperatura do tratamento térmico que induz acoplamento perpendicular àquela direção.

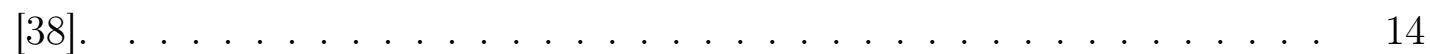

1.11 Dependência do $H_{E B}$ de bicamadas $\operatorname{Py}(30 \mathrm{~nm}) / \operatorname{AFM}(50 \mathrm{~nm})$ em relação à temperatura, 3 materiais diferentes para AFM, todos depositados por sputtering. [39] . . . . . . . . . . . . . . . . . . .

1.12 Dependência do $H_{E B}$ de válvulas de spin $\mathrm{NiFe}(5,1 \mathrm{~nm}) / \mathrm{Co}(2,2 \mathrm{~nm}) / \mathrm{Cu}(2,2$ $\mathrm{nm}) / \mathrm{Co}(2.7 \mathrm{~nm}) / \mathrm{NiO}(10 \mathrm{~nm})$ em relação à pressão parcial de $O_{2}$ durante a deposição de níquel. [41]. . . . . . . . . . . . . . . . . . . .

1.13 Dependência do $H_{E B}$ de bicamadas $\mathrm{Py}(40 \mathrm{~nm}) / \mathrm{NiO}(100 \mathrm{~nm})$ em relação à temperatura com diversas pressões de argônio para a deposição via sputtering do NiO. [42]. . . . . . . . . . . . . . . . . . . 16

1.14 Diagrama de fases Ir-Mn.[44]. . . . . . . . . . . . . . . . . 17

1.15 Intensidade do pico (l 11 1) em função da concentração de Ir na liga. [14].

1.16 Variação do tamanho do pico (l 111 ) em difratogramas de raios-x e de $H_{E B}$ com tensão e corrente utilizados na deposição de IrMn em amostras $\mathrm{Si} / \mathrm{Ta}(6 \mathrm{~nm}) / \mathrm{Py}(5 \mathrm{~nm}) / \operatorname{IrMn}(14 \mathrm{~nm}) / \mathrm{Ta}(7 \mathrm{~nm}) . \quad[46] . . . . .$.

1.17 Curva de magnetização apresentando duplo exchange bias. [52]

1.18 Diagrama de fases Ni-Cu. Inclui a transição ferromagnética-paramagnética e um gap de miscibilidade calculado pelo comportamento em uma liga ternária com $\mathrm{Cr}$ e associado à formação de aglomerados $\left(\alpha_{1}+\alpha_{2}\right)$, mas aindã não foi observado experimentalmente. [58]. . . . . . . . . . . . . . 
1.19 Variação de $\mathrm{T}_{C}$ com a estequiometria da liga. Símbolos diferentes para autores diferentes. [58]. . . . . . . . . . . . . . . . . . .

1.20 Variação de $\mathrm{H}_{C}$ e $\chi_{0}$ com a estequiometria da liga em casos com tratamento térmico e resfriado. A coercividade no caso resfriado é uma exceção ao padrão observado.[61]

1.21 Acima, singularidades no máximo de variação da resistência de Ni (a)[65] e curvas da resistência para diferentes concentrações de cobre em $\mathrm{NiCu}$ (b)[62] em função da temperatura, amostras bulk. Logo abaixo, filmes finos da liga $\mathrm{Ni}_{58} \mathrm{Cu}_{42}$, com um mínimo da resistência na temperatura de transição magnética.[64] . . . . . . . . . . . . . . . . . . .

1.22 Comparação de bicamadas convencionais com não-convencionais $\left(\mathrm{T}_{C}<\right.$ $\left.\mathrm{T}_{N}\right)$ : dependência de $\mathrm{H}_{E B}$ e $\mathrm{H}_{C}$ com a temperatura para $\mathrm{Py} / \mathrm{CoO}(30$ nm) (a); dependência de $\mathrm{H}_{E B}$ (b) e $\mathrm{H}_{C}$ (c) com a temperatura para $\left[\mathrm{Fe}_{0,1} \mathrm{Ni}_{0,9}\right]_{8} \mathrm{~B}_{2}(90 \mathrm{~nm}) / \mathrm{CoO}(30 \mathrm{~nm}) .[66] \ldots \ldots \ldots \ldots$

1.23 Influência da temperatura e campo aplicado no tratamento térmico em bicamadas $\mathrm{NiO}(50 \mathrm{~nm}) / \mathrm{Ni}_{75} \mathrm{Cu}_{25}$. [67].

2.1 Esquema de deposição via magnetron sputtering. Íons do plasma (5) confinados no campo magnético (4) de ímãs permanentes (2) são acelerados contra o alvo (3) por um eletrodo (1). No detalhe, a ejeção de átomos do alvo pelos íons incidentes. Os átomos são então depositados no substrato $(6)$

2.2 Esquema de difração de raios-x. Adaptado de [69].

3.1 Amostras 1A $(x=50, d=50), 1 A-I I(x=50, d=30), 1 B(x=70, d=30)$ e $1 \mathrm{C}$ $(\mathrm{x}=90, \mathrm{~d}=30)$.

3.2 À esquerda: bicamadas $2 \mathrm{~A}(\mathrm{x}=50), 2 \mathrm{~B}(\mathrm{x}=70), 2 \mathrm{C}(\mathrm{x}=90)$ e $2 \mathrm{D}(\mathrm{x}=100$, ou seja, níquel puro). À direita: multicamadas $2 \mathrm{E}(\mathrm{x}=50), 2 \mathrm{~F}(\mathrm{x}=70), 2 \mathrm{G}$

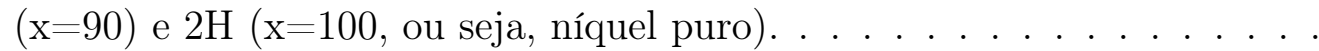


3.3 À esquerda: bicamadas $3 \mathrm{~A}(\mathrm{x}=50), 3 \mathrm{~B}(\mathrm{x}=70), 3 \mathrm{C}(\mathrm{x}=90)$ e $3 \mathrm{D}(\mathrm{x}=100$, ou seja, níquel puro). À direita: multicamadas $3 \mathrm{E}(\mathrm{x}=50), 3 \mathrm{~F}(\mathrm{x}=70), 3 \mathrm{G}$ $(\mathrm{x}=90)$ e $3 \mathrm{H}(\mathrm{x}=100$, ou seja, níquel puro $) \ldots \ldots . . . . . . . .40$

3.4 Espectro de RBS para a bicamada $\mathrm{Ni}_{90} \mathrm{Cu}_{10} / \mathrm{Ir}-\mathrm{Mn}$ e válvula $\mathrm{Ni}_{50} \mathrm{Cu}_{50} / \mathrm{FeMn}$. Os pontos vermelhos são esperimentais, interligados para facilitar a visão. As linhas coloridas são simulações ajustadas de cada elemento, com a azul sendo a curva resultante. . . . . . . . . . . . . . . . . . . . . . .

3.5 Difração de raios-x com incidência a baixo ângulo de cada conjunto de amostras: $\mathrm{Ni}_{x} \mathrm{Cu}_{1-x} / \mathrm{Cu}(\mathrm{a}), \mathrm{NiO} / \mathrm{Ni}_{x} \mathrm{Cu}_{1-x} / \mathrm{Cu}(\mathrm{b}), \mathrm{Ni}_{x} \mathrm{Cu}_{1-x} / \mathrm{FeMn} / \mathrm{Cu}$ (c) e $\mathrm{Ni}_{x} \mathrm{Cu}_{1-x} / \mathrm{IrMn} / \mathrm{Cu}(\mathrm{d}) . \ldots \ldots \ldots \ldots$

3.6 Curvas ZFC/FC para as bicamadas do grupo 1. . . . . . . . . . . .

3.7 Curvas de magnetização e $\mathrm{H}_{C}$ e $\mathrm{H}_{E B}$ em função de $\mathrm{T}$ para bicamadas $\mathrm{NiO} / \mathrm{Ni}_{50} \mathrm{Cu}_{50} / \mathrm{Cu}$. Em (a) e (c). A espessura da camada $\mathrm{Ni}_{50} \mathrm{Cu}_{50}$ é de $50 \mathrm{~nm}$ em $(\mathrm{a})$ e $(\mathrm{b}), 30 \mathrm{~nm}$ em $(\mathrm{c})$ e $(\mathrm{d}) \ldots \ldots \ldots \ldots . \ldots . \ldots 46$

3.8 Curvas de magnetização e $\mathrm{H}_{C}$ e $\mathrm{H}_{E B}$ em função de $\mathrm{T}$ para bicamadas $\mathrm{NiO} / \mathrm{Ni}_{70} \mathrm{Cu}_{30}[30 \mathrm{~nm}] / \mathrm{Cu} \ldots \ldots \ldots \ldots . \ldots . \ldots . \ldots . \ldots$

3.9 Curvas de magnetização e $\mathrm{H}_{C}$ e $\mathrm{H}_{E B}$ em função de $\mathrm{T}$ para bicamadas $\mathrm{NiO} / \mathrm{Ni}_{90} \mathrm{Cu}_{10} / \mathrm{Cu}$

3.10 Ciclos de histerese da bicamada $\mathrm{NiO} / \mathrm{Ni}_{70} \mathrm{Cu}_{30} / \mathrm{Cu}$, com diferença de 180 graus entre a orientação das duas cores. . . . . . . . . . . . . . . . .

3.11 Curvas ZFC/FC das bicamadas $\mathrm{Ni}_{x} \mathrm{Cu}_{1-x} / \mathrm{FeMn} / \mathrm{Cu}$ com $\mathrm{x}=50$ (a), $\mathrm{x}=70$ (b) e $\mathrm{x}=90$ (c).

$3.12 \mathrm{H}_{C}$ e $\mathrm{H}_{E B}$ em função da temperatura para bicamadas $\mathrm{Ni}_{x} \mathrm{Cu}_{1-x} / \mathrm{FeMn} / \mathrm{Cu}$ : $\mathrm{x}=50$ (a), $\mathrm{x}=70$ (b), $\mathrm{x}=90$ (c) e $\mathrm{x}=100$ (d). A cor vermelha dos dados em (c) se refere a uma tentativa de tratamento térmico da amostra dentro do SQUID após as medidas usuais, como descrito na seção 2.4. . . . . . . . . 
3.13 Ciclos de histerese da bicamada 2C. A medida orientada em 0 graus (cor laranja) corresponde aproximadamente ao maior valor de $\mathrm{H}_{E B}$ (associado ao eixo mais longo das amostras retangulares). Medida em 180 graus (rotacionada no plano do filme) em preto. À direita, detalhe para mostrar a histerese. . . . . . . . . . . . . . . . . . . . .

$3.14 \mathrm{H}_{C}$ e $\mathrm{H}_{E B}$ em função da direção do campo aplicado em relação a uma direção específica para bicamadas 2C (a) e 2D (b). 0 graus corresponde aproximadamente ao maior valor de $\mathrm{H}_{E B}$ (associado ao eixo mais longo das amostras retangulares). Ciclos extremamente ruidosos dificultam muito os ajustes das derivadas na outras amostras do grupo. . . . . . . . . . . .

3.15 Curvas ZFC/FC das bicamadas $\mathrm{Ni}_{x} \mathrm{Cu}_{1-x} / \mathrm{IrMn} / \mathrm{Cu}$ com $\mathrm{x}=50$ (a) e $\mathrm{x}=70$

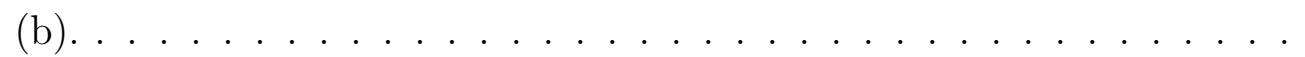

$3.16 \mathrm{H}_{C}$ e $\mathrm{H}_{E B}$ em função da temperatura para bicamadas $\mathrm{Ni}_{x} \mathrm{Cu}_{1-x} / \mathrm{IrMn} / \mathrm{Cu}$ : $\mathrm{x}=50(\mathrm{a}), \mathrm{x}=70$ (b), $\mathrm{x}=90$ (c) e $\mathrm{x}=100(\mathrm{~d}) \ldots \ldots \ldots \ldots$

$3.17 \mathrm{H}_{C}$ e $\mathrm{H}_{E B}$ em função da direção do campo aplicado em relação a uma direção específica para bicamadas $\mathrm{Ni}_{x} \mathrm{Cu}_{1-x} / \mathrm{IrMn} / \mathrm{Cu}$. 0 graus corresponde aproximadamente ao maior valor de $\mathrm{H}_{E B}$ (associado ao eixo mais longo das amostras retangulares). Ciclos extremamente ruidosos dificultam muito os ajustes das derivadas nas outras amostras. . . . . . . . . . . .

3.18 Medidas no SQUID para as multicamadas do grupo 2. Nos gráficos da direita, foram incluídas as medidas $\mathrm{H}_{C} \mathrm{x} \mathrm{T}$ das bicamadas correspondentes. 61

$3.19 \mathrm{H}_{C}$ e $\mathrm{H}_{E B}$ em função da direção do campo aplicado em relação a uma direção específica para multicamadas $2 \mathrm{G}$ (a) e $2 \mathrm{H}$ (b). 0 graus corresponde aproximadamente ao maior valor de $\mathrm{H}_{E B}$ (associado ao eixo mais longo das amostras retangulares). . . . . . . . . . . . . . .

3.20 Medidas no SQUID para as multicamadas do grupo 3. Nos gráficos da direita, foram incluídas as medidas $\mathrm{H}_{C} \mathrm{x} \mathrm{T}$ das bicamadas correspondentes. 63 
$3.21 \mathrm{H}_{C}$ e $\mathrm{H}_{E B}$ em função da direção do campo aplicado em relação a uma direção específica para multicamadas $3 \mathrm{G}$ (a) e $3 \mathrm{H}$ (b). 0 graus corresponde aproximadamente ao maior valor de $\mathrm{H}_{E B}$ (associado ao eixo mais longo das

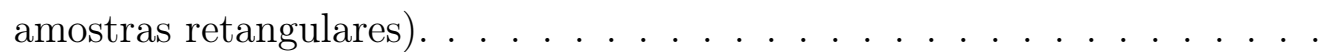

3.22 Anisotropia das curvas de magnetização para a bicamada $\mathrm{Ni} / \operatorname{IrMn}\left(\theta=0^{\circ}\right.$ em bege, $180^{\circ}$ em preto, $90^{\circ}$ em cinza). . . . . . . . . . 


\section{Lista de Tabelas}

1.1 Exemplos de sistemas de GMR: as primeiras tricamadas e multicamadas, a primeira válvula de spin com a composição típica da atualidade, o maior valor de GMR obtido nesses tipos de sistemas, uma aplicação usual. . . .

2.1 Parâmetros de deposição para cada alvo. As camadas de $\mathrm{NiCu}$ foram obtidas por co-deposição dos alvos de níquel e cobre, as demais camadas foram obtidas por deposição do alvo já na estequiometria desejada. . . .

3.1 Estequiometria e espessuras encontradas nas bicamadas através do ajuste da simulação do SIMNRA sobre os espectros de RBS. . . . . . . . . . . .

3.2 Parâmetros nas principais direções de $\mathrm{Ni}_{x} \mathrm{Cu}_{1-x}$ obtidos com os difratogramas de raios-x. As letras (a), (b), (c) e (d) das camadas de IrMn correspondem àquelas usadas em bicamadas com ordem crescente em quantidade de níquel, logo abaixo de cada uma. . . . . . . . . . . . . . .

3.3 Constantes de troca das bicamadas a 5K. Algumas amostras* possuem incerteza apenas na área, já que o ajuste nas derivadas das curvas $\mathrm{MxH}$ não foi possível (nesses casos, $\mathrm{H}_{E B}$ foi estimado graficamente). . . . . . . 58

3.4 Constantes de troca das bicamadas em temperatura ambiente, via VSM. 


\section{Sumário}

1 Introdução 1

1.1 Contextualização . . . . . . . . . . . . . . . . . . . . . 1

1.2 Fundamentos . . . . . . . . . . . . . . . . . . . . . 2

1.2.1 Ordenamento Magnético . . . . . . . . . . . . . . 2

1.2.2 Exchange Bias . . . . . . . . . . . . . . . . . 5

1.2.3 Válvulas de Spín . . . . . . . . . . . . . . . . . . . . . . . . . . . 7

1.3 Antiferromagnetos de Anisotropia Cúbica . . . . . . . . . . . . . 9

1.3.1 Ferro-Manganês . . . . . . . . . . . . . . . . . . . . . . 10

1.3.2 Óxido de Níquel . . . . . . . . . . . . . . . . . . . . 13

1.3.3 Irídio-Manganês . . . . . . . . . . . . . . . . . . . . . . . 17

1.4 Ferromagnetismo Fraco . . . . . . . . . . . . . . . . . . . . . 21

1.4.1 Níquel-Cobre . . . . . . . . . . . . . . . . 22

1.5 Sistemas $\mathrm{NiCu} / \mathrm{AFM}$ cúbico . . . . . . . . . . . . . . . . 26

1.6 Motivação . . . . . . . . . . . . . . . . . . . . . . . . . . . . . 29

2 Descrição Experimental $\quad 30$

2.1 Produção de Amostras . . . . . . . . . . . . . . . . . . . . . . . 30

2.2 Caracterização Estrutural . . . . . . . . . . . . . . . . 32

2.2 .1 Difração de Raios-X . . . . . . . . . . . . . . . . . . . . . 32

2.2.2 Retroespalhamento Rutherford . . . . . . . . . . . . . . . 34 
2.3 Medidas de Magnetização . . . . . . . . . . . . . . . . 35

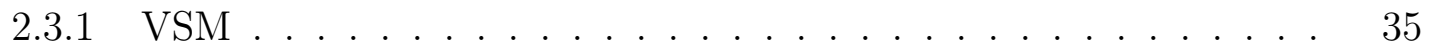

$2.3 .2 \quad$ SQUID . . . . . . . . . . . . . . . . . . . . 36

2.4 Tratamentos Térmicos . . . . . . . . . . . . . . . . 37

$\begin{array}{lll}3 & \text { Resultados } & 38\end{array}$

3.1 Descrição das Amostras . . . . . . . . . . . . . . . . . . . . 38

3.2 Análise Estrutural . . . . . . . . . . . . . . . . . . . . . . . . . 42

3.3 Propriedades Magnéticas . . . . . . . . . . . . . . . . . . 45

3.3.1 Bicamadas .......................... 45

3.3.2 Multicamadas . . . . . . . . . . . . . . . . . . 61

3.3.3 Exchange Bias Duplo . . . . . . . . . . . . . . 65

$\begin{array}{lll}4 & \text { Conclusão } & 67\end{array}$

4.1 Discussão . . . . . . . . . . . . . . . . . . . . . . . . 67

4.2 Perspectivas . . . . . . . . . . . . . . . . . . . 69 


\section{Capítulo 1}

\section{Introdução}

\subsection{Contextualização}

Nas últimas décadas, a capacidade de armazenamentos de dados em discos rígidos tem praticamente dobrado a cada ano[1], como pode ser visualizado na figura 1.1. Com bits cada vez menores, a capacidade de distingüir campos magnéticos cada vez mais sutis também precisou crescer, o que foi só possível graças a propriedades de filmes finos.

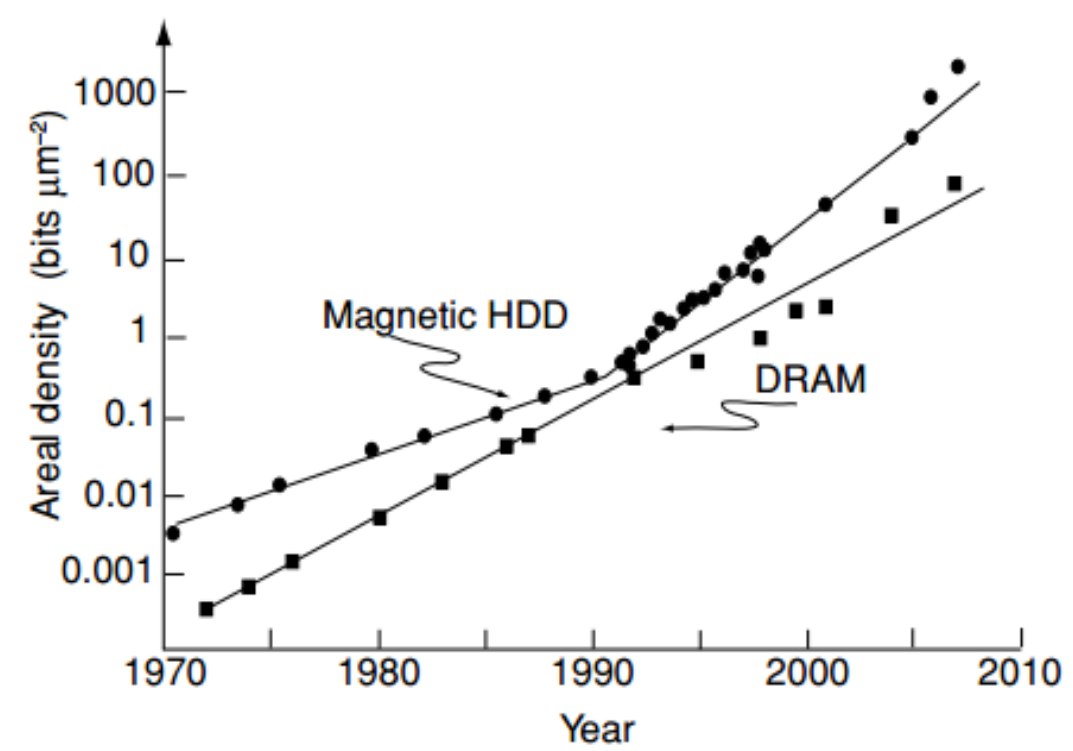

Figura 1.1: Lei de Moore para semicondutores (curva DRAM) e o análogo para mídias de gravação magnética (curva HDD). [1].

Descoberta em 1988 por Albert Fert et al[2] em um sistema de filmes finos multicamadas consolidado por Peter Grünberg et al[3], a magnetorresistência gigante (GMR) consiste em um aumento significativo (0,5 a 100\%) da resistividade elétrica de um sistema com a variação do campo magnético a que ele está submetido. Essa mudança abrupta da resistividade sob uma leve variação do campo magnético foi o que permitiu a leitura de bits cada vez menores nos discos rígidos a partir da década de 1990 e rendeu a 
ambos o Prêmio Nobel de Física em 2007.

Atualmente, uma das tecnologias mais promissoras para o armazenamento de dados é a memória de acesso aleatório magnetorresistiva (MRAM), que, ao contrário das RAM atuais, é não-volátil. O princípio de armazenamento vem da magnetorresistência de tunelamento (TMR), que lembra o da GMR: estados de magnetização diferentes implicam em valores de resistência elétrica diferentes. A adoção de aplicações tão valorizadas desses fenômenos tem gerado um grande interesse no estudo de filmes finos multicamadas.

\subsection{Fundamentos}

\subsubsection{Ordenamento Magnético}

Classicamente, a resposta de um material a um campo magnético aplicado seria apenas linear:

$$
\vec{M}=\chi \vec{H}
$$

sendo $\vec{M}$ a magnetização do material, $\vec{H}$ o campo magnético aplicado e $\chi$ a susceptibilidade magnética, uma propriedade própria do material.

O primeiro efeito de $\vec{H}$ sobre um material qualquer segue a lei de Lenz: o campo induz a produção de dipólos magnéticos no material, que acaba produzindo um campo antiparalelo ao campo aplicado em uma tentativa de anulá-lo. Nesse caso, $\chi<0$ e esse efeito é chamado diamagnetismo.

Alguns materiais possuem átomos com um momento magnético não-nulo (devido à presença de elétrons desenparelhados). Sem interagirem entre si, seus momentos magnéticos se distribuem em direções aleatórias devido à agitação térmica. Quando um campo magnético é aplicado, os momentos tendem a se alinhar paralelamente a ele para minimizar a energia de Zeeman:

$$
U=-\mu_{0} \vec{H} \cdot \vec{M}
$$

sendo $\mu_{0}$ a constante de permeabilidade do vácuo. 
Esse efeito é mais intenso que a lei de Lenz, então a magnetização do material tende a ficar paralela a $\vec{H}$. Assim, $\chi>0$ e esse efeito é chamado paramagnetismo.

Ambos os efeitos são reversíveis mesmo alcançando a saturação, possuindo magnetização nula se não há campo magnético aplicado, como pode ser visto na figura 1.2.

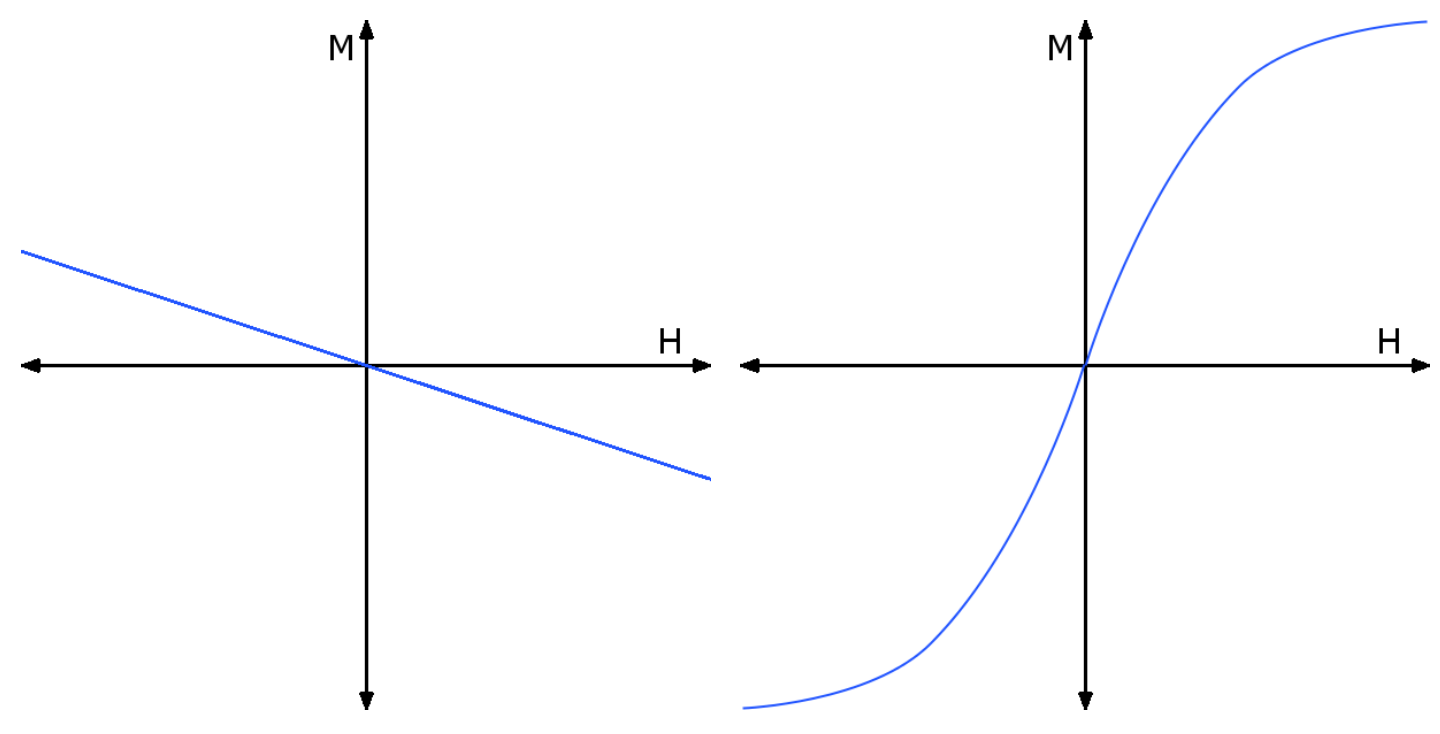

(a)

(b)

Figura 1.2: Curvas de magnetização típicas para um diamagneto (a) e um paramagneto (b). Note que a curva sigmoidal do paramagneto atinge um limite de magnetização (o material é saturado quando todos os momentos atômicos estão alinhados paralelamente), enquanto, a princípio, não há limite para a indução magnética no diamagneto.

Essa visão clássica não explica a possibilidade de magnetização espontânea, observada na natureza. Com o tratamento quântico, certos elementos possuem múltiplos elétrons com spins desemparelhados devido às regras de Hund. Isso aumenta o momento magnético de cada átomo, levando-os a interagirem entre si. São essas interações de troca (direta, dupla, etc.), identificadas por Heisenberg, as responsáveis por alinhar os spins dos átomos e produzir a magnetização espontânea sem a necessidade de campo magnético aplicado. Esse efeito é chamado ferromagnetismo.

Outras interações, mais fracas que as de troca, são as dipolares. Devido a elas, um corpo macroscópico é dividido em regiões cujas magnetizações se anulam globalmente (domínios), a fim de minimizar a energia total. Isso explica a aparente magnetização nula de um corpo classificado como ferromagnético. Aplicar um campo magnético externo afeta a competição entre os termos de energia, alterando a magnetização do corpo. Os domínios com magnetização mais próxima à direção do campo aplicado são favorecidos 
pela energia de Zeeman, magnetizando o material nessa direção. Retirando o campo, o corpo permanece magnetizado, pois as interações de troca favorecem a permanência do alinhamento paralelo, como se houvesse um campo magnético interno ("campo de troca"). A intensidade de tal efeito depende da rede cristalina do material e pode variar com a direção do campo aplicado em relação a algum eixo definido pela rede (anisotropia magneto-cristalina).

A curva de magnetização do ferromagneto depende de sua "história", por isso é chamada de ciclo de histerese. A figura 1.3a marca alguns pontos importantes do ciclo: $\mathrm{M}_{S}$ é a magnetização de saturação, quando todos os spins estão alinhados paralelamente; $\mathrm{M}_{R}$ é a magnetização remanente (ou remanência), o valor para $\mathrm{M}(\mathrm{H}=0) ; \mathrm{H}_{C}$ é o campo coercivo (ou coercividade), o valor tal que $\mathrm{M}\left(\mathrm{H}_{C}\right)=0$ partindo da saturação.

Existem casos em que a interação de troca favorece um ordenamento dos spins na rede cristalina dividido em duas ou mais sub-redes que resultam em uma magnetização espontânea nula. Esse efeito é chamado antiferromagnetismo.

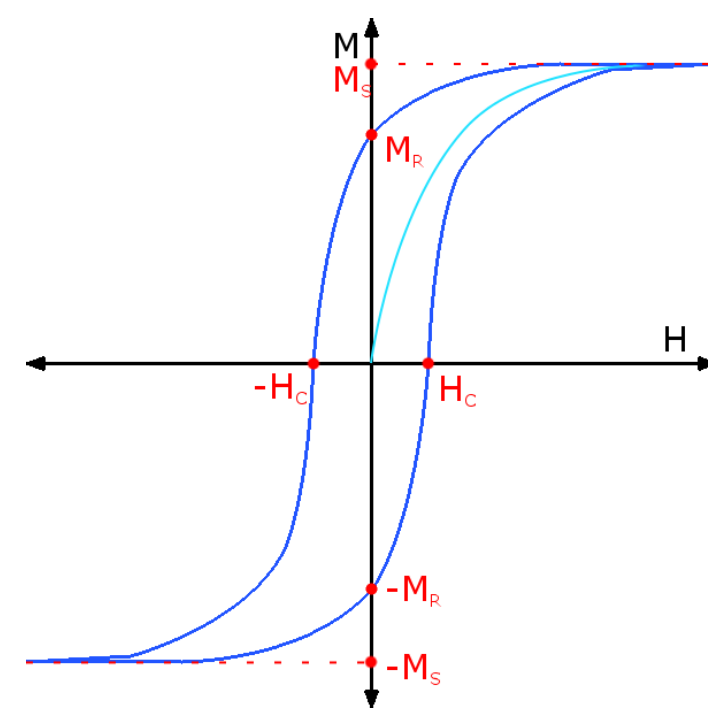

(a)

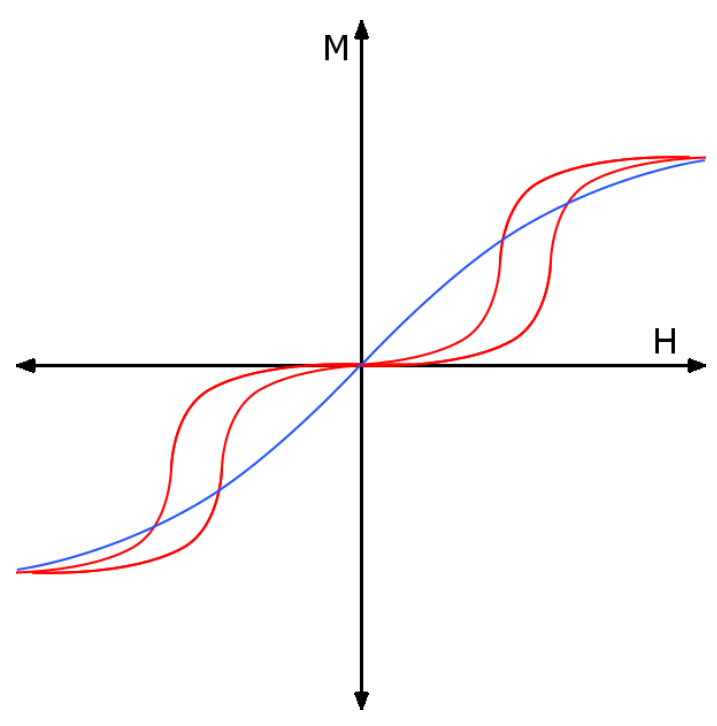

(b)

Figura 1.3: Curvas de magnetização típicas para um ferromagneto (a) e antiferromagneto (b). A linha mais clara em (a) é uma curva de magnetização inicial, partindo de um estado desmagnetizado. A curva vermelha em (b) reflete o caso de campo magnético aplicado na direção da magnetização das sub-redes: a rede favorecida em cada região se comporta como um ferromagneto. A curva azul em (b) reflete o caso mais geral, onde o campo aplicado perturba o equilíbrio das redes, lembrando a curva de um paramagneto. 
O caso intermediário entre ferromagneto e antiferromagneto ocorre quando a soma das magnetizações espontâneas das sub-redes não é zero, e esse efeito é chamado ferrimagnetismo.

\subsubsection{Exchange Bias}

Se um ferromagneto e um antiferromagneto dividem uma interface, é esperado que haja interações entre os spins de um e de outro. Se o lado antiferromagnético (AFM) da interface apresentar spins não-compensados em uma direção, a interação de troca com os spins do lado ferromagnético (FM) gera uma anisotropia unidirecional no sistema: a direção citada é favorecida magneticamente. Em uma medida macroscópica, isso se traduz em um deslocamento do ciclo de histerese, já que é necessário um valor maior de campo magnético para inverter a magnetização e um valor menor para recuperar a magnetização nessa direção. Esse efeito é chamado de exchange bias.[4]

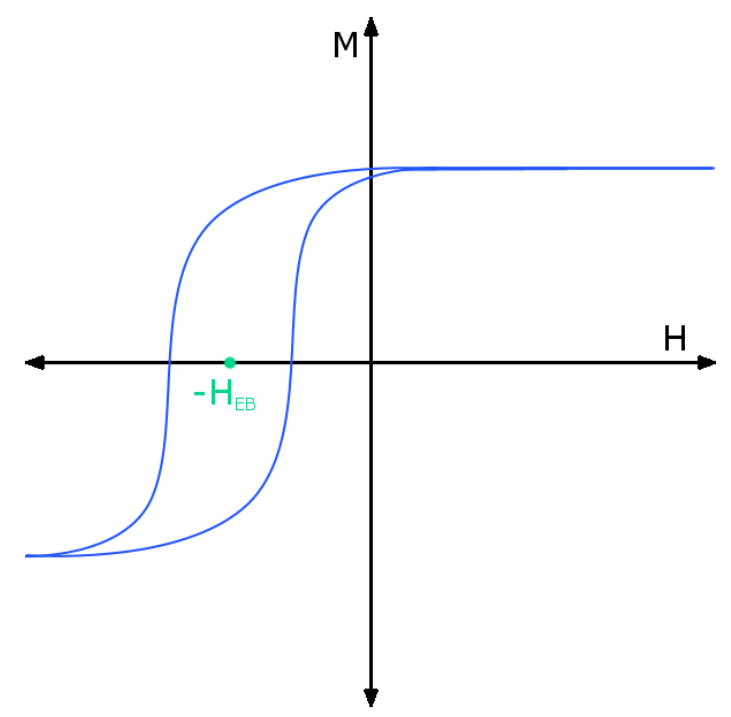

Figura 1.4: Curva de magnetização típica de um sistema com interface FM/AFM. $H_{E B}$ é o campo de exchange bias. O contato também gera uma aumento da coercividade do ferromagneto. $\mathrm{H}$ é positivo quando paralelo ao campo da anisotropía unidirecional induzida.

Geralmente, a anisotropia unidirecional é induzida com um tratamento térmico através resfriamento sob campo magnético ("Field-Cooling"). O sistema é aquecido a uma temperatura acima da temperatura de Néel $\left(T_{N}\right)$ do antiferromagneto e abaixo da temperatura de Curie $\left(T_{C}\right)$ do ferromagneto. Dessa forma, o antiferromagneto perde o ordenamento magnético, mas o ferromagneto ainda possui ordenamento, se magnetizando 
com o campo externo. Durante o FC, o antiferromagneto recupera seu ordenamento magnético, privilegiando a direção do campo aplicado uma vez que os spins da interface interagem com os spins do ferromagneto magnetizado naquela direção.

Apesar do fenômeno requerer qualquer tipo de interface, o tipo de sistema mais usado para estudá-lo são filmes finos com uma camada ferromagnética em contato com uma camada antiferromagnética. Isso se deve a uma maior facilidade no controle de parâmetros, tais como espessura dos filmes, direções cristalográficas, homogeneidade da superfície, etc.

Um modelo simples para descrever o fenômeno é a seguinte relação[5]:

$$
H_{E B}=\frac{J_{i n t}}{M_{F M} t_{F M}}
$$

onde $\mathrm{J}_{\text {int }}$ é a constante de troca na interface, $\mathrm{M}_{F M}$ é a magnetização de saturação do ferromagneto e $t_{F M}$ sua espessura (quando na forma de filme).

No entanto, valores de $H_{E B}$ observados correspondem a constantes de troca até 2 ordens de grandeza menor que o esperado para interfaces com planos de spin não-compensados, além de apresentar valores não-nulos no caso de planos compensados. Admitindo-se imperfeições da rede cristalina do AFM na interface em uma distribuição estatística, foi possível prever valores mais adequados.[6] 


\subsubsection{Válvulas de Spín}

Um sistema de filmes multicamadas pode acumular mais camadas e complexidade. Por exemplo, um sistema formado por uma bicamada AFM/FM e uma camada FM extra (separada por uma camada sem ordenamento magnético) possui uma curva de magnetização como a da figura $1.5 \mathrm{~b}$ :

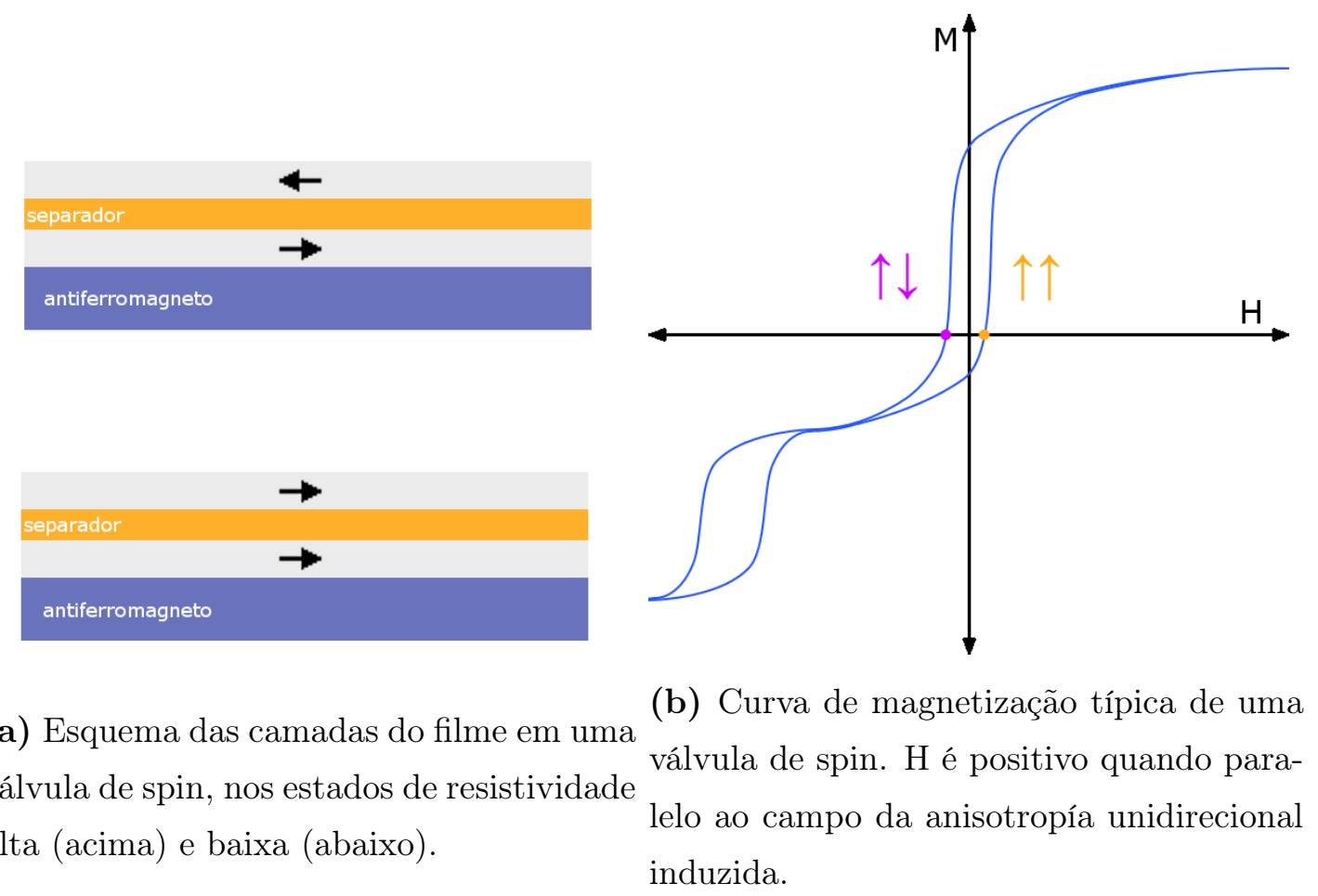

Figura 1.5

Para variações de $\mathrm{H}$ em torno do zero, o sistema possui dois estados magnéticos remanentes. Partindo de $\mathrm{H}$ positivo, tanto a camada FM "presa" (em contato com o AFM) quanto a "livre" (separada da bicamada FM/AFM) possuem magnetizações positivas: o sistema está no estado paralelo. Partindo de H negativo, a camada livre possui magnetização negativa, mas a presa tem magnetização positiva: o sistema está no estado antiparalelo. Tais sistemas são chamados de "válvulas de spin"[7]. Uma corrente elétrica aplicada paralelamente ao plano do filme encontra uma resistividade mais alta no estado antiparalelo do que no estado paralelo. Esse é o efeito da magnetorresistência gigante, que foi descoberto em multicamadas ferromagnéticas com acoplamento antiferromagnético[3] necessitando assim um campo magnético muito mais intenso que o necessário para as válvulas. A tabela 1.1 dá uma idéia dos valores em questão. 
Tabela 1.1: Exemplos de sistemas de GMR: as primeiras tricamadas e multicamadas, a primeira válvula de spin com a composição típica da atualidade, o maior valor de GMR obtido nesses tipos de sistemas, uma aplicação usual.

\begin{tabular}{|c|c|c|c|}
\hline sistema & $\mathrm{T}$ & $\mathrm{H}$ & $\mathrm{MR}$ \\
\hline \hline Fe-Cr-Fer001 & ambiente & $500 \mathrm{Oe}$ & $1,5 \%$ \\
\hline super-redes $[\mathrm{Fe}-\mathrm{Cr}]_{\sim 30}[2]$ & $4,2 \mathrm{~K}$ & $20 \mathrm{kOe}$ & $100 \%$ \\
\hline $\mathrm{Si} / \mathrm{NiFe} / \mathrm{Cu} / \mathrm{NiFe} / \mathrm{FeMn} / \mathrm{Ag}[7]$ & ambiente & $10 \mathrm{Oe}$ & $5 \%$ \\
\hline super-redes $[\mathrm{Fe}-\mathrm{Cr}]_{50}[8]$ & $1,5 \mathrm{~K}$ & $110 \mathrm{kOe}$ & $220 \%$ \\
\hline válvulas em cabeças de leitura $[9]$ & até $373 \mathrm{~K}$ & $<5 \mathrm{Oe}$ & $15 \%(3 \%$ efetivos $)$ \\
\hline
\end{tabular}

Com uma corrente elétrica aplicada perpendicularmente ao plano do filme, a probabilidade de tunelamento por um separador isolante também depende do estado magnético da válvula. Esse é o efeito da magnetorresistência de tunelamento.[10]

No estado antiparalelo, os elétrons de condução da primeira camada estão majoritariamente com spin $\uparrow$ e não mudam de spin se o separador não for muito espesso. Quando chegam na próxima camada (cuja maioria de elétrons tem spin $\downarrow$ ) a probabilidade de espalhamento (ou tunelamento) é muito reduzida, resultando em uma baixa condutividade. Já no estado paralelo, a maioria dos elétrons da camada seguinte também tem spin $\uparrow$, aumentando a probabilidade de espalhamento (ou tunelamento), a resistividade diminui em comparação com o estado antiparalelo.

As características de uma válvula de spin dependem das propriedades dos materiais utilizados. 


\subsection{Antiferromagnetos de Anisotropia Cúbica}

As propriedades de materiais antiferromagnéticos são fortemente dependentes de sua anisotropia cristalina.

Anisotropia magneto-cristalina uniaxial, normalmente decorrente de uma estrutura cristalina tetragonal ou hexagonal, possui a seguinte expressão para energia de anisotropia:

$$
E_{A}=-K \cos ^{2}(\theta)
$$

$\operatorname{com} \theta$ sendo o ângulo entre o eixo cristalino principal e a direção da magnetização; e $K$ sendo a constante de anisotropia (positiva no caso da direção fácil ser paralela ao eixo, negativa para o plano fácil ortogonal a ele).

Anisotropia magneto-cristalina cúbica (de qualquer uma das estruturas cristalinas cúbicas) possui uma expressão diferente para o termo de primeira ordem da energia de anisotropia:

$$
E_{A}=-K \cos ^{2}(\theta) \operatorname{sen}^{2}(\theta)
$$

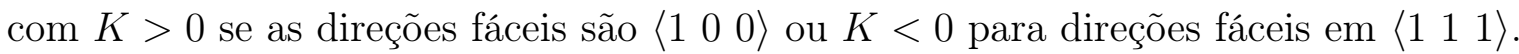

Com isso, as condições de estabilidade para materiais de anisotropia cúbica são mais numerosas, levando a uma maior variedade e complexidade nas curvas de magnetização do que os exemplos na figura 1.3b.[11]

Dois dos antiferromagnetos cúbicos mais conhecidos são FeMn e NiO. Ambos apresentam $T_{N}$ acima dos $470 \mathrm{~K}$ e estruturas cúbicas de face centrada (fcc). Enquanto o primeiro é uma liga metálica, sem ordenamento químico, sem alinhamento colinear de spins, com leve distorção tetragonal; o segundo é um óxido, com estrutura tipo $\mathrm{NaCl}$, spins do Ni alinhados paralelamente em sentidos alternados em planos $\left\{\begin{array}{lll}1 & 1 & 1\end{array}\right\}$, com leve distorção romboédrica. Tratando-se de aplicações, FeMn possui uma resistência razoável à contaminação e oxidação[12], enquanto $\mathrm{NiO}$ é ainda mais resistente à degradação, especialmente sob influência de umidade e acidez.[13].

Outro que vem ganhando importância nos últimos anos é o IrMn. Metálico e desordenado como o FeMn, o IrMn apresenta uma resistência a degradação superior, além de sua constante de anisotropia ser uma das maiores em qualquer AFM,[14] resultando em uma espessura crítica menor que os demais antiferromagnetos e permitindo o uso de espessuras menores para os filmes finos. 


\subsubsection{Ferro-Manganês}

Entre 570 e 1370K (dependendo da composição), as ligas de FeMn transitam para a fase $\gamma$ fcc, a qual é AFM (ver fig. 1.6). Sua $T_{N}$ possui um máximo em torno da composição equiatômica: sobe de $67 \mathrm{~K}\left(\gamma\right.$-Fe) para aproximadamente $500 \mathrm{~K}\left(\gamma-\mathrm{Fe}_{50} \mathrm{Mn}_{50}\right)$, estabilizando em $473 \mathrm{~K}$ para o lado rico em manganês até $\gamma$-Mn. Em temperaturas mais baixas para essa composição, a liga entra na fase $\alpha^{\prime}$, cúbica de corpo centrado (bcc) e ferromagnética com temperatura de Curie por volta dos 290K. Tanto $\alpha^{\prime}$ meta-estável quanto $\gamma$ abaixo de $T_{N}$ apresentam uma pequena distorção tetragonal. Átomos de $\mathrm{Fe}$ e Mn ocupam os sítios da rede aleatoriamente.[15]

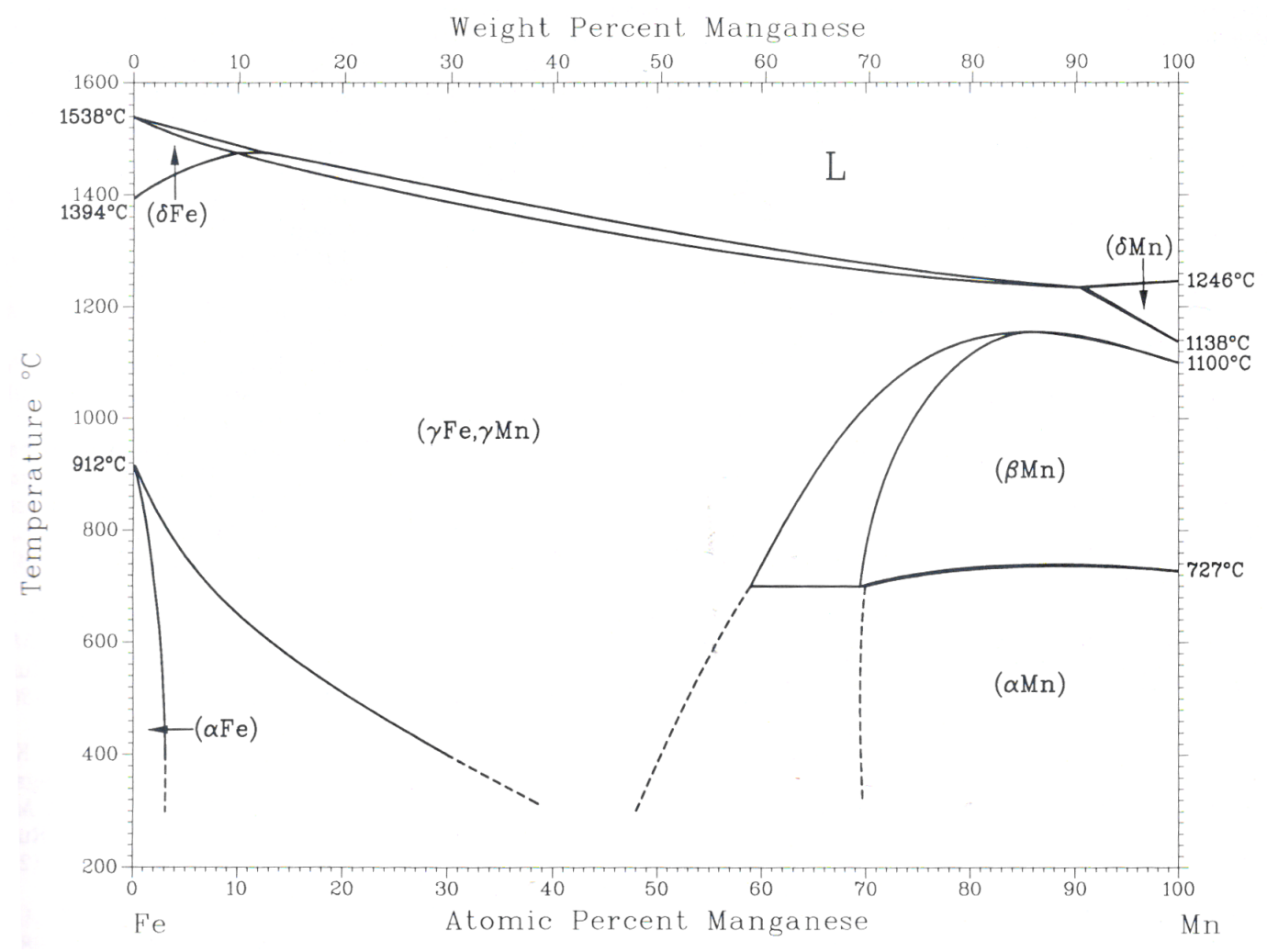

Figura 1.6: Diagrama de fase da liga FeMn. [15].

Em geral, deposição de FeMn em substratos amorfos produz filmes na fase $\alpha$, como esperado do diagrama de fases. No entanto, deposição em substratos fcc resulta na fase $\gamma \cdot[16]$ Ainda assim, apenas as primeiras poucas dezenas de nanometros depositadas permanecem nessa fase: a fase $\alpha$ começa a se formar à medida que a distância da interface fcc aumenta, até se tornar completamente $\alpha$-FeMn após 500nm .[17] 
Cálculos teóricos[18] e diferentes tipos de medidas, tais como XMCD-PEEM[19] (microscopia eletrônica de fotoemissão e dicroismo magnético circular de raios-X, na sigla em inglês) e espectroscopia Mössbauer[20], indicam que os spins da liga $\gamma$-FeMn assumem uma configuração não-colinear. Mais especificamente, cálculos e medidas apontam para a configuração 3Q (ver fig. 1.7), apesar do estado fundamental poder apresentar alguns desvios.[21]

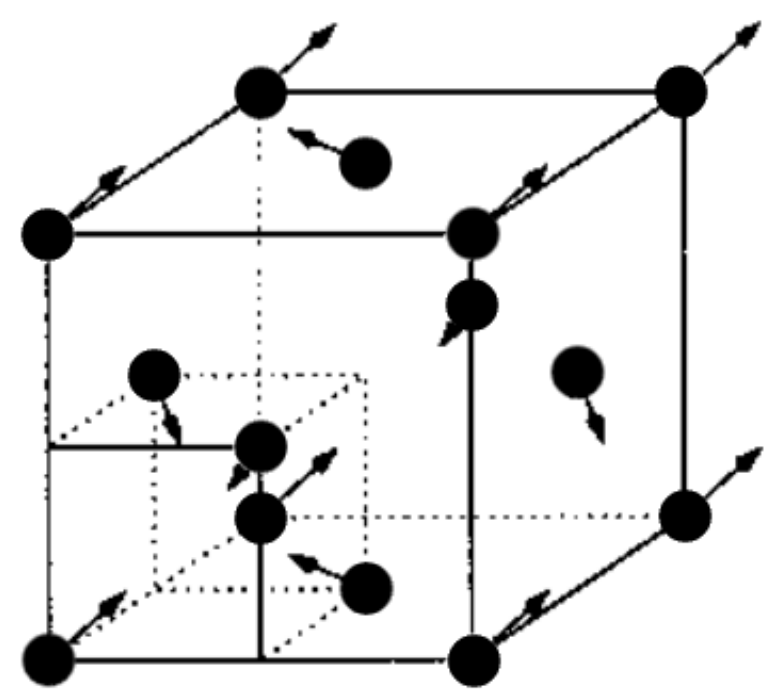

Figura 1.7: Configuração de spin 3Q: os spins da célula unitária apontam para o centro do tetraedro descrito pelas posições dos átomos - ou seja, para as direções $\left\langle\begin{array}{llll}1 & 1 & 1\end{array}\right\rangle$. [18].

A configuração 3Q do $\gamma$-FeMn faz com que os planos $\left\{\begin{array}{lll}1 & 0 & 0\end{array}\right\}$ e $\left\{\begin{array}{lll}1 & 1 & 1\end{array}\right\}$ tenham spins compensados. O primeiro plano (1 110$)$ também estaria compensado, mas o segundo plano é não-compensado, como mostra a figura 1.8 .

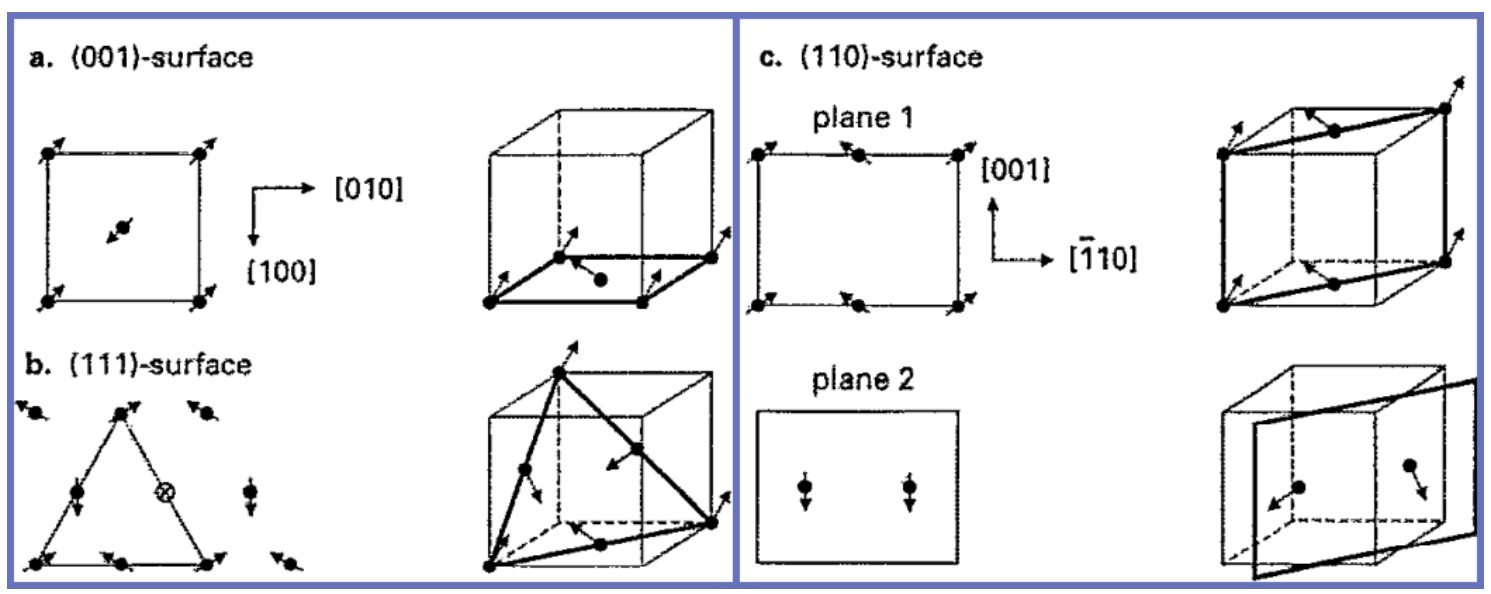

Figura 1.8: Possíveis planos atômicos do modelo $\left\langle\begin{array}{llll}1 & 1 & 1\end{array}\right\rangle$. [22]. 
Sendo um AFM com alta $T_{N}$, metálico e relativamente simples, o FeMn tem sido estudado há mais de 25 anos.[23] Em diversos sistemas com permalloy (Py, liga $\mathrm{Ni}_{81} \mathrm{Fe}_{19}$ ), os maiores valores de exchange bias são observados quando a interface contempla o plano $\left\{\begin{array}{lll}1 & 1 & 1\end{array}\right\}$ compensado, obtido por epitaxia em substratos monocristalinos[22] ou voltagem aplicada durante a deposição.[24] Esse fato sustenta a consideração de imperfeições citada anteriormente, uma vez que o número de spins não-compensados em uma superfície com $N$ átomos seria proporcional a $\sqrt{N}$. A maior densidade atômica é encontrada nos planos $\left\{\begin{array}{lll}1 & 1 & 1\end{array}\right\}$, o que causaria o maior número de spins não compensados e, conseqüentemente, uma interação de troca na interface mais forte: até $0,19 \mathrm{erg} / \mathrm{cm}^{2}$ em $\left\{\begin{array}{lll}1 & 1 & 1\end{array}\right\}[24]$ contra $0,07 \mathrm{erg} / \mathrm{cm}^{2}$ no plano $\left\{\begin{array}{lll}1 & 0 & 0\end{array}\right\}$ e um máximo de $0,06 \mathrm{erg} / \mathrm{cm}^{2}$ no plano não-compensado $\left\{\begin{array}{lll}1 & 1 & 0\end{array}\right\} \cdot[22]$ 


\subsection{2 Óxido de Níquel}

$\mathrm{NiO}$ é um antiferromagneto do tipo II (ver fig. 1.9). Isso significa que apresenta estrutura fcc, ordenamento B1 (tipo $\mathrm{NaCl}$ ), átomos de níquel em planos $\left\{\begin{array}{lll}1 & 1 & 1\end{array}\right\}$ possuindo momentos magnéticos alinhados ferromagneticamente na direção $\left\langle\begin{array}{llll}1 & 1 & 0\end{array}\right\rangle$, com planos sucessivos alinhados antiferromagneticamente.[26] A interação de supertroca entre esses planos causa uma contração na direção [1 11 1], resultando em uma deformação romboédrica abaixo da $T_{N}$ de 323K.[27] No caso de alguma tensão suprimir essa deformação, o antiferromagnetismo do NiO também é suprimido.[28] Sua espessura crítica (abaixo da qual o filme não possui anisotropia o bastante para influenciar a magnetização da camada FM) para sistemas de exchange bias se encontra por volta de 15nm.[29]

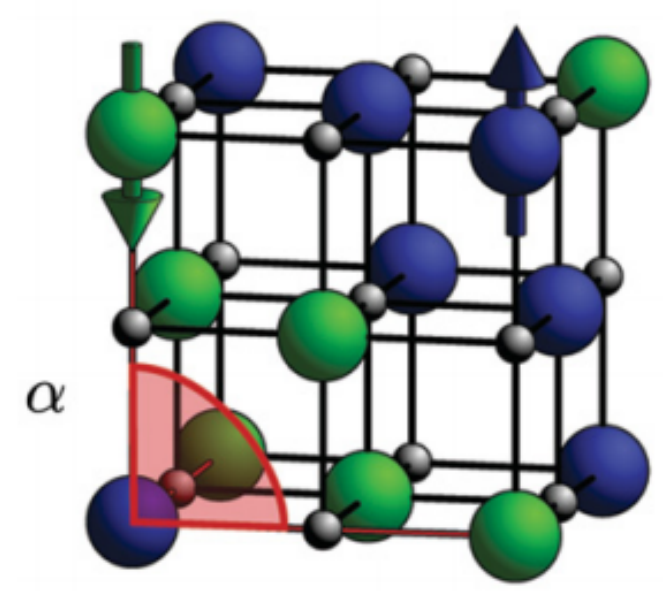

Figura 1.9: Estrutura cristalina de um AFM tipo II. Para o NiO, as esferas menores cinzentas representam íons de oxigênio enquanto as esferas maiores representam íons de níquel (uma cor para cada orientação de spin, a direção das setas não representando a direção real dos momentos magnéticos). A deformação romboédrica é denotada com o ângulo $\alpha \neq 90^{\circ}\left(\alpha=90,1^{\circ}\right)$. [30].

Resistência a corrosão[31] e a ausência de calor gerado por desvio de corrente elétrica (por se tratar de um isolante), além da alta $T_{N}$, são atrativos na adoção deste óxido em válvulas de spin.[32] No entanto, a adoção de $\mathrm{NiO}$ em sistemas de exchange bias é relativamente recente apesar de ter sido estudado desde a década de 1960, pois nenhum $H_{E B}$ era obtido na época devido às dificuldades na resolução de sua baixa anisotropia.[33]

Na falta de momento orbital, a principal contribuição para a anisotropia do óxido de níquel vem de interações secundárias, como a dipolar.[30] Com isso, observa-se pouca diferença entre as constantes de troca nos diferentes planos[34], quase sempre menores que 
$0,10 \mathrm{erg} / \mathrm{cm}^{2}$. Alguns casos se sobressaem, como a interface em plano não compensado $\left\{\begin{array}{lll}1 & 1 & 1\end{array}\right\}$ a baixas temperaturas alcançando $0,31 \mathrm{erg} / \mathrm{cm}^{2}$ [35] ou superfícies oxidadas de níquel metálico alcançando $0,29 \mathrm{erg} / \mathrm{cm}^{2}$.[36] As diferenças nas propriedades magnéticas são mais atribuídas a outros fatores como rugosidade na interface com o ferromagneto e, principalmente, tamanho de grão.[37]

Novamente, o modelo mais simples para $H_{E B}$ prevê um valor muito mais alto que o observado, o que pode ser corrigido levando-se em conta a rugosidade atômica[6] ou ainda uma distribuição de temperaturas de bloqueio $\left(T_{B}\right)$, como inferido na figura 1.10.[38]
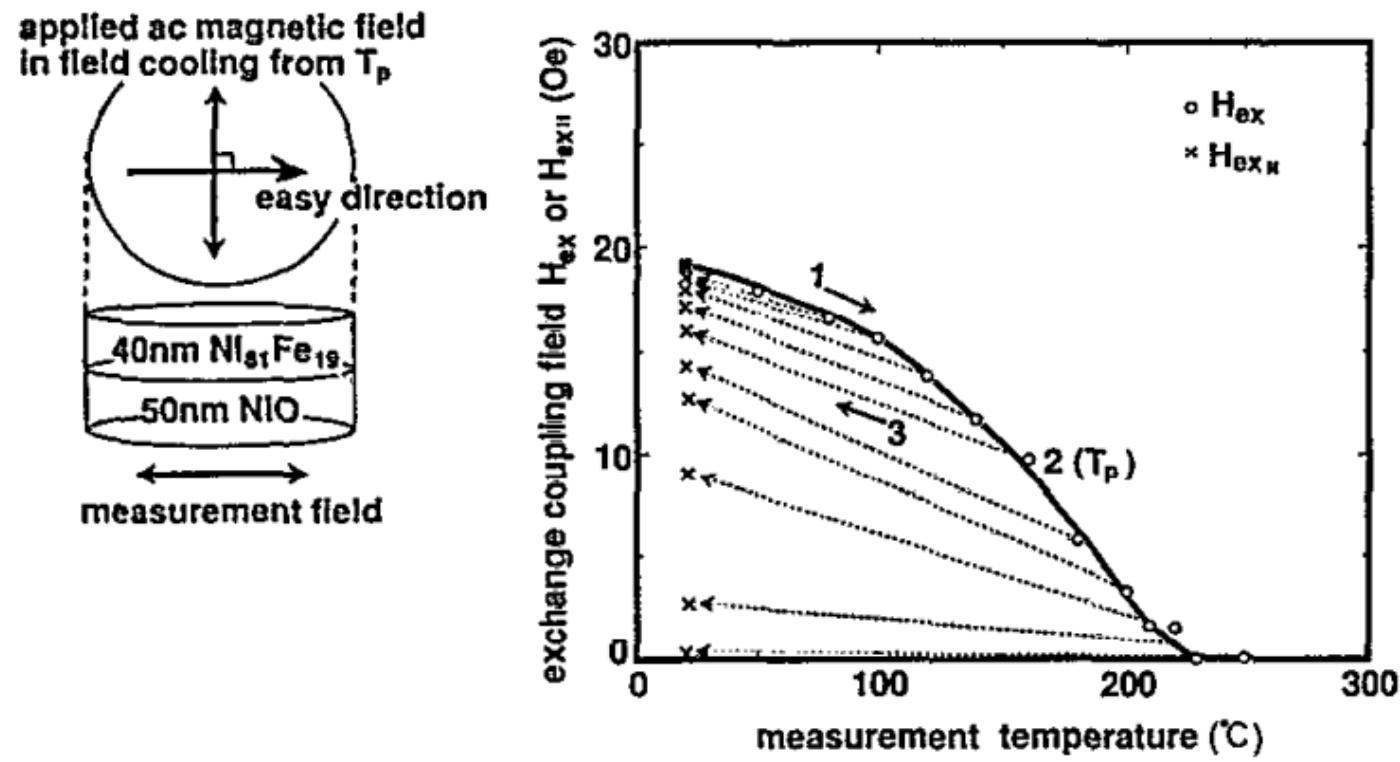

Figura 1.10: Diminuição da fração de regiões acopladas paralelamente ao eixo fácil. Valores de $H_{E B}$ cada vez menores são obtidos em medidas com campo aplicado na direção do eixo fácil após cada acréscimo na temperatura do tratamento térmico que induz acoplamento perpendicular àquela direção. [38].

Misturas com óxido de cobalto (que possui alta anisotropia mas $T_{N}$ inferior a $290 \mathrm{~K}$ ) se mostraram promissoras ao combinar as melhores características de ambos, como pode ser visto na figura 1.11: proporcionando um acréscimo de até $30 \%$ no $H_{E B}$ em relação ao $\mathrm{NiO}$ e uma temperatura de bloqueio $\left(T_{B}\right) 50 \mathrm{~K}$ maior que a do CoO.[39] A substituição do cobalto por ferro não replica esse resultado: há um leve aumento de $H_{E B}$ em bicamadas com Py até $18 \%$ de $\mathrm{Fe}_{2} \mathrm{O}_{3}$ seguido de uma grande diminuição, além de $H_{C}$ e $T_{B}$ diminuirem monotonicamente.[40] 


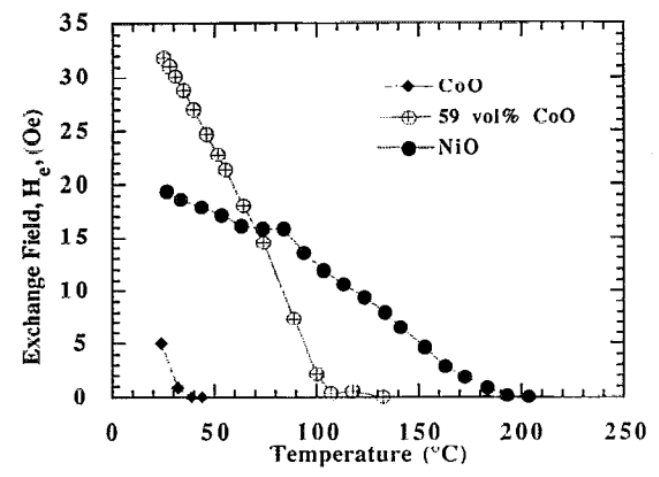

Figura 1.11: Dependência do $H_{E B}$ de bicamadas $\operatorname{Py}(30 \mathrm{~nm}) / \operatorname{AFM}(50 \mathrm{~nm})$ em relação à temperatura, 3 materiais diferentes para AFM, todos depositados por sputtering. [39].

Os parâmetros na oxidação do níquel também devem ser considerados. No caso de deposição de níquel metálico via plasma de $\mathrm{Ar}-\mathrm{O}_{2}$, se a pressão estiver baixa demais, níquel metálico é depositado; se estiver alta demais, a camada anterior também é oxidada desordenando a interface.[41]

A figura 1.12 mostra sensibilidade perto do ponto ótimo. O difícil controle de tal parâmetro justifica a preferência de deposição direta a partir de um alvo de NiO.

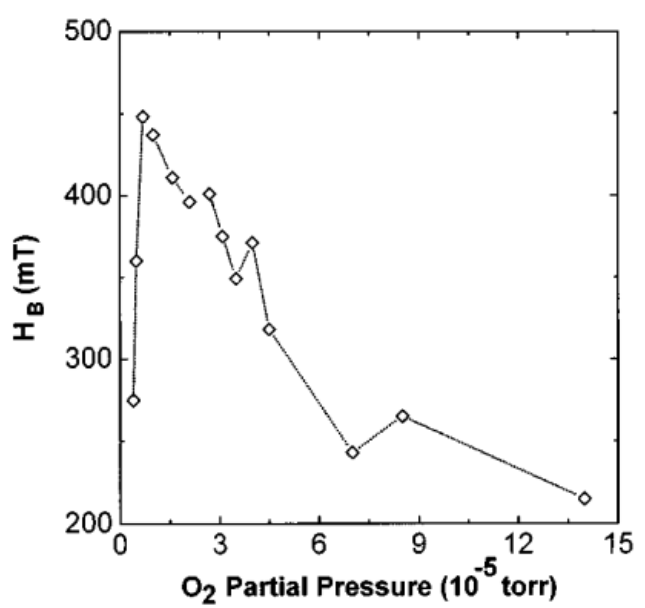

Figura 1.12: Dependência do $H_{E B}$ de válvulas de spin $\operatorname{NiFe}(5,1 \mathrm{~nm}) / \mathrm{Co}(2,2 \mathrm{~nm}) / \mathrm{Cu}(2,2$ $\mathrm{nm}) / \mathrm{Co}(2.7 \mathrm{~nm}) / \mathrm{NiO}(10 \mathrm{~nm})$ em relação à pressão parcial de $O_{2}$ durante a deposição de níquel. [41]. 
A pressão de argônio para a deposição direta de um alvo de NiO também se mostra importante na figura 1.13: acima de 1 mTorr, a rugosidade macroscópica da interface aumenta, reduzindo o tamanho das regiões com acoplamento e, conseqüentemente, o acoplamento global na interface.[42]

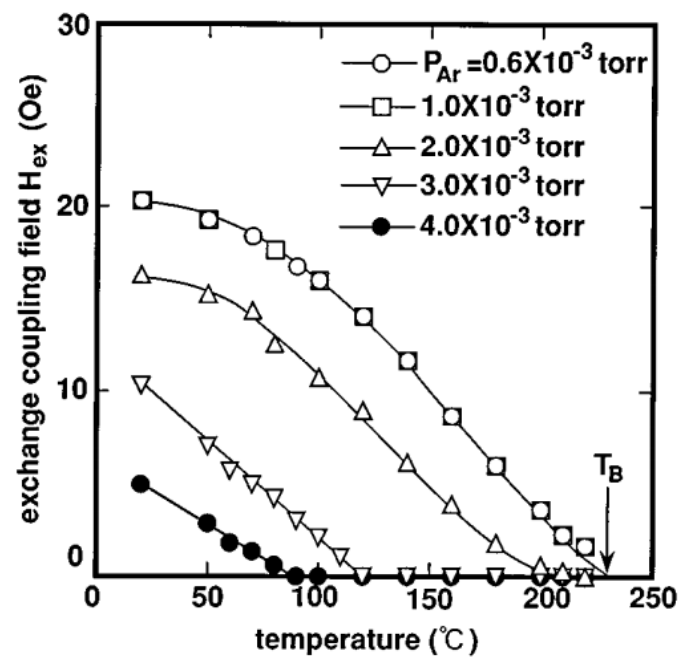

Figura 1.13: Dependência do $H_{E B}$ de bicamadas $\mathrm{Py}(40 \mathrm{~nm}) / \mathrm{NiO}(100 \mathrm{~nm})$ em relação à temperatura com diversas pressões de argônio para a deposição via sputtering do $\mathrm{NiO}$. [42]. 


\subsubsection{Irídio-Manganês}

Ligas de IrMn são antiferromagnéticas em uma faixa de composições com porcentagem atômica de Ir entre 20 e 46, apresentando $T_{N}$ de 400K.[43] Tal fase é corresponde ao $\mathrm{IrMn}_{3}$ no diagrama de fases a seguir.

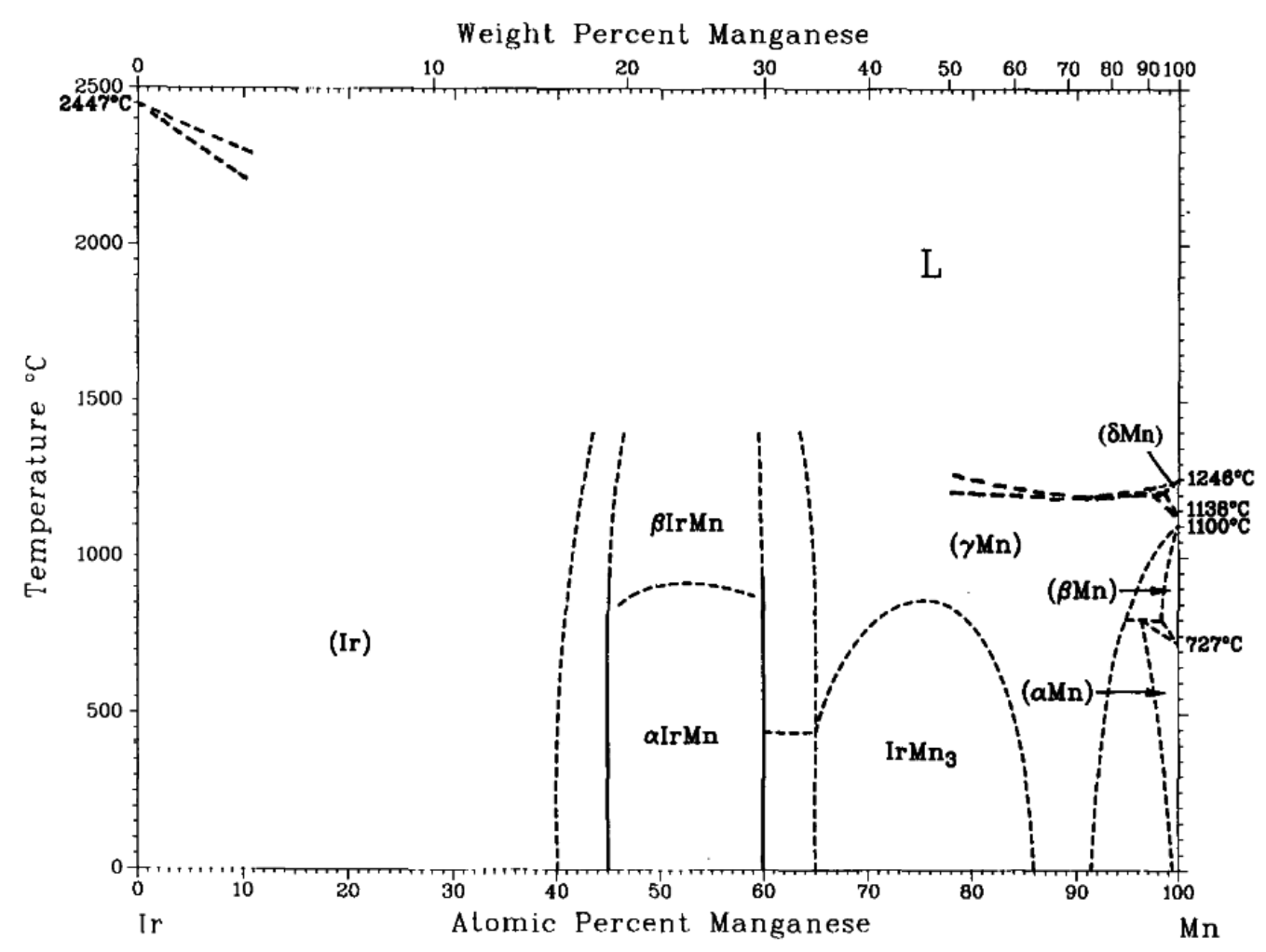

Figura 1.14: Diagrama de fases Ir-Mn.[44].

Existem 2 fases antiferromagnéticas naquela região: $\gamma-\operatorname{IrMn}_{3}$ (desordenada quimicamente) e $\mathrm{L}_{2}$ - $\mathrm{IrMn}_{3}$ (ordenamento tipo $\mathrm{AuCu}_{3}$ ). A fase $\gamma$ é muito mais utilizada, visto que são necessárias condições específicas para a produção da fase ordenada.

Assim como FeMn, exchange bias em filmes multicamadas é mais favorecido em planos $\left\{\begin{array}{lll}1 & 1 & 1\end{array}\right\}$, obtidos mais facilmente com uma estequiometria em torno de $\operatorname{Ir}_{20} \mathrm{Mn}_{80}$ (ver fig. 1.15) apresentando um parâmetro de rede entre 377 a 380 pm.[14][45] Essa configuração é alcançada através de deposições sobre sementes fcc como Hf[46], Ru[47], Zr, Ta[48] ou mesmo Si (1 0 0) oxidado termicamente[14] e camada FM de CoFe.[49][50] 


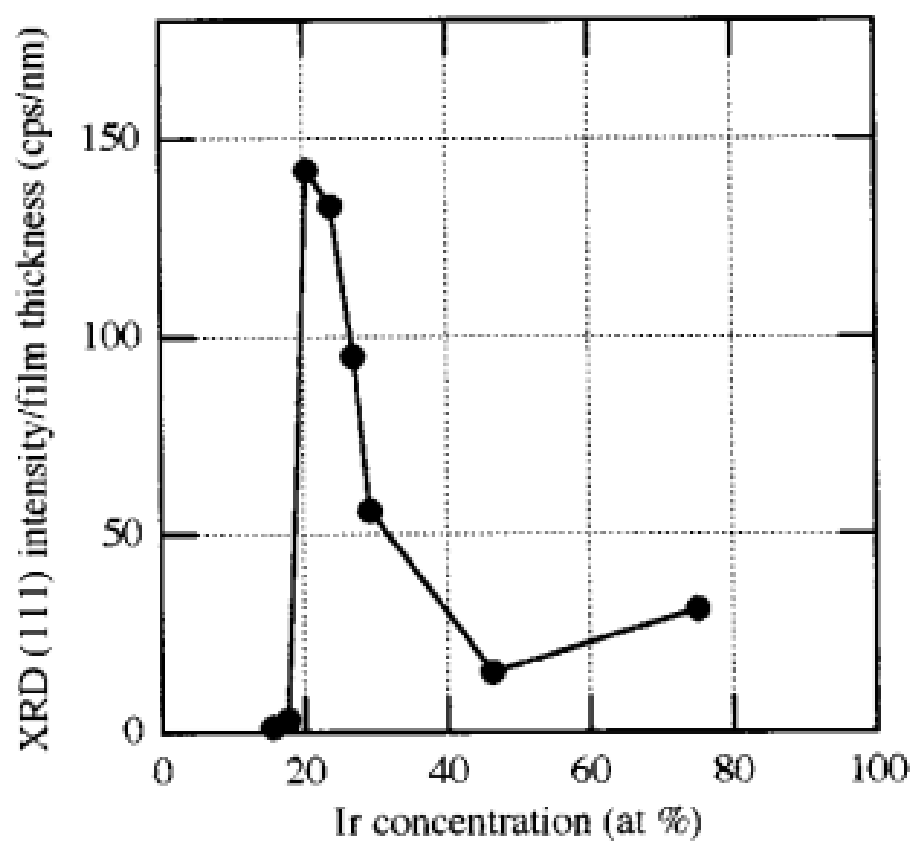

Figura 1.15: Intensidade do pico $\left(\begin{array}{lll}1 & 1 & 1\end{array}\right)$ em função da concentração de Ir na liga. [14].

A liga possui uma constante de troca de até $0,192 \mathrm{erg} / \mathrm{cm}^{2}[14]$, apresentando exchange bias em bicamadas a uma espessura mínima de 3nm[45] e atingindo o valor máximo já a 5nm.[45] A baixa espessura crítica se reflete em uma alta estabilidade térmica, uma vez que ambas são conseqüências de uma elevada constante de anisotropia: $2 \times 10^{6}$ $\mathrm{erg} / \mathrm{cm}^{3} \cdot[50]$

As condições de deposição via sputtering afetam o tamanho dos grãos do filme de IrMn, que por sua vez afeta a magnitude do $H_{E B}$ em bicamadas com Py.[46] Essas dependências podem ser visualizadas na figura 1.16 . 

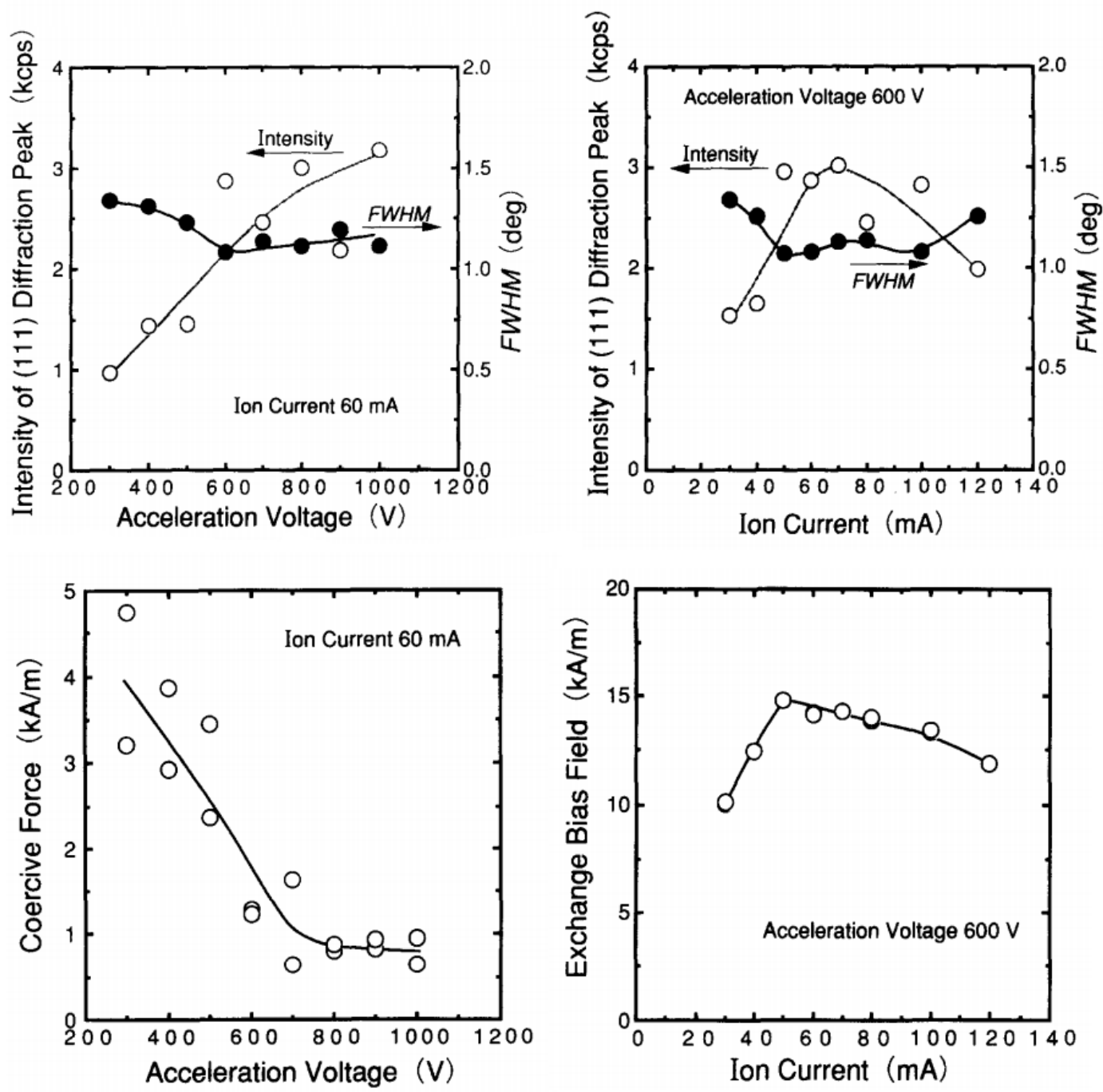

Figura 1.16: Variação do tamanho do pico $\left(\begin{array}{lll}1 & 1 & 1\end{array}\right)$ em difratogramas de raios-x e de $H_{E B}$ com tensão e corrente utilizados na deposição de $\mathrm{IrMn}$ em amostras $\mathrm{Si} / \mathrm{Ta}(6 \mathrm{~nm}) / \mathrm{Py}(5 \mathrm{~nm}) / \mathrm{IrMn}$ $(14 \mathrm{~nm}) / \mathrm{Ta}(7 \mathrm{~nm}) .[46]$.

Com tensão e corrente maiores, o tamanho dos grãos de IrMn também fica maior (o que causa a diminuição da largura dos picos no difratograma de raios-X). Com grãos relativamente maiores há uma constante de anisotropia maior, favorecendo o acoplamento com a camada ferromagnética e maior exchange bias.

É esperado que não haja nucleação de domínios magnéticos no filme FM. No entanto, há situações em que são formados domínios com uma extensão menor que a dos domínios no AFM, o que pode resultar em regiões acopladas tanto ferromagneticamente quanto antiferromagneticamente. O exchange bias de um sistema assim não se cancela mutualmente, mas aparece em dois deslocamentos opostos na curva de magnetização.[51] 
A figura 1.17 mostra um exemplo do fenômeno descrito, observado justamente em uma bicamada com IrMn. O efeito desaparece depois de um tratamento térmico convencional, dando lugar à anisotropia unidirecional esperada.

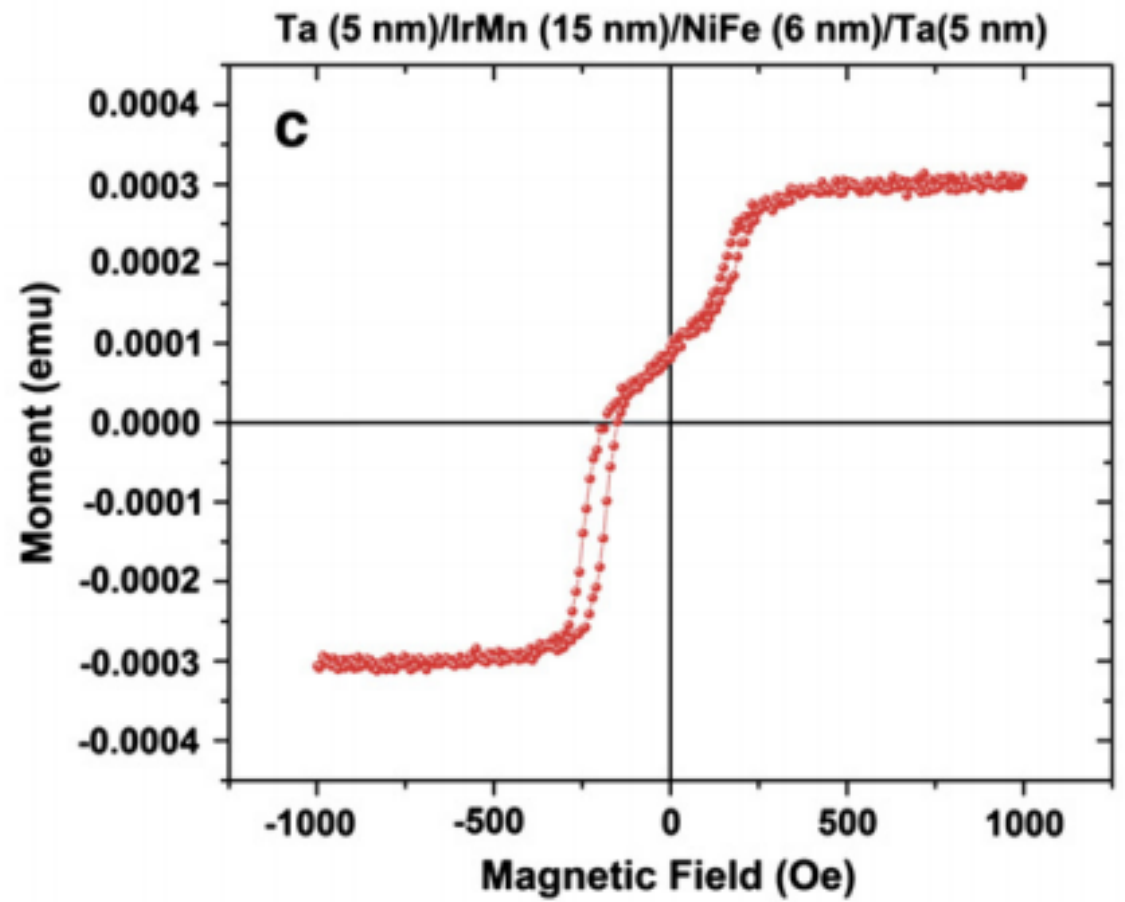

Figura 1.17: Curva de magnetização apresentando duplo exchange bias. [52]. 


\subsection{Ferromagnetismo Fraco}

Ferromagnetismo fraco é um termo originalmente usado para designar um momento magnético residual em materiais antiferromagnéticos. Esse momento residual se origina de um desalinhamento das sub-redes, provocado por uma perturbação do campo cristalino aos íons magnéticos ou pela interação de troca antissimétrica (DzyaloshinskiiMoriya). Tal desalinhamento faz com que haja um momento magnético resultante nãonulo das sub-redes, de até $0,1 \mu_{B}$ por célula unitária. [53] Mais recentemente, esse baixo momento magnético aliado a um baixo campo de troca em um material não-AFM tem sido o suficiente para classificar um material como fracamente ferromagnético, apesar de não corresponder ao efeito original.

Um dos principais campos de pesquisa desse tipo de material tem sido em conjunto com supercondutores. A princípio, supercondutividade e ferromagnetismo seriam propriedades antagônicas: enquanto uma necessita de pares de spins antiparalelos, a outra tende a alinhá-los paralelamente, impossibilitando ordenamento de longo alcance.[54] No entanto, a coexistência de superparamagnetismo e ordenamento magnético[55] e a oscilação da corrente crítica por efeitos de proximidade em interfaces supercondutorferromagnético[56] abriu muitas possibilidades de estudos dos mais diversos fenômenos originados pela competição entre esses dois estados.

O efeito de proximidade em estruturas supercondutor/ferromagneto exige ferromagnetismo fraco: a oscilação só ocorre com um campo de troca não-nulo, mas um campo típico de materiais ferromagnéticos usuais é intenso demais para sustentar o efeito.[57] Ligas de $\mathrm{NiCu}$ e NiPd são as mais utilizadas para materiais fracamente ferromagnéticos graças ao controle das propriedades magnéticas através da estequiometria da liga. 


\subsubsection{Níquel-Cobre}

Níquel e cobre são extremamente miscíveis. Sendo vizinhos na tabela periódica (o que implica raio e massa atômica semelhantes), esses metais formam uma solução sólida substitucional fcc em qualquer proporção a temperatura ambiente, como pode ser visto no diagrama da figura 1.18.

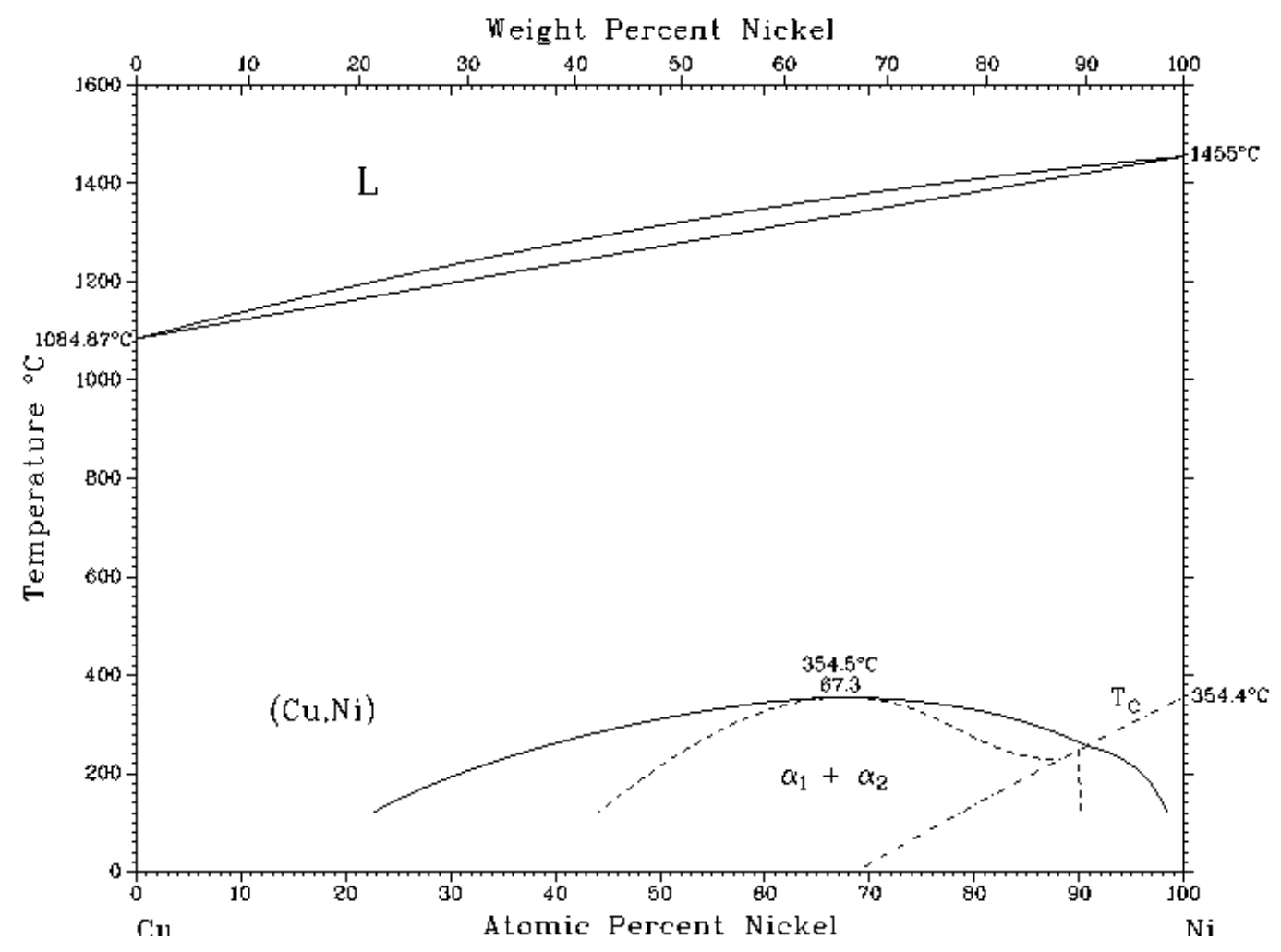

Figura 1.18: Diagrama de fases Ni-Cu. Inclui a transição ferromagnética-paramagnética e um gap de miscibilidade calculado pelo comportamento em uma liga ternária com $\mathrm{Cr}$ e associado à formação de aglomerados $\left(\alpha_{1}+\alpha_{2}\right)$, mas aindã não foi observado experimentalmente. [58].

A liga tem sido intensamente utilizada sob o nome "constantan" (em torno de $55 \%$ de cobre, com pequenas quantidades de Fe e Mn), apresentando uma resistividade praticamente constante na faixa de temperaturas entre 290K e 570K.[59] Além disso, o constantan é um dos materiais mais relevantes para o efeito termoelétrico, com um coeficiente de Seebeck bastante negativo em filmes com espessuras de 100nm, encontrando aplicações em sensores de temperatura com resposta rápida.[60] 
A temperatura de Curie da liga varia linearmente com a concentração de níquel, como é melhor observado na figura 1.19.

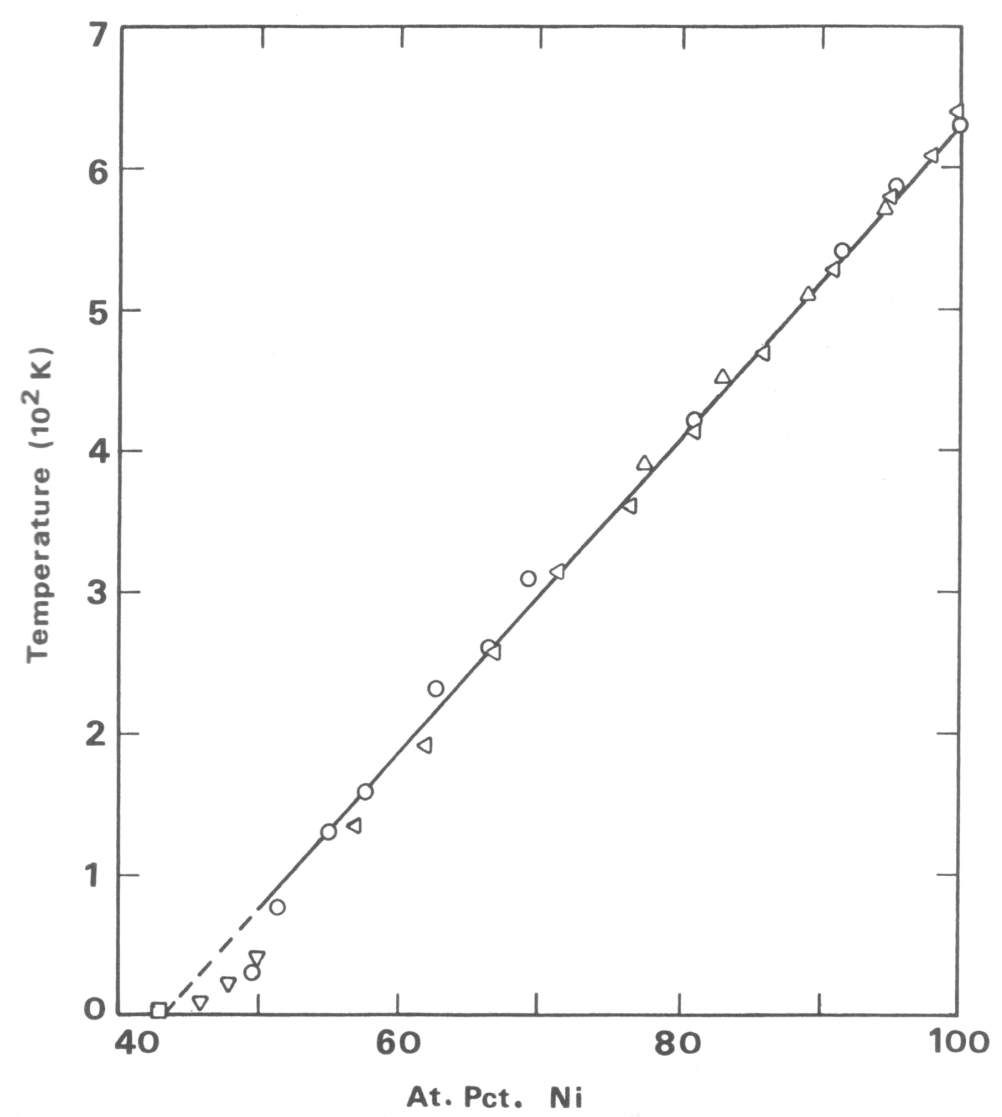

Figura 1.19: Variação de $\mathrm{T}_{C}$ com a estequiometria da liga. Símbolos diferentes para autores diferentes. [58].

Cada átomo de cobre cede um elétron para a camada $3 d$ de um átomo de níquel, cancelando o momento magnético do elétron desemparelhado, o que resulta em um enfraquecimento linear das propriedades magnéticas como temperatura de Curie e magnetização de saturação. O acréscimo de $33 \%$ at de $\mathrm{Cu}$ em Ni já é o suficiente para trazer o valor de $\mathrm{T}_{C}$ para a temperatura ambiente, enquanto $62 \%$ at de $\mathrm{Cu}$ já anula o momento magnético atômico médio da liga.[61] No entanto, ainda é observado ferromagnetismo nessa fase paramagnética por causa de aglomerados, formados tanto por inomogeneidade química de formação quanto por flutuações estatísticas.[58] 
A diluição das propriedades magnéticas também afeta a coercividade, cuja diminuição decorre de uma menor energia das paredes de domínio. Uma magnetização de saturação mais baixa também causa uma susceptibilidade inicial menor[61], como evidenciado na figura 1.20 .

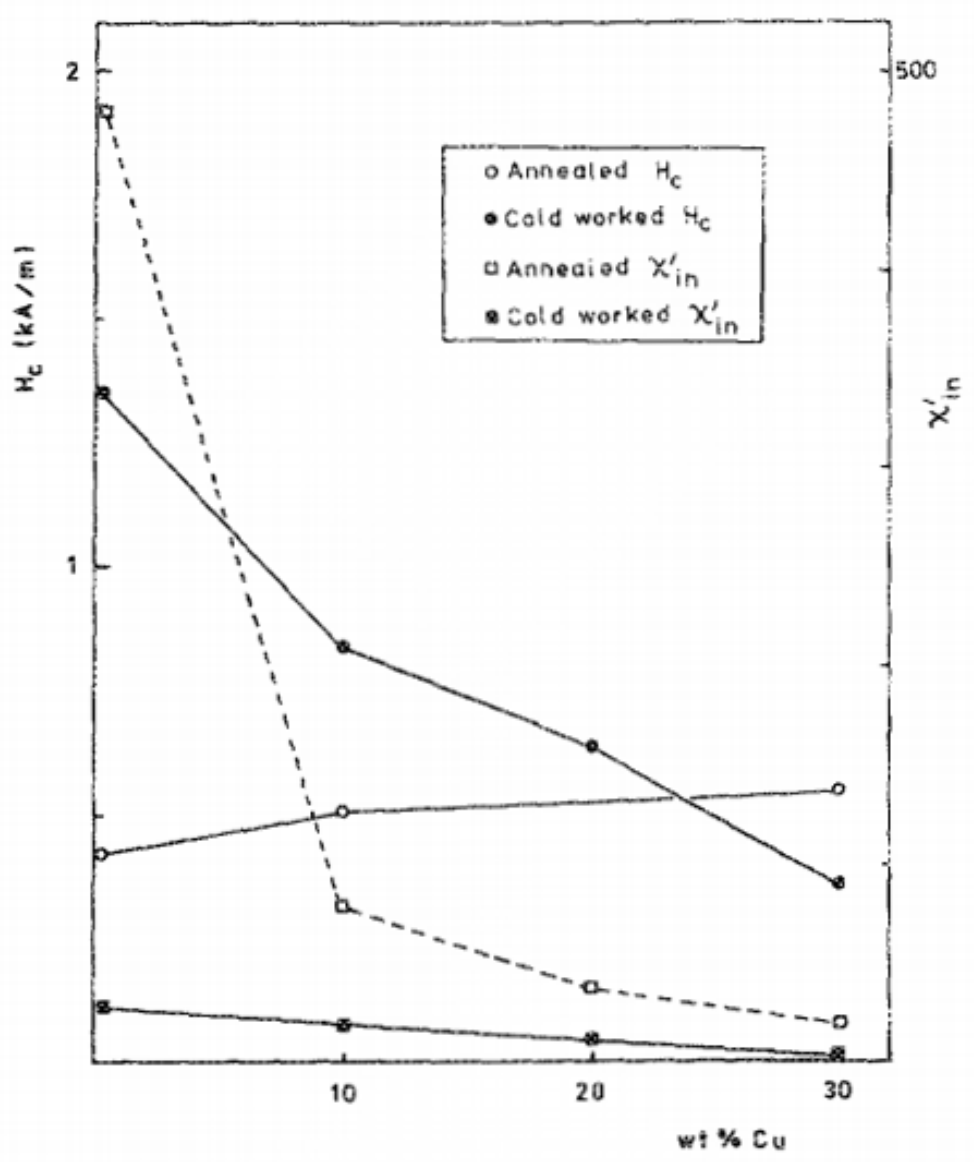

Figura 1.20: Variação de $\mathrm{H}_{C}$ e $\chi_{0}$ com a estequiometria da liga em casos com tratamento térmico e resfriado. A coercividade no caso resfriado é uma exceção ao padrão observado.[61].

Sabe-se que há anomalias na resistividade elétrica de um material em torno de sua transição magnética. No caso de níquel puro, a aplicação de campo magnético externo diminui sua resistividade devido à metade dos eletrons de condução de spin $\uparrow$ serem sempre espalhadas, enquanto a metade $\downarrow$ se emparelhar com os elétrons desemparelhados $\uparrow$ da rede responsáveis pela magnetização espontânea.[62] Acima da temperatura de Curie, a magnetização espontânea desaparece, destruindo a seletividade de spins para o emparelhamento. Assim, a resistividade aumenta abruptamente, com a variação de seu coeficiente dependente da temperatura divergindo em $\mathrm{T}_{C} \cdot[63]$ 
Embora tais anomalias também estejam presentes nas ligas $\mathrm{NiCu}$ (em temperaturas de Curie mais baixas, facilitando os experimentos), o comportamento da variação da resistividade não é tão uniforme, como se observa nos gráficos da figura 1.21.[64]

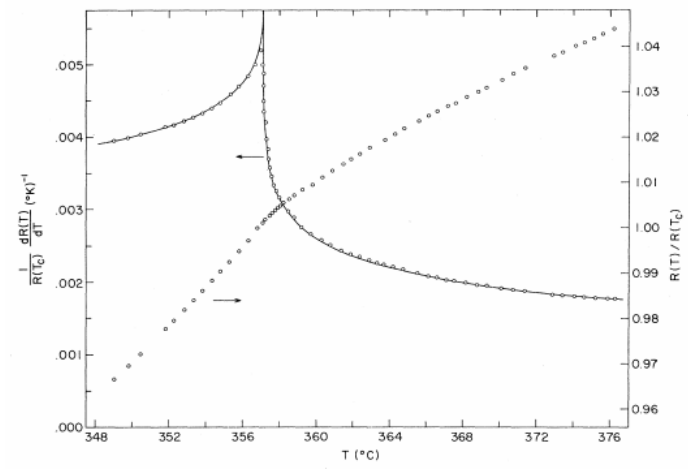

(a)

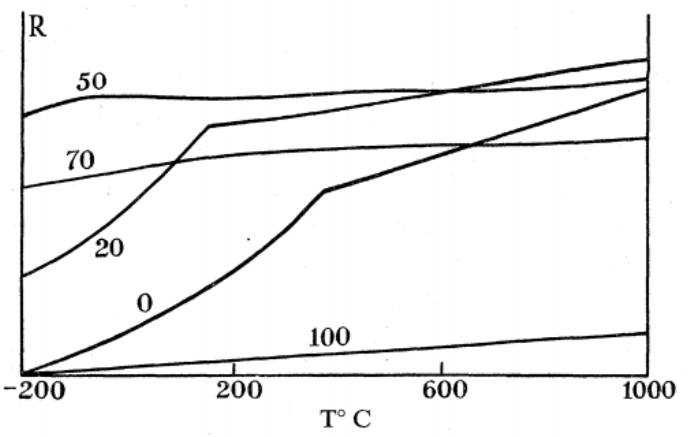

(b)

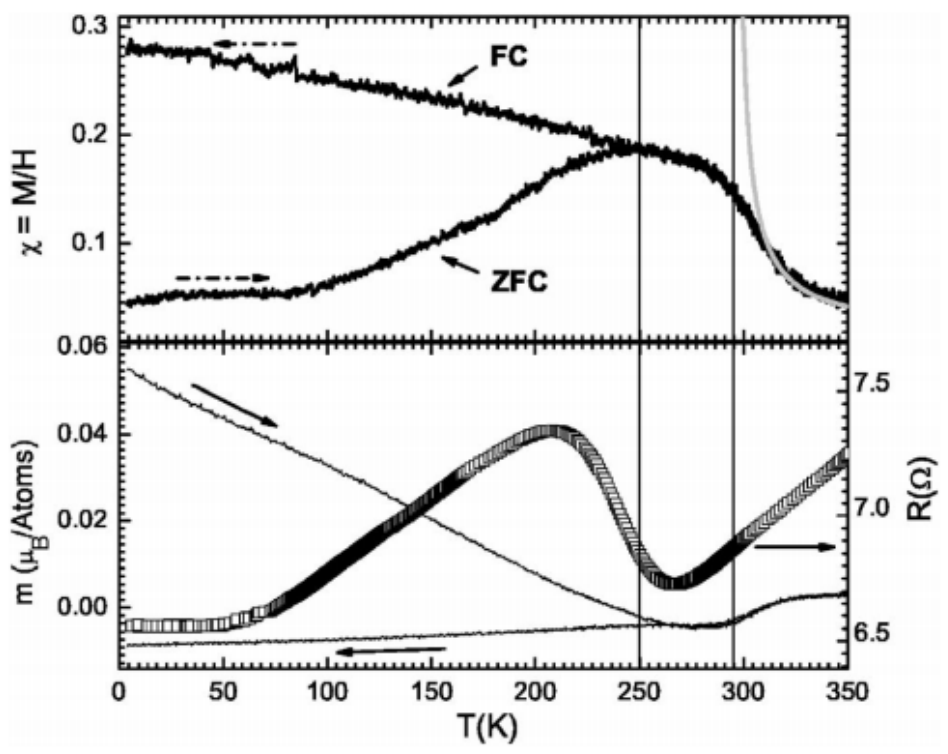

Figura 1.21: Acima, singularidades no máximo de variação da resistência de $\mathrm{Ni}$ (a)[65] e curvas da resistência para diferentes concentrações de cobre em $\mathrm{NiCu}$ (b)[62] em função da temperatura, amostras bulk. Logo abaixo, filmes finos da liga $\mathrm{Ni}_{58} \mathrm{Cu}_{42}$, com um mínimo da resistência na temperatura de transição magnética.[64] 


\subsection{Sistemas $\mathrm{NiCu} / \mathrm{AFM}$ cúbico}

Geralmente, bicamadas FM/AFM utilizam materiais tais que a temperatura de Curie do ferromagneto seja maior que a temperatura de Neél do antiferromagneto. Desse modo, a anisotropia unidirecional é induzida através de um field-cooling partindo de uma temperatura $\mathrm{T}_{C}>\mathrm{T}_{\max }>\mathrm{T}_{N}$ possibilitando que o ordenamento magnético da camada FM seja aplicado no ordenamento da camada AFM enquanto o sistema passa por $\mathrm{T}_{N}$.

No entanto, existe a possibilidade de bicamadas com exchange bias onde $\mathrm{T}_{C}<$ $\mathrm{T}_{N}$. Tal investigação começou em um sistema $\left[\mathrm{Fe}_{0,1} \mathrm{Ni}_{0,9}\right]_{8} \mathrm{~B}_{2} / \mathrm{CoO}\left(\mathrm{T}_{C}=240 \mathrm{~K}, \mathrm{~T}_{N}=\right.$ $290 \mathrm{~K}$ ), cujo FC induziu a anisotropia unidirecional apenas com o campo magnético do íma permanente.[66] Os efeitos de exchange bias e coercividade aumentada permaneceram no sistema até em temperaturas acima de $\mathrm{T}_{C}$, com uma dependência diferente da apresentada dos sistemas convencionais, como mostra a figura 1.22 a seguir. 


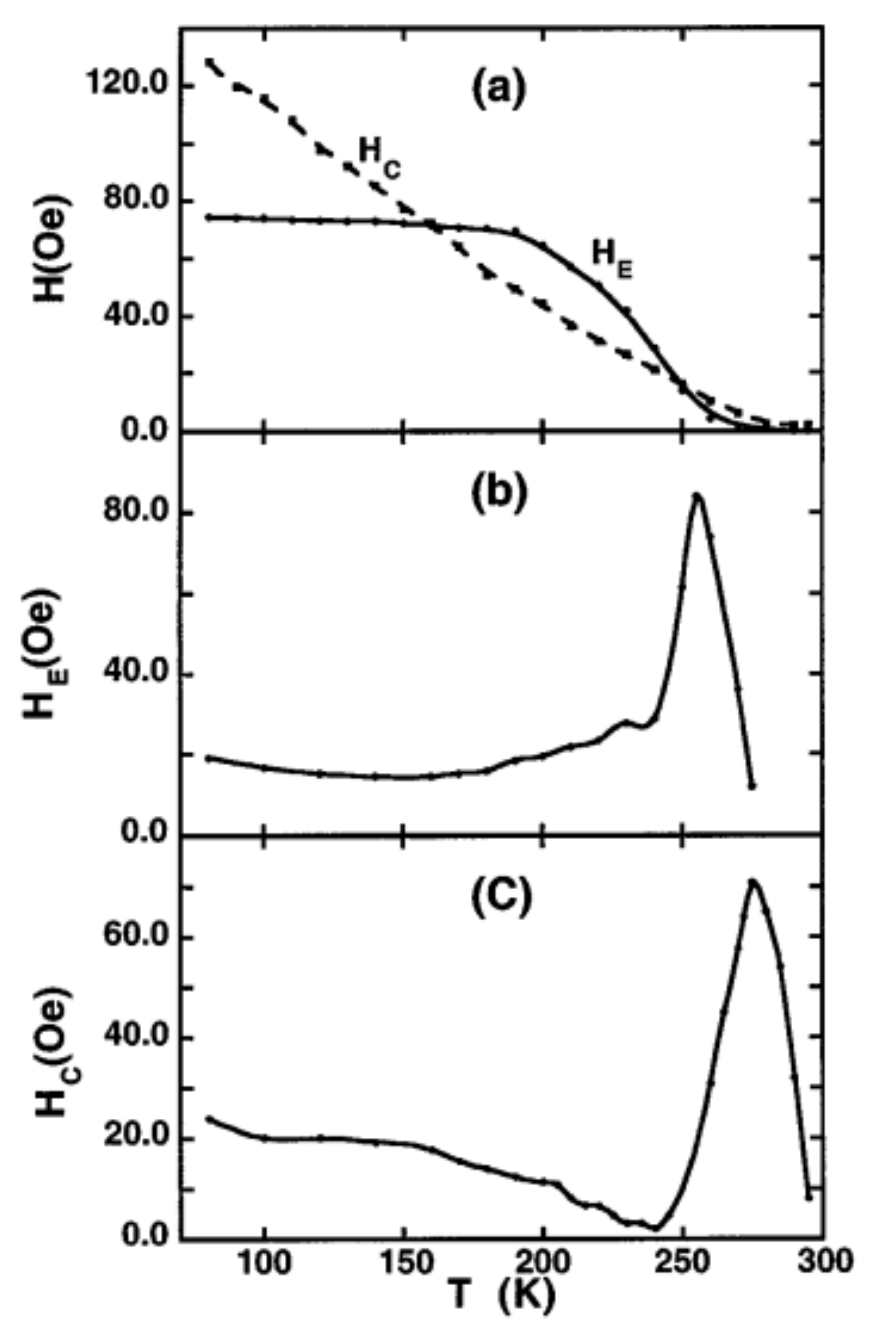

Figura 1.22: Comparação de bicamadas convencionais com não-convencionais $\left(\mathrm{T}_{C}<\mathrm{T}_{N}\right)$ : dependência de $\mathrm{H}_{E B}$ e $\mathrm{H}_{C}$ com a temperatura para $\mathrm{Py} / \mathrm{CoO}\left(30 \mathrm{~nm}\right.$ ) (a); dependência de $\mathrm{H}_{E B}$ (b) e $\mathrm{H}_{C}$ (c) com a temperatura para $\left[\mathrm{Fe}_{0,1} \mathrm{Ni}_{0,9}\right]_{8} \mathrm{~B}_{2}(90 \mathrm{~nm}) / \mathrm{CoO}(30 \mathrm{~nm})$. [66].

A diferença dos comportamentos se dá pela variação de $\mathrm{M}_{F M}$ : no caso convencional, essa grandeza quase não varia com $\mathrm{T}$, então $\mathrm{H}_{E B}(\mathrm{~T})$ e $\mathrm{H}_{C}(\mathrm{~T})$ respondem apenas por $\mathrm{J}_{\text {int }}(\mathrm{T})$ e $\mathrm{K}(\mathrm{T})$. Já no caso não convencional, $\mathrm{M}_{F M}$ diminui muito ao atingir $\mathrm{T}_{C}$, causando o crescimento de $\mathrm{H}_{E B}$ e $\mathrm{H}_{C}$ antes do sistema atingir $\mathrm{T}_{N}$.

Sistemas com $\mathrm{NiCu}$ também possuem um grau de controle de $\mathrm{T}_{C}$, e bicamadas não-convencionais com essa liga também foram estudadas (ver fig. 1.23). Acoplamento de $\mathrm{Ni}_{75} \mathrm{Cu}_{25}$ com $\mathrm{NiO}$ apresentou exchange bias tanto sob campo magnético durante a deposição quanto por irradiação de íons[67], mas o mesmo ferromagneto acoplado com IrMn apresentou apenas um aumento da coercividade. Acoplamento com FeMn apresentou exchange bias apenas com o AFM acoplado com cobalto.[68] 


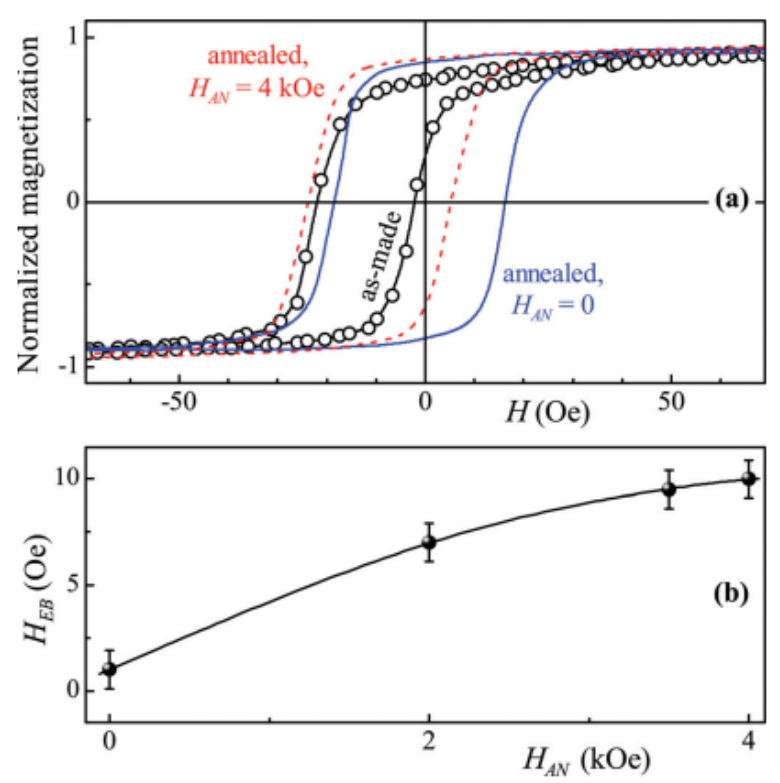

Figura 1.23: Influência da temperatura e campo aplicado no tratamento térmico em bicamadas $\mathrm{NiO}(50 \mathrm{~nm}) / \mathrm{Ni}_{75} \mathrm{Cu}_{25}$. [67].

Até então, era suposto que o ordenamento magnético da camada AFM vinha apenas da interação com a camada FM ordenada durante o FC. Porém, alguns dos resultados acima mostram que, mesmo a uma temperatura maior que $\mathrm{T}_{C}$, é possível ordenar o antiferromagneto para induzir a anisotropia unidirecional, abrindo um novo horizonte de possibilidades em sistemas de exchange bias. 


\subsection{Motivação}

As observações de Wu et al[67], Sossmeier et al[68] e Blamire et al[69] são completamente inesperadas mesmo para quem possui alguma experiência com sistemas de exchange bias. O estudo feito aqui pretende reproduzir algumas delas enquanto compara diferentes materiais.

Por um lado, há a comparação entre diferentes estequiometrias para a liga de níquel e cobre usada como ferromagneto fraco, incluindo algumas comparações com o níquel puro. Por outro, o uso de diferentes antiferromagnetos. O objetivo de ambas foi verificar se há alguma condição dentre as combinações possíveis que seja mais favorável para a anisotropia unidirecional em sistemas dessa natureza. Também foi explorada a possibilidade da construção de válvulas de spin funcionais com esse perfil não-usual utilizando os materiais apresentados. 


\section{Capítulo 2}

\section{Descrição Experimental}

\subsection{Produção de Amostras}

O equipamento utilizado para a deposição foi o ATC 2000 Magnetron Sputtering, da AJA International Inc. adquirido pelo Laboratório de Materiais Magnéticos do Departamento de Física dos Materiais e Mecânica do Instituto de Física da Universidade de São Paulo. A técnica consiste em ejetar material de alvos para uma superfície via colisão com íons e está esquematizada na figura 2.1. No caso, a fonte de íons é um plasma gasoso confinado em campo magnético de ímas permanentes localizados abaixo do alvo.

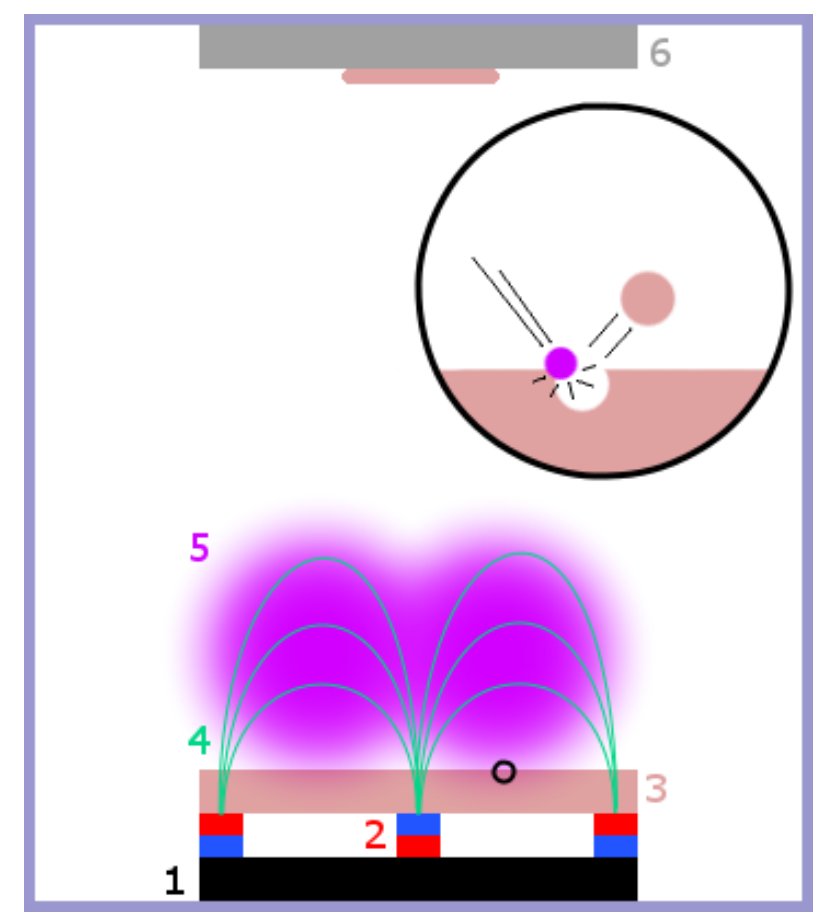

Figura 2.1: Esquema de deposição via magnetron sputtering. Íons do plasma (5) confinados no campo magnético (4) de ímãs permanentes (2) são acelerados contra o alvo (3) por um eletrodo (1). No detalhe, a ejeção de átomos do alvo pelos íons incidentes. Os átomos são então depositados no substrato (6). 
A pressão inicial da câmara de deposição foi de $7,0 \times 10^{-7}$ Torr ou menor por uma bomba turbomolecular. O gás utilizado para o plasma foi argônio (99,9999\% de pureza), por ser o mais inerte. Podem ser usados até quatro alvos (discos de duas polegadas de diâmetro e alguns milímetros de espessura) em uma sessão de deposições, que ficam acomodados acima de cada um dos quatro canhões de plasma. Alvos comerciais (99,99\% de pureza) dos seguintes materiais foram utilizados: $\mathrm{NiO}, \mathrm{Ni}, \mathrm{Py}\left(\mathrm{Ni}_{81} \mathrm{Fe}_{19}\right), \mathrm{Cu}$ para uma primeira sessão de deposições; $\mathrm{NiO}, \mathrm{Ni}, \mathrm{Cu}$ para uma segunda sessão; $\mathrm{Fe}_{50} \mathrm{Mn}_{50}$, $\operatorname{Ir}_{19} \mathrm{Mn}_{81}, \mathrm{Ni}, \mathrm{Cu}$ para a última. Um sistema de shutters impede que o material de um alvo se deposite sobre outro, evitando contaminações.

Placas de silício (100) foram utilizadas como substrato, tendo sido cortadas manualmente em quadrados com $10 \mathrm{~mm}$ de lado e retângulos de $5 \mathrm{~mm}$ por $10 \mathrm{~mm}$. As placas foram presas no porta-amostra com fita capton, três conjuntos por vez. Cada conjunto foi formado por um pedaço quadrado e dois pedaços retangulares. Um tipo de filme foi depositado em cada conjunto, formando três amostras de composição idêntica para cada filme. O porta-amostra possui tampas para cada conjunto, fazendo com que fosse possível depositar três filmes diferentes em cada transferência. O porta-amostra é preso a uma plataforma rotativa durante a deposição: esse movimento garante uniformidade e evita efeitos de sombra.

Uma fonte DC é utilizada para gerar o plasma sob alvos metálicos. Para o óxido de níquel, foi necessário utilizar uma fonte RF. Em ambos os casos, apenas a potência foi manipulada, com a tensão e corrente apenas vistoriadas para controle. Os parâmetros utilizados na deposição de cada camada estão detalhados na tabela a seguir, escolhidos a partir do histórico de uso do equipamento. 
Tabela 2.1: Parâmetros de deposição para cada alvo. As camadas de $\mathrm{NiCu}$ foram obtidas por co-deposição dos alvos de níquel e cobre, as demais camadas foram obtidas por deposição do alvo já na estequiometria desejada.

\begin{tabular}{|c|c|c|c|}
\hline camada & $\mathrm{P}(\mathrm{W})$ & $\mathrm{p}_{A r}$ (mTorr) & $\Phi_{A r}$ \\
\hline \hline $\mathrm{Py}$ & 120 & 3,0 & 20 \\
\hline $\mathrm{NiO}$ & 150 & 3,0 & 20 \\
\hline $\mathrm{Cu}$ & 100 & 3,0 & 20 \\
\hline $\mathrm{Ni}_{10} \mathrm{Cu}_{90}$ & $15(\mathrm{Ni})$ e $100(\mathrm{Cu})$ & 3,0 & 20 \\
\hline $\mathrm{Ni}_{30} \mathrm{Cu}_{70}$ & $40(\mathrm{Ni})$ e $65(\mathrm{Cu})$ & 3,0 & 20 \\
\hline $\mathrm{Ni}_{50} \mathrm{Cu}_{50}$ & $60(\mathrm{Ni})$ e $42(\mathrm{Cu})$ & 3,0 & 20 \\
\hline $\mathrm{Ni}_{70} \mathrm{Cu}_{30}$ & $115(\mathrm{Ni})$ e $35(\mathrm{Cu})$ & 3,0 & 20 \\
\hline $\mathrm{Ni}_{90} \mathrm{Cu}_{10}$ & $150(\mathrm{Ni})$ e $18(\mathrm{Cu})$ & 3,0 & 20 \\
\hline $\mathrm{Ni}$ & 150 & 3,0 & 20 \\
\hline $\mathrm{FeMn}$ & 100 & 5,0 & 20 \\
\hline $\mathrm{IrMn}$ & 120 & 4,0 & 70 \\
\hline
\end{tabular}

O valor da tensão elétrica esteve por volta dos $380 \mathrm{~V}$ com uma corrente de aproximadamente $300 \mathrm{~mA}$.

\subsection{Caracterização Estrutural}

\subsubsection{Difração de Raios-X}

Uma das técnicas mais fundamentais na análise de materiais sólidos é a difração de raios-X (XRD na sigla em inglês). A estrutura cristalina do material gera um padrão de difração para as ondas eletromagnéticas com alguns Angstroms de comprimento de onda, sem danificá-lo. As características do padrão de difração revelam detalhes sobre a estrutura cristalina, morfológica, composicional, etc.

A idéia geral foi desenvolvida por William Lawrence Bragg, assumindo que o feixe monocromático (comprimento de onfa $\lambda$ ) e paralelo incidindo sobre uma rede cristalina com um ângulo $\theta$ é refletido especularmente, como mostra a figura 2.2 . 


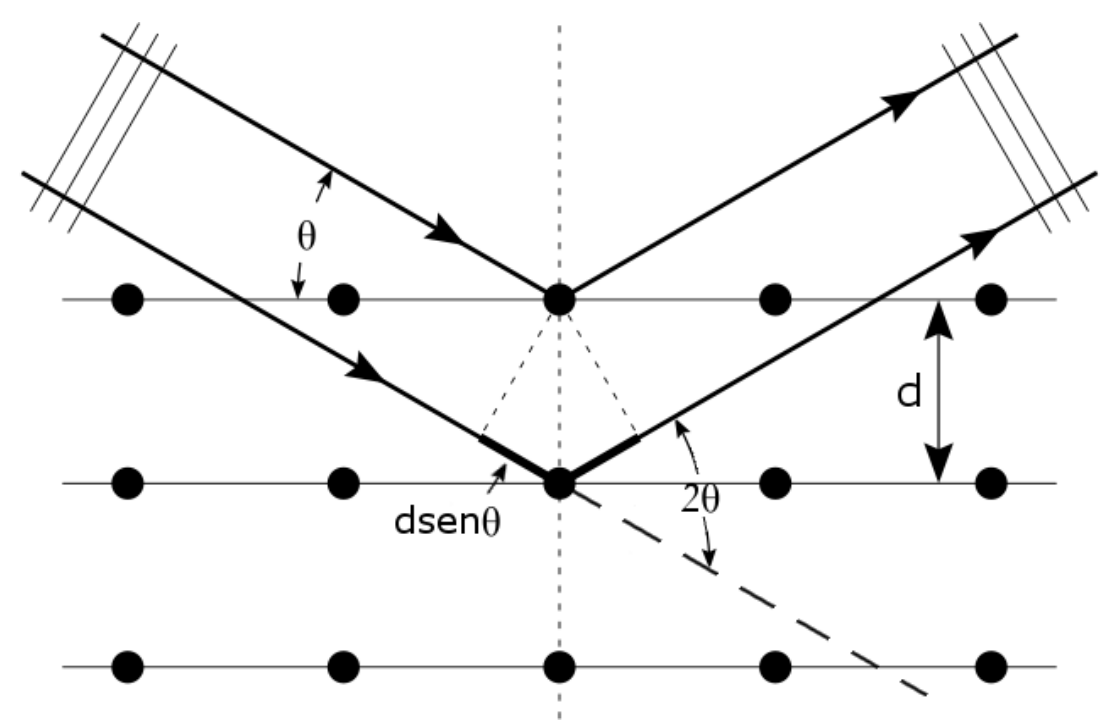

Figura 2.2: Esquema de difração de raios-x. Adaptado de [69].

Os raios são espalhados como ondas esféricas em cada átomo, e sofrem interferência construtiva de planos adjacentes (espaçados por uma distância $d$ ) com a seguinte condição:

$$
2 d \operatorname{sen}(\theta)=n \lambda
$$

Com o acúmulo de vários planos, apenas a intensidade da interferência construtiva é detectada.

A distância entre planos $d$ está relacionada com o parãmetro de rede $a$ do cristal através dos índices de Miller (h k l). Com as devidas substituições para uma rede cúbica e considerando apenas o pico de primeira ordem $(n=1)$, é obtida a seguinte equação:

$$
\left(\frac{\lambda}{2 a}\right)^{2}=\frac{\operatorname{sen}^{2}(\theta)}{h^{2}+k^{2}+l^{2}}
$$

O equipamento utilizado foi o difratômetro DR8 Advance, da Bruker, adquirido pelo Laboratório de Cristalografia do Departamento de Física Aplicada do IF-USP. As medidas foram realizadas com incidência rasante, $\theta$ fixado em $1,5^{\circ}$. O detector em $2 \theta$ cobriu de $38^{\circ}$ a $55^{\circ}$, com passo de $0,01^{\circ}$ na tentativa de distingüir os picos de FeMn e $\mathrm{NiCu}$. O passo durou entre 35s e 100s dependendo de cada amostra, por causa do baixo número de contagens. 
Varreduras em $\phi$ foram realizadas antes da varredura $2 \theta$ de cada amostra. Isso foi feito para fixar uma posição $\phi$ na qual os picos do substrato de silício não fossem incluídos no difratograma da varredura $2 \theta$ das diferentes amostras. O comprimento de onda utilizado em todas as medidas foi o da linha $\mathrm{K}_{\alpha}$ do cobre, $\lambda=1,5418 \AA$. Os difratogramas foram anaisados pelo programa Fityk com ajustes de função Voigt para a obtenção da largura a meia-altura de cada pico.

\subsubsection{Retroespalhamento Rutherford}

O experimento clássico de Ernest Rutherford consistiu em observar partículas alfa espalhadas por um filme fino de ouro, mostrando que os átomos são na maior parte "vazios" com um núcleo massivo de carga positiva, capaz até de espalhar as partículas para trás.

Esse arranjo batizado com seu nome (RBS na sigla em inglês) se mostrou eficaz para estudar filmes finos sem degradá-los. Um feixe monoenergético de íons incide sobre a amostra, a energia e intensidade com que são retroespalhados (detector a $170^{\circ}$ ) depende da espessura e composição das camadas.

O espectro pode ser calculado por primeiros princípios apenas com a suposição de espalhamento clássico com força central, gerando resultados precisos para a análise. A energia com que o íon é retroespalhado depende da razão entre as massas do íon e do átomo da amostra, o que identifica o elemento. O número de íons retroespalhados com aquela energia depende do número de átomos daquele elemento (e sua seção de choque de espalhamento) coberto pelo feixe incidente, o que identifica a estequiometria ao comparar com as contagens referentes aos outros elementos da mesma camada. Correções no valor da energia são aplicadas para camadas mais internas, uma vez que o feixe perde energia á medida que penetra na amostra (principalmente por desvios causados pelos elétrons).

O feixe utilizado foi de $\mathrm{He}^{+}$com energia de $2,2 \mathrm{MeV}$, acelerado pelo PelletronTandem 5SDH, construído pela National Electrostatic Corporation e mantido pelo Laboratório de Análises de Materiais por Feixes Iônicos, localizado no IF-USP. Os espectros foram analisados pelo programa SIMNRA. 


\subsection{Medidas de Magnetização}

\subsubsection{VSM}

Um magnetômetro de amostra vibrante (VSM na sigla em inglês), como o nome indica, mede a magnetização de uma amostra que vibra a uma certa freqüência. A amostra é magnetizada por um eletroímã, sua vibração faz com que o fluxo do campo magnético produzido por ela varie com o período da vibração, passando por bobinas coletoras. Pela lei de Faraday, uma corrente elétrica proporcional ao momento magnético da amostra e com o período da vibração é induzida nas bobinas.

O equipamento utilizado foi o VSM 7404 da LakeShore, adquirido pelo LMMDFMT-IF-USP. A magnetização da amostra é medida por um gaussímetro montado em quadrupólo acoplado a um sensor Hall orientado perpendicularmente ao campo aplicado pelo eletroíma, com precisão de medida dentro de 1\%. A abertura entre os pólos do eletroímã onde as amostras foram posicionadas media 33,0 mm.

As amostras foram fixadas em uma haste de acrílico com graxa Apiezon. Mais tarde, a última série de amostras foi medida novamente sem a graxa, mas atravessadas em um canudo de polipropileno fixado na haste com fita capton. Esse procedimento foi adotado para tentar diminuir o ruído nas medidas, uma vez que o sinal captado é relativamente baixo. O sistema de vibração ligado na haste vibra a uma freqüência de 82 Hz. A base da haste é acoplada a um motor de passo com precisão $<1^{\circ}$, possibilitando girar a amostra no plano horizontal automaticamente.

O eletroíma é alimentado por uma fonte de $2450 \mathrm{~W}, 35 \mathrm{~V}$ de tensão máxima de saída, 70 A de corrente máxima de saída. As peças polares possuem 2 polegadas de diâmetro, com abertura variável entre 16,3 mm e 38,1 mm. A homogeneidade do campo magnético aplicado é de $1 \mathrm{~cm}^{3} \pm 1 \%$. Na abertura utilizada nas medidas, o campo magnético máximo alcançado pelo equipamento corresponde a 1,17 T. 


\subsubsection{SQUID}

O dispositivo supercondutor de interfência quântica (SQUID na sigla em inglês) é um equipamento utilizado para medidas de momentos magnéticos extremamente sutis.

A idéia original foi de usar junções Josephson para identificar corrente elétrica induzida em um anel supercondutor devido ao fluxo magnético da amostra, com resolução de $\Phi_{0} / 2$ (meio quantum de fluxo magnético). Mas o sistema mais comum é o de amplificação de sinal.

Cada amostra foi magnetizada por um solenóide supercondutor que fica imerso em hélio líquido, se movendo lentamente durante a medida. Bobinas de Helmholtz coletam o fluxo pelo mesmo princípio do VSM, enquanto rejeitam o campo do solenóide com precisão de 0,1\%. O sinal das bobinas é acoplado no sensor SQUID através de um transformador supercondutor e amplificado.

Cada ponto de uma medida é uma média obtida por ajustes gaussianos de 32 deslocamentos cobrindo $4 \mathrm{~cm}$, realizado duas vezes. Por exemplo, o ponto $\mathrm{M}(\mathrm{H}=200 \mathrm{Oe})$ é a média de dois ajustes da curva $\mathrm{M}_{200 O e}(\mathrm{x})$, onde houveram 32 valores de $\mathrm{x}$ dentro de $4 \mathrm{~cm}$.

O equipamento utilizado foi o MPMS XL da Quantum Design, adquirido pelo DFMT-IF-USP. Sensibilidade de posicionamento da amostra de 0,0003 $\mathrm{cm}$ e possibilidade de operação em temperaturas de 1,9 K até $400 \mathrm{~K}$. Para um campo aplicado de até $5 \mathrm{kOe}$, a resolução alcançada é de 0,1 Oe. O campo máximo alcançado pelo equipamento corresponde a $7 \mathrm{~T}$.

Os valores de $\mathrm{H}_{C}$ e $\mathrm{H}_{E B}$ das curvas de magnetização obtidas tanto pelo SQUID quanto pelo VSM foram calculados com as seguintes fórmulas:

$$
H_{C}=\frac{H_{+}-H_{-}}{2} \quad H_{E B}=\frac{H_{+}+H_{-}}{-2}
$$

com $\mathrm{H}_{-}$e $\mathrm{H}_{+}$sendo o máximo da derivada da curva de desmagnetização (primeira metade do ciclo de histerese) e remagnetização (segunda metade), respectivamente.

Os valores acima foram encontrados assumindo uma distribuição gaussiana das coercividades dos filmes. No entanto, medidas muito ruidosas geravam ajustes de baixa qualidade, nesse caso os valores foram identificados visualmente, sem estimar incertezas. 


\subsection{Tratamentos Térmicos}

Para induzir (ou reforçar) uma anisotropia unidirecional, foi utilizado um forno de montagem própria do LMM-DFMT-IF-USP. A amostra permanece em uma câmara com pressão de 5,0 $\times 10^{-6}$ Torr ou menor mantida por uma bomba turbomolecular. Acima da câmara há um ímã permanente aplicando um campo magnético de $5 \mathrm{kOe}$. A temperatura máxima alcançada foi logo acima de $\mathrm{T}_{N}$ de cada antiferromagneto $\left(250^{\circ} \mathrm{C}\right.$ para o $\mathrm{NiO}, 230^{\circ} \mathrm{C}$ para o $\mathrm{FeMn}$ ), permanecendo apenas por 10 segundos, em seguida sendo resfriada lentamente (isto é, forno desligado, mas câmara ainda fechada).

Outra tentativa de tratamento térmico se deu no SQUID. Aplicando a temperatura mais alta possível $(400 \mathrm{~K})$ e resfriando a amostra imediatamente sob o campo mais intenso possível $(70 \mathrm{kOe})$. 


\section{Capítulo 3}

\section{Resultados}

Neste capítulo são apresentados os resultados dos procedimentos descritos no capítulo 2. A princípio, é apresentada uma lista das amostras produzidas, seguida dos espectros de RBS e difratogramas de raios-X com suas respectivas análises. Após as características estruturais, serão apresentadas as propriedades magnéticas, que incluem análises das curvas ZFC/FC, curvas de magnetização a diferentes temperaturas no SQUID e curvas de magnetização a temperatura ambiente em função do ângulo no VSM com as análises correspondentes.

\subsection{Descrição das Amostras}

No escopo deste trabalho, foram realizadas deposições de três seqüências distintas. Foram utilizados os parâmetros da tabela 2.1, sendo que a espessura de cada camada foi controlada pelo tempo de deposição e uma camada de cobre sempre foi adicionada no topo para proteção contra oxidação.

Depois das medidas mais gerais nas amostras do grupo 1, novas decisões a respeito dos parâmetros foram tomadas: considerar o uso dos outros 2 antiferromagnetos, fixar a espessura da camada de $\mathrm{Ni}_{x} \mathrm{Cu}_{1-x}$ em 30nm e trabalhar apenas com as três composições mais ricas em níquel. 
A figura seguinte descreve as amostras do grupo 1:

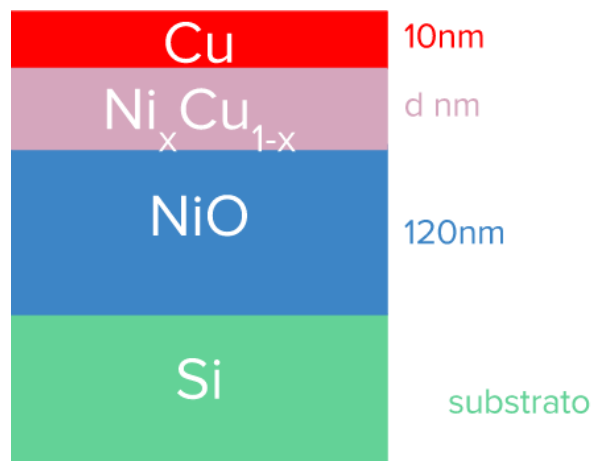

Figura 3.1: Amostras 1A $(x=50, d=50), 1 A-I I ~(x=50, d=30), 1 B(x=70, d=30)$ e $1 \mathrm{C}(x=90$, $\mathrm{d}=30)$.

A próxima figura descreve as amostras do grupo 2:

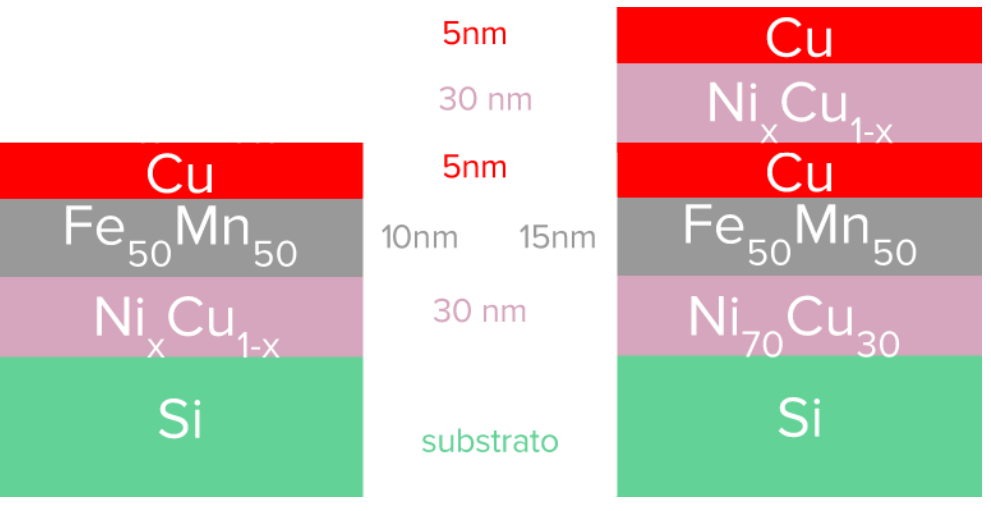

Figura 3.2: À esquerda: bicamadas $2 \mathrm{~A}(\mathrm{x}=50), 2 \mathrm{~B}(\mathrm{x}=70), 2 \mathrm{C}(\mathrm{x}=90)$ e $2 \mathrm{D}(\mathrm{x}=100$, ou seja, níquel puro). À direita: multicamadas $2 \mathrm{E}(\mathrm{x}=50), 2 \mathrm{~F}(\mathrm{x}=70), 2 \mathrm{G}(\mathrm{x}=90)$ e $2 \mathrm{H}(\mathrm{x}=100$, ou seja, níquel puro). 
A figura seguinte descreve as amostras do grupo 3:

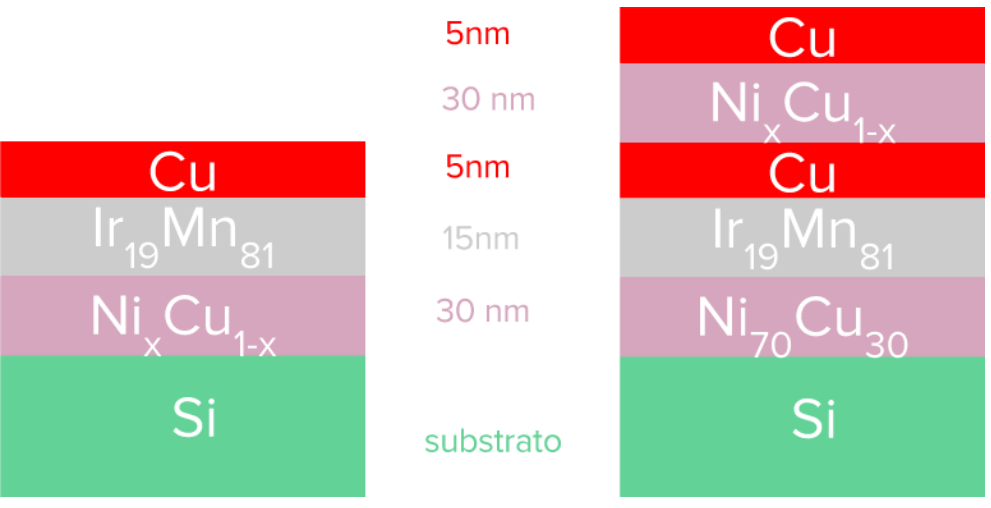

Figura 3.3: À esquerda: bicamadas 3A $(x=50), 3 B(x=70), 3 C(x=90)$ e 3D $(x=100$, ou seja, níquel puro). À direita: multicamadas $3 \mathrm{E}(\mathrm{x}=50), 3 \mathrm{~F}(\mathrm{x}=70), 3 \mathrm{G}(\mathrm{x}=90)$ e $3 \mathrm{H}(\mathrm{x}=100$, ou seja, níquel puro). 
A tabela 3.1 resultante da análise dos espectros RBS descreve os resultados para as amostras que receberam mais ênfase.

Tabela 3.1: Estequiometria e espessuras encontradas nas bicamadas através do ajuste da simulação do SIMNRA sobre os espectros de RBS.

\begin{tabular}{|c|c|}
\hline valores nominais & valores encontrados \\
\hline $\begin{array}{l}\mathrm{Ni}_{50} \mathrm{Cu}_{50}(30 \mathrm{~nm}) / \\
\mathrm{Fe}_{50} \mathrm{Mn}_{50}(10 \mathrm{~nm}) / \mathrm{Cu}(5 \mathrm{~nm})\end{array}$ & $\mathrm{Ni}_{41,4} \mathrm{Cu}_{58,6}(29,5 \mathrm{~nm}) / \mathrm{Fe}_{55,6} \mathrm{Mn}_{44,4}(8,5 \mathrm{~nm}) / \mathrm{Cu}(7,3 \mathrm{~nm})$ \\
\hline $\begin{array}{l}\mathrm{Ni}_{70} \mathrm{Cu}_{30}(30 \mathrm{~nm}) / \\
\mathrm{Fe}_{50} \mathrm{Mn}_{50}(10 \mathrm{~nm}) / \mathrm{Cu}(5 \mathrm{~nm})\end{array}$ & $\mathrm{Ni}_{54,8} \mathrm{Cu}_{45,2}(30,1 \mathrm{~nm}) / \mathrm{Fe}_{44,0} \mathrm{Mn}_{56,0}(13,0 \mathrm{~nm}) / \mathrm{Cu}(5,5 \mathrm{~nm})$ \\
\hline $\begin{array}{l}\mathrm{Ni}_{90} \mathrm{Cu}_{10}(30 \mathrm{~nm}) / \\
\mathrm{Fe}_{50} \mathrm{Mn}_{50}(10 \mathrm{~nm}) / \mathrm{Cu}(5 \mathrm{~nm})\end{array}$ & $\mathrm{Ni}_{72,0} \mathrm{Cu}_{28,0}(15,8 \mathrm{~nm}) / \mathrm{Fe}_{47,4} \mathrm{Mn}_{52,6}(12,7 \mathrm{~nm}) / \mathrm{Cu}(3,4 \mathrm{~nm})$ \\
\hline $\begin{array}{l}\mathrm{Ni}(30 \mathrm{~nm}) / \\
\mathrm{Fe}_{50} \mathrm{Mn}_{50}(10 \mathrm{~nm}) / \mathrm{Cu}(5 \mathrm{~nm})\end{array}$ & $\mathrm{Ni}(17,8 \mathrm{~nm}) / \mathrm{Fe}_{52,0} \mathrm{Mn}_{48,0}(12,0 \mathrm{~nm}) / \mathrm{Cu}(5,0 \mathrm{~nm})$ \\
\hline $\begin{array}{l}\mathrm{Ni}_{50} \mathrm{Cu}_{50}(30 \mathrm{~nm}) / \\
\mathrm{Ir}_{20} \mathrm{Mn}_{80}(15 \mathrm{~nm}) / \mathrm{Cu}(5 \mathrm{~nm})\end{array}$ & $\mathrm{Ni}_{38,6} \mathrm{Cu}_{61,4}(19,4 \mathrm{~nm}) / \mathrm{Ir}_{26,1} \mathrm{Mn}_{73,9}(16,6 \mathrm{~nm}) / \mathrm{Cu}(6,1 \mathrm{~nm})$ \\
\hline $\begin{array}{l}\mathrm{Ni}_{90} \mathrm{Cu}_{10}(30 \mathrm{~nm}) / \\
\mathrm{Ir}_{20} \mathrm{Mn}_{80}(15 \mathrm{~nm}) / \mathrm{Cu}(5 \mathrm{~nm})\end{array}$ & $\mathrm{Ni}_{70,1} \mathrm{Cu}_{29,9}(23,4 \mathrm{~nm}) / \mathrm{Ir}_{22,9} \mathrm{Mn}_{77,1}(19,9 \mathrm{~nm}) / \mathrm{Cu}(6,3 \mathrm{~nm})$ \\
\hline $\begin{array}{l}\mathrm{Ni}(30 \mathrm{~nm}) / \\
\mathrm{Ir}_{20} \mathrm{Mn}_{80}(15 \mathrm{~nm}) / \mathrm{Cu}(5 \mathrm{~nm})\end{array}$ & $\mathrm{Ni}(21,9 \mathrm{~nm}) / \operatorname{Ir}_{29,6} \operatorname{Mn}_{70,4}(15,3 \mathrm{~nm}) / \mathrm{Cu}(6,3 \mathrm{~nm})$ \\
\hline
\end{tabular}

A estequiometria alcançada para a maioria das camadas FM se mostrou mais rica em $\mathrm{Cu}$ do que o planejado, devido à alta taxa de deposição desse elemento.

As camadas AFM possuem espessura e estequiometria razoavelmente próximas dos valores nominais.

Entretanto, assim como no caso das multicamadas, alguns resultados da análise de RBS para as bicamadas foram afetados negativamente devido ao grande numero de sobreposições de picos. Essa situação pode ser visualisada na figura 3.4. 


\subsection{Análise Estrutural}

Os espectros obtidos por RBS são tipicamente como mostra a figura 3.4 a seguir.
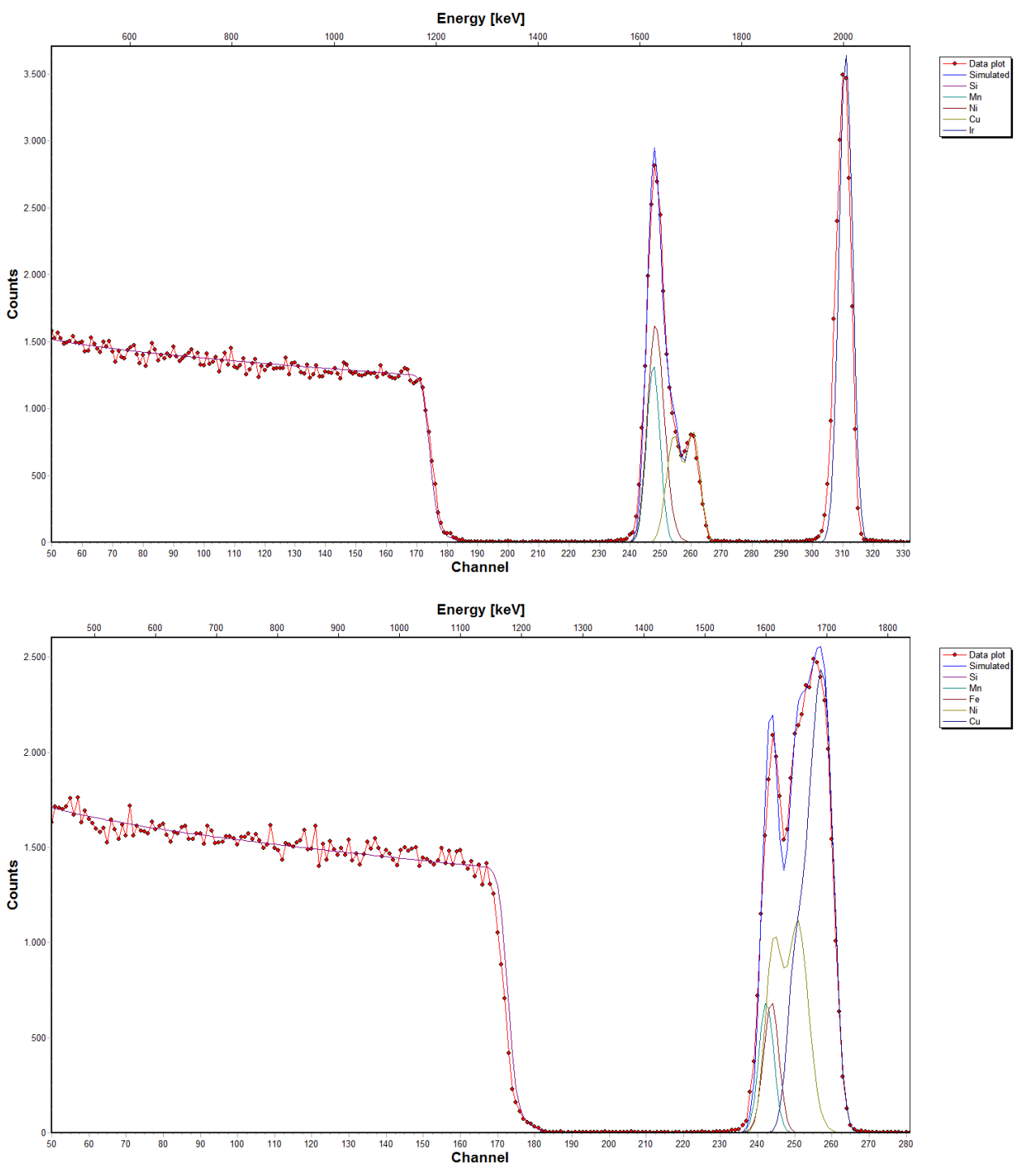

Figura 3.4: Espectro de RBS para a bicamada $\mathrm{Ni}_{90} \mathrm{Cu}_{10} / \mathrm{Ir}-\mathrm{Mn}$ e válvula $\mathrm{Ni}_{50} \mathrm{Cu}_{50} / \mathrm{FeMn}$. Os pontos vermelhos são esperimentais, interligados para facilitar a visão. As linhas coloridas são simulações ajustadas de cada elemento, com a azul sendo a curva resultante.

Nem todos os picos estão isolados (lembrando que as posições dependem tanto da localização da camada no filme quanto da seção de choque de espalhamento do átomo de cada elemento), complicando o ajuste da simulação. Com ainda mais picos sobrepostos, a realização de um ajuste razoável para os espectros das multicamadas não levou a resultados conclusivos. 
A figura 3.5 mostra os difratogramas de raios-X para as monocamadas ferromagnéticas e bicamadas produzidas.

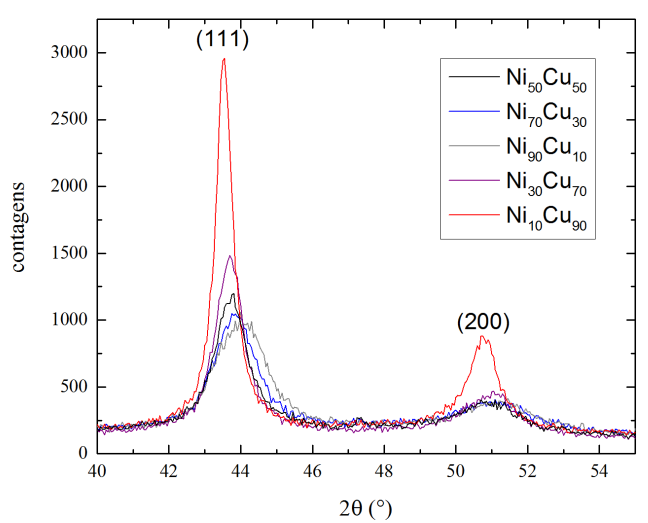

(a)

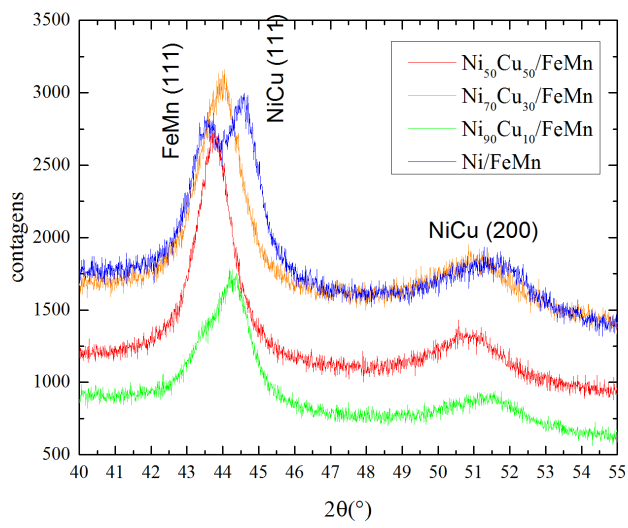

(c)

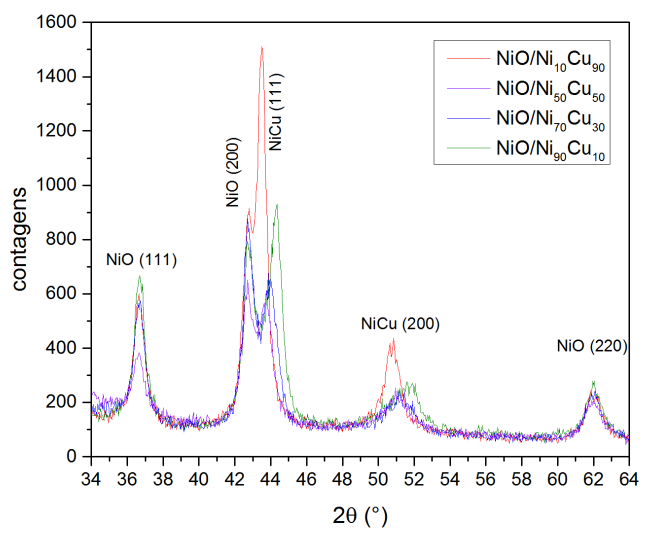

(b)

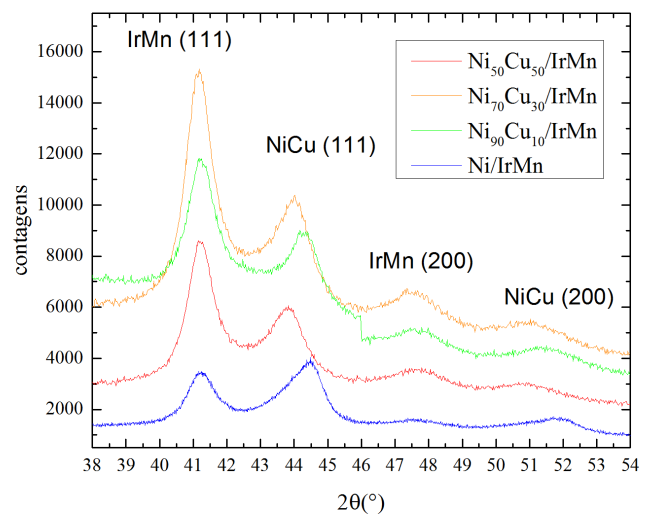

$(d)$

Figura 3.5: Difração de raios-x com incidência a baixo ângulo de cada conjunto de amostras: $\mathrm{Ni}_{x} \mathrm{Cu}_{1-x} / \mathrm{Cu}(\mathrm{a}), \mathrm{NiO} / \mathrm{Ni}_{x} \mathrm{Cu}_{1-x} / \mathrm{Cu}$ (b), $\mathrm{Ni}_{x} \mathrm{Cu}_{1-x} / \mathrm{FeMn} / \mathrm{Cu}$ (c) e $\mathrm{Ni}_{x} \mathrm{Cu}_{1-x} / \mathrm{IrMn} / \mathrm{Cu}$ (d).

Os picos obtidos são relativamente largos, o que significa que os grãos são pequenos o bastante para espalhar os raios-X em uma faixa ampla de ângulos. Desse modo, foi possível aplicar a equação de Scherrer para obter a extensão do grão em cada direção cristalográfica:

$$
d=\frac{K \lambda}{\beta \cos \theta}
$$

sendo $d$ é a extensão do grão, $K$ é o parâmetro de forma (aproximado para 0,9 no caso de grão esférico), $\lambda$ é o comprimento de onda do raio-X, $\beta$ é a largura total a meia altura do pico e $\theta$ sua posição. 
Além do tamanho do grão, o parâmetro de rede em algumas direções cristalográficas foi calculado através da equação 2.2. Os resultados dos cálculos estão apresentados na tabela 3.2.

Tabela 3.2: Parâmetros nas principais direções de $\mathrm{Ni}_{x} \mathrm{Cu}_{1-x}$ obtidos com os difratogramas de raios-x. As letras (a), (b), (c) e (d) das camadas de IrMn correspondem àquelas usadas em bicamadas com ordem crescente em quantidade de níquel, logo abaixo de cada uma.

\begin{tabular}{|c|c|c|}
\hline camada (direção) & tamanho do grão $(\mathrm{nm})$ & parâmetro de rede (nm) \\
\hline \hline $\mathrm{IrMn}(111)^{(a)}$ & $8,7 \pm 2,5$ & $0,38 \pm 0,08$ \\
\hline $\mathrm{Ni}_{50} \mathrm{Cu}_{50}(111)$ & $6,1 \pm 1,8$ & $0,36 \pm 0,18$ \\
\hline \hline $\mathrm{IrMn}(111)^{(b)}$ & $8,6 \pm 2,6$ & $0,38 \pm 0,08$ \\
\hline $\mathrm{Ni}_{70} \mathrm{Cu}_{30}(111)$ & $5,7 \pm 1,6$ & $0,38 \pm 0,21$ \\
\hline \hline${\mathrm{IrMn}(111)^{(c)}}^{(a)}$ & $9,3 \pm 2,2$ & $0,38 \pm 0,06$ \\
\hline $\mathrm{Ni}_{90} \mathrm{Cu}_{10}(111)$ & $9,5 \pm 2,3$ & $0,35 \pm 0,07$ \\
\hline \hline $\mathrm{IrMn}(111)^{(d)}$ & $7,9 \pm 3,0$ & $0,38 \pm 0,10$ \\
\hline $\mathrm{Ni}(111)$ & $5,7 \pm 2,0$ & $0,35 \pm 0,09$ \\
\hline
\end{tabular}

Ainda que os valores de incerteza sejam altos (devido ao ruído e baixo número de contagens, mesmo com até $24 \mathrm{~h}$ de medida), é possível notar uma alta regularidade nos valores de cada parâmetro de rede $a$, embora fosse esperado um aumento para o $a$ da liga $\mathrm{NiCu}$ proporcional à quantidade de cobre. O parâmetro de rede do IrMn observado está compatível com o valor encontrado por Anderson[45].

Mesmo assim, o parâmetro de rede de $\mathrm{NiCu}$ se encontra dentro dos limites esperados: os menores valores de $a$ estão nas camadas com mais $\mathrm{Ni}$, até o parâmetro de rede do níquel $(0,350 \mathrm{~nm})$ e sempre menor que o do cobre $(0,359 \mathrm{~nm}$, exceto quando $\mathrm{x}=70$, que teve a maior incerteza).[70]

O tamanho dos grãos também ficou aproximadamente constante, sendo os de IrMn maiores que os de $\mathrm{NiCu}$ em todas as amostras. É importante salientar que os resultados (inferiores a 10nm) estão dentro dos limites aplicáveis da equação de Scherrer (até algumas centenas de $\mathrm{nm}$ ). 


\subsection{Propriedades Magnéticas}

\subsubsection{Bicamadas}

Uma medida eficaz para encontrar a temperatura de bloqueio das bicamadas é a partir das curvas ZFC/FC. Utilizando o SQUID, cada amostra foi resfriada a $6 \mathrm{~K}$ sem campo magnético aplicado (em inglês: "Zero Field-Cooled"), para em seguida aplicar um campo de 100 Oe e medir a curva de magnetização em função da temperatura até $300 \mathrm{~K}$. Ainda sob esse campo, a amostra é então resfriada para $6 \mathrm{~K}$ novamente, com sua magnetização registrada para formar a curva FC ("Field-Cooled").

A figura 3.6 mostra as curvas $\mathrm{ZFC} / \mathrm{FC}$ para as bicamadas $\mathrm{NiO} / \mathrm{Ni}_{x} \mathrm{Cu}_{1-x} / \mathrm{Cu}$.

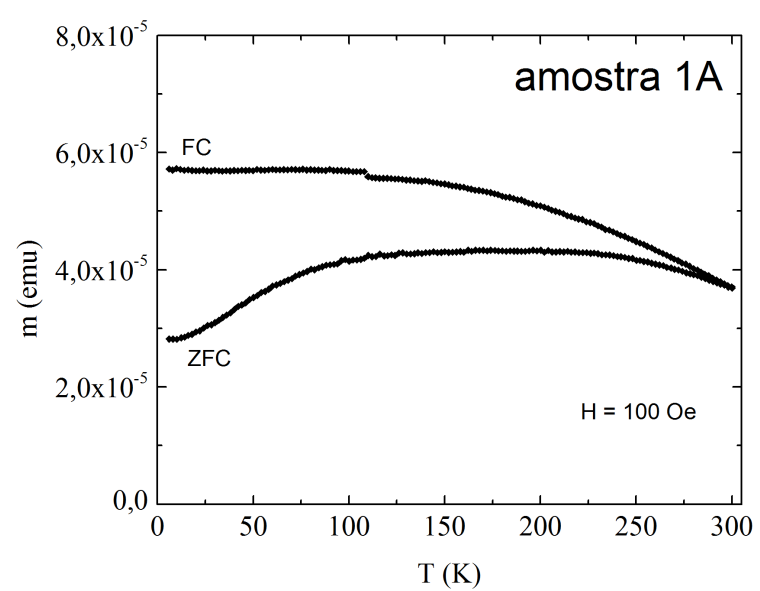

(a)

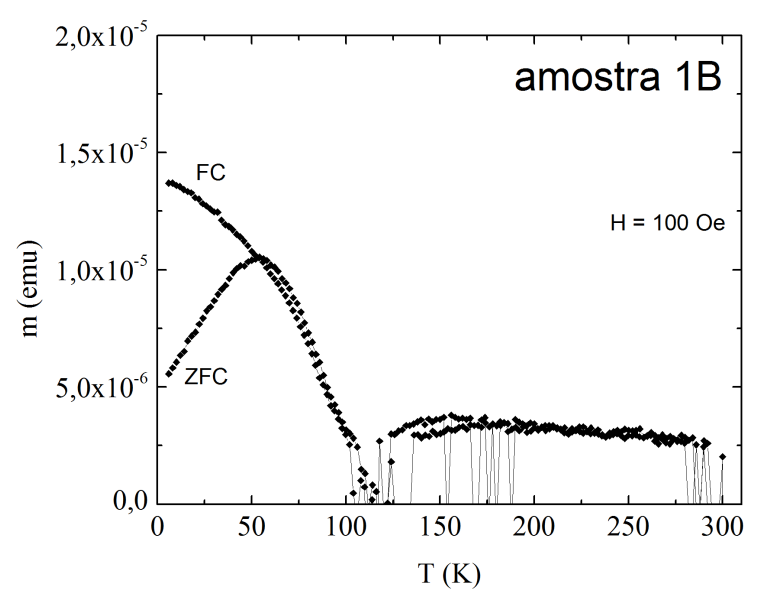

(b)

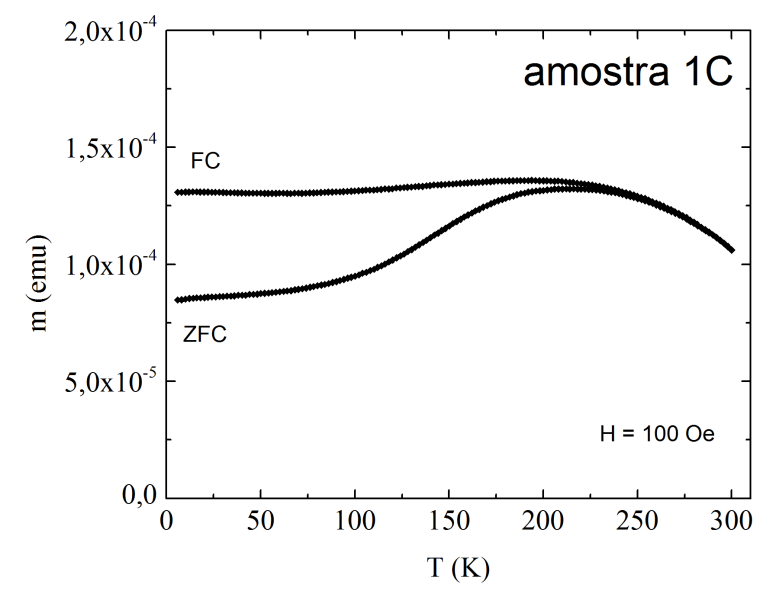

(c)

Figura 3.6: Curvas ZFC/FC para as bicamadas do grupo 1. 
A diferença entre as curvas ZFC e FC mostra a região de irreversibilidade na magnetização do sistema, ou seja, a faixa de temperaturas onde existe coercividade. A temperatura de bloqueio, acima da qual o regime superparamagnético seria atingido nas medidas com o SQUID, é identificada com o máximno da curva ZFC, e está em torno dos $50 \mathrm{~K}$ para $1 \mathrm{~A}$ e $1 \mathrm{~B}$ e de $210 \mathrm{~K}$ para $1 \mathrm{C}$. No entanto, para a primeira amostra, a separação das duas curvas indica uma grande distribuição de coercividades para os grãos, possibilitando histerese magnética para temperaturas até $250 \mathrm{~K}$.

Curvas de magnetização em função do campo magnético foram então medidas em diferentes temperaturas para observar a variação dos campos coercivo e de exchange bias em função da temperatura.

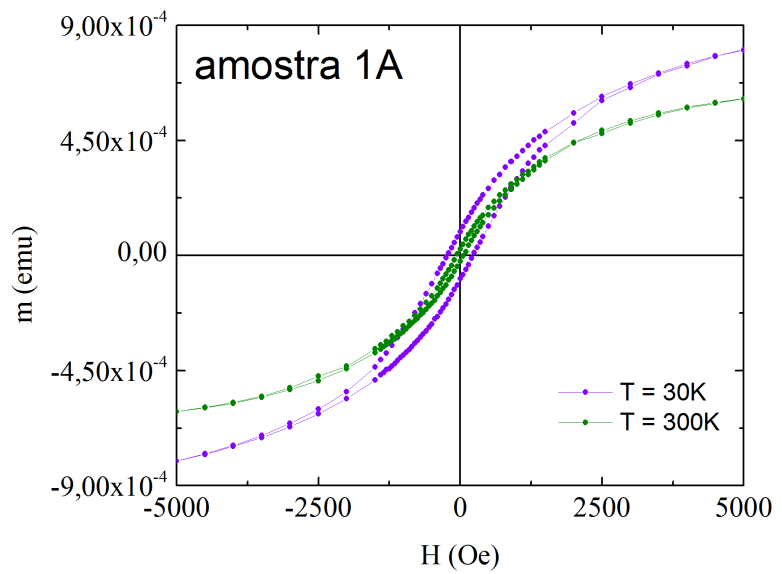

(a)

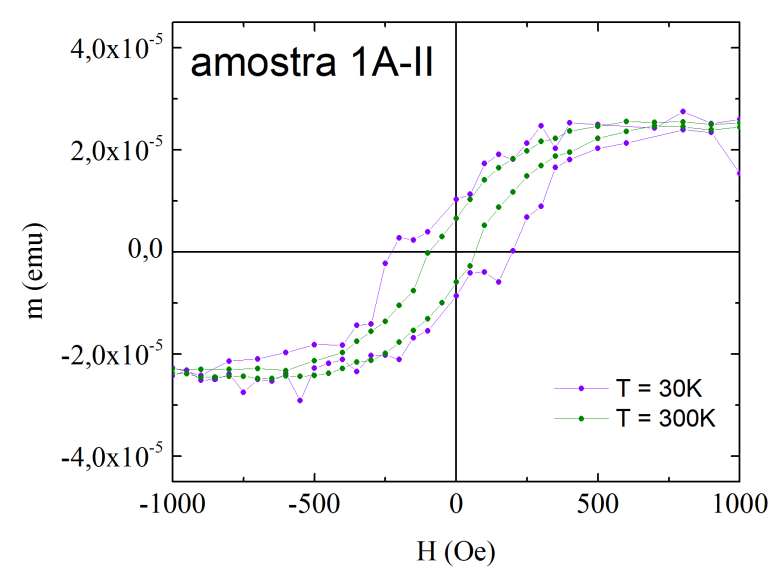

(c)

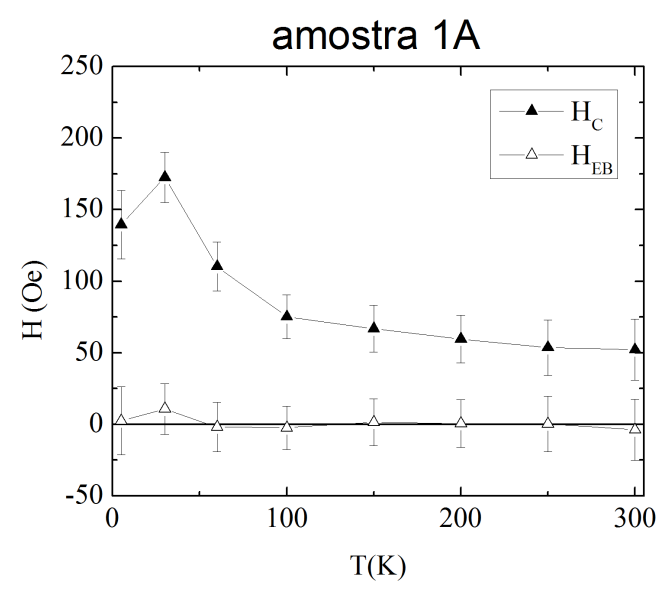

(b)

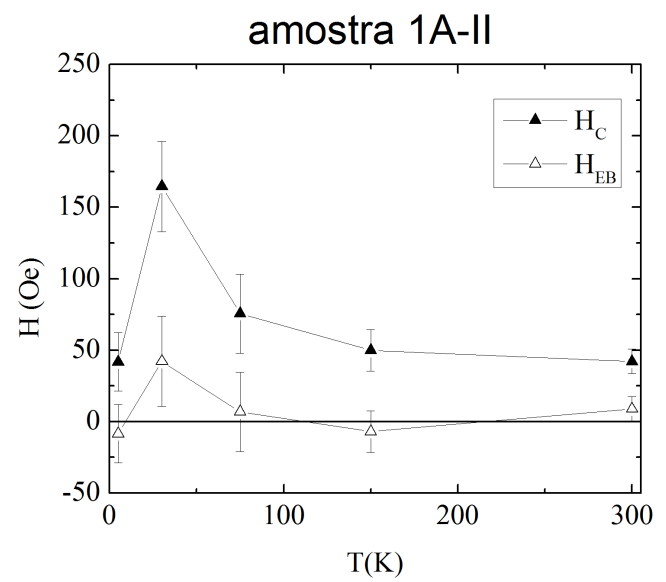

(d)

Figura 3.7: Curvas de magnetização e $\mathrm{H}_{C}$ e $\mathrm{H}_{E B}$ em função de $\mathrm{T}$ para bicamadas $\mathrm{NiO} / \mathrm{Ni}_{50} \mathrm{Cu}_{50} / \mathrm{Cu}$. Em (a) e (c). A espessura da camada $\mathrm{Ni}_{50} \mathrm{Cu}_{50}$ é de $50 \mathrm{~nm}$ em (a) e (b), $30 \mathrm{~nm}$ em (c) e (d). 
A figura 3.7 compara os efeitos das diferentes espessuras de $\mathrm{Ni}_{50} \mathrm{Cu}_{50}$ nas propriedades das bicamadas $\mathrm{NiO} / \mathrm{Ni}_{50} \mathrm{Cu}_{50} / \mathrm{Cu}$. A variação de $\mathrm{H}_{C}$ e $\mathrm{H}_{E B}$ com a temperatura segue o mesmo padrão para ambas, com valores um pouco maiores para a camada mais espessa, justificando o uso da espessura de 30nm nas outras amostras.

A seguir, curvas de magnetização para a amostra 1B.

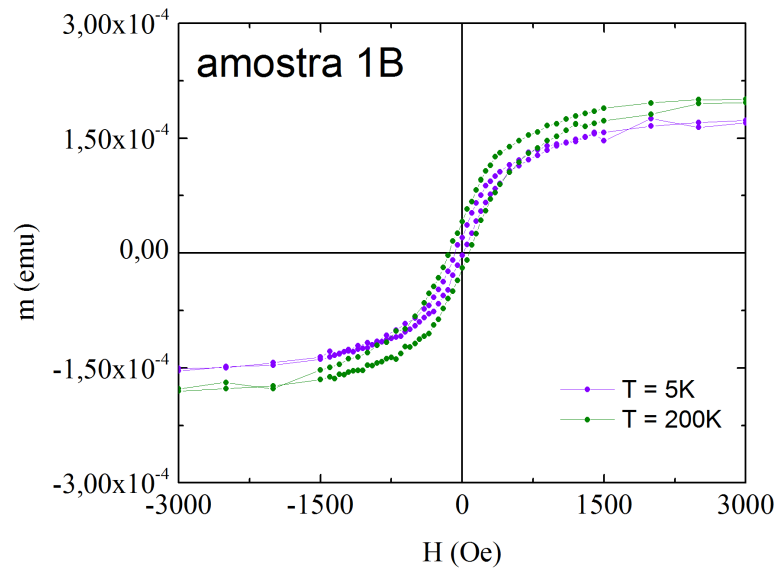

(a)

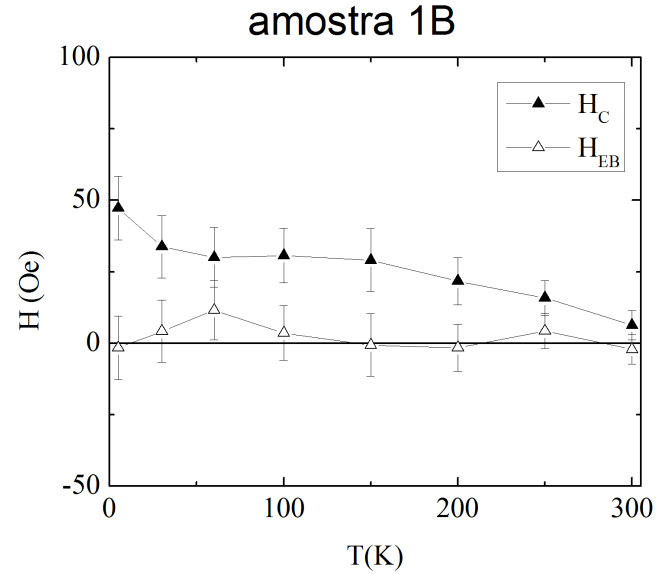

(b)

Figura 3.8: Curvas de magnetização e $\mathrm{H}_{C}$ e $\mathrm{H}_{E B}$ em função de $\mathrm{T}$ para bicamadas $\mathrm{NiO} / \mathrm{Ni}_{70} \mathrm{Cu}_{30}[30 \mathrm{~nm}] / \mathrm{Cu}$. 
A figura 3.9 mostra a magnetização da bicamada $\mathrm{NiO} / \mathrm{Ni}_{90} \mathrm{Cu}_{10} / \mathrm{Cu}$ em função da temperatura, utilizando a espessura $30 \mathrm{~nm}$ para a camada $\mathrm{Ni}_{90} \mathrm{Cu}_{10}$. A coercividade desaparece depois dos 200K, concordando com a figura 3.6c.

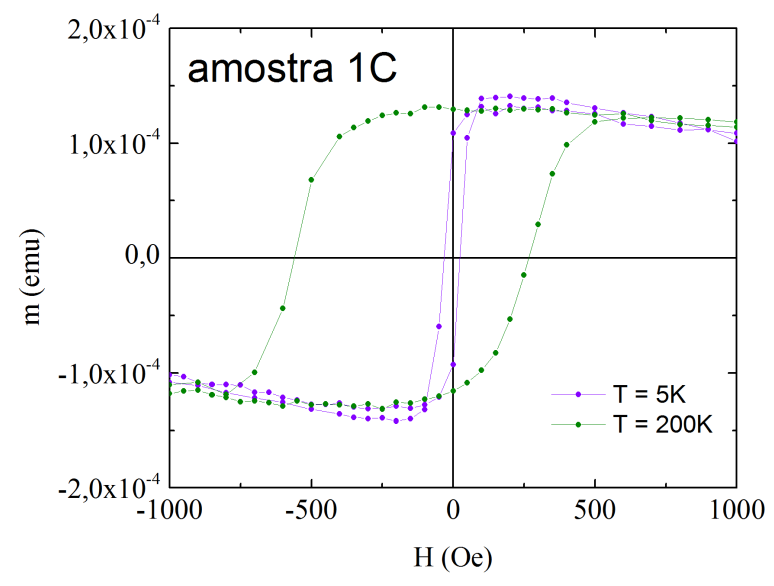

(a)

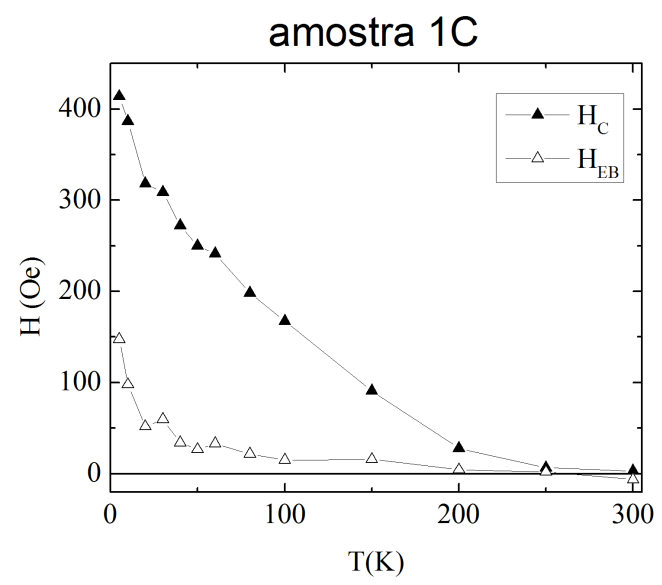

(b)

Figura 3.9: Curvas de magnetização e $\mathrm{H}_{C}$ e $\mathrm{H}_{E B}$ em função de $\mathrm{T}$ para bicamadas $\mathrm{NiO} / \mathrm{Ni}_{90} \mathrm{Cu}_{10} / \mathrm{Cu}$.

Ainda nas medidas com o SQUID, é possível perceber que nenhuma das bicamadas $\mathrm{NiO} / \mathrm{Ni}_{x} \mathrm{Cu}_{1-x} / \mathrm{Cu}$ mantem $\mathrm{H}_{E B}$ a $300 \mathrm{~K}$, além de apresentarem uma coercividade muito baixa nas temperaturas mais altas. Esse fato se repetiu nas medidas no VSM: baixa coercividade e ausência de anisotropia unidirecional em praticamente todas as amostras, como ilustra a figura 3.10 a seguir. 


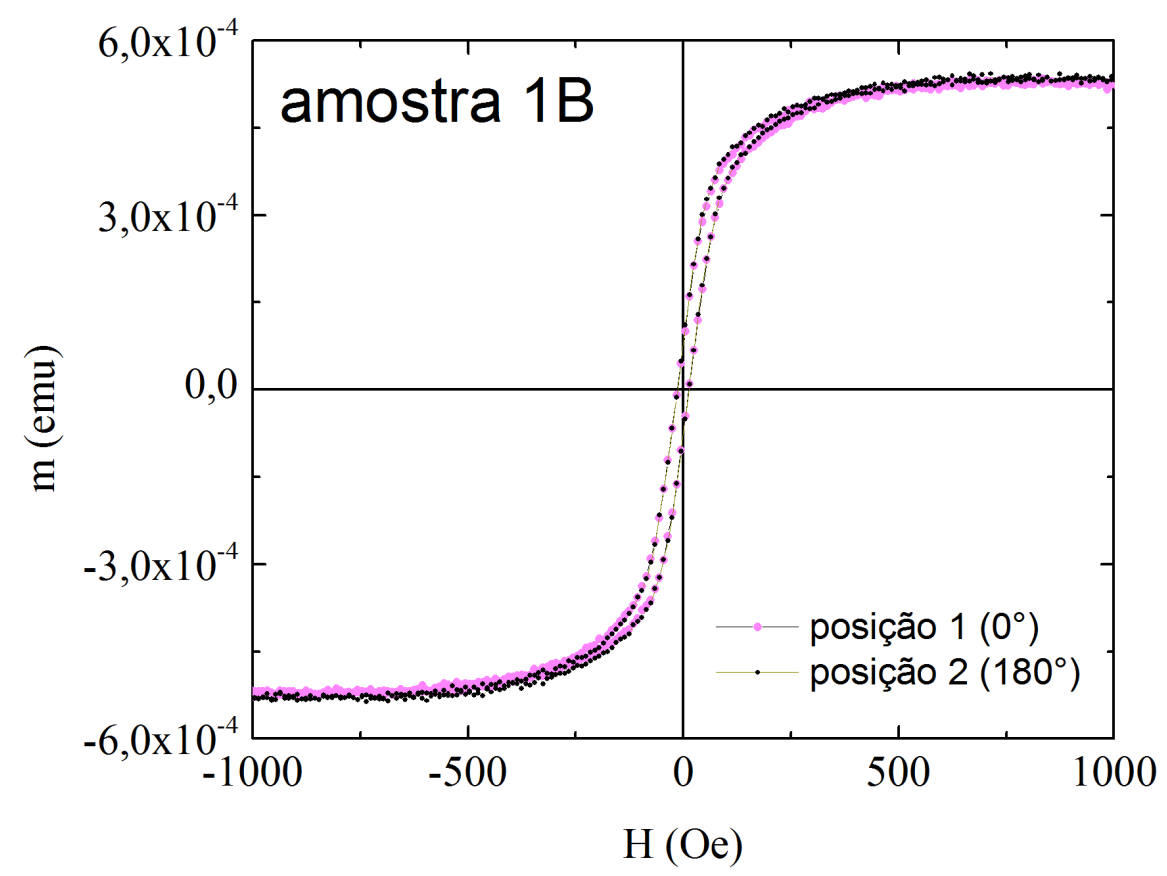

Figura 3.10: Ciclos de histerese da bicamada $\mathrm{NiO} / \mathrm{Ni}_{70} \mathrm{Cu}_{30} / \mathrm{Cu}$, com diferença de 180 graus entre a orientação das duas cores.

Mesmo apresentando uma baixa constante de interação, o enfraquecimento do acoplamento nas bicamadas $\mathrm{NiO} / \mathrm{Ni}_{x} \mathrm{Cu}_{1-x} / \mathrm{Cu}$ com a magnitude vista aqui não foi esperado, principalmente sabendo que a temperatura de Néel do óxido de níquel é relativamente alta. Mesmo em camadas espessas, o óxido de níquel não manteve a anisotropia unidirecional das bicamadas em temperatura ambiente. 
As curvas ZFC/FC das bicamadas do grupo 2 foram obtidas da mesma maneira que o grupo 1, e são apresentadas na figura 3.11.

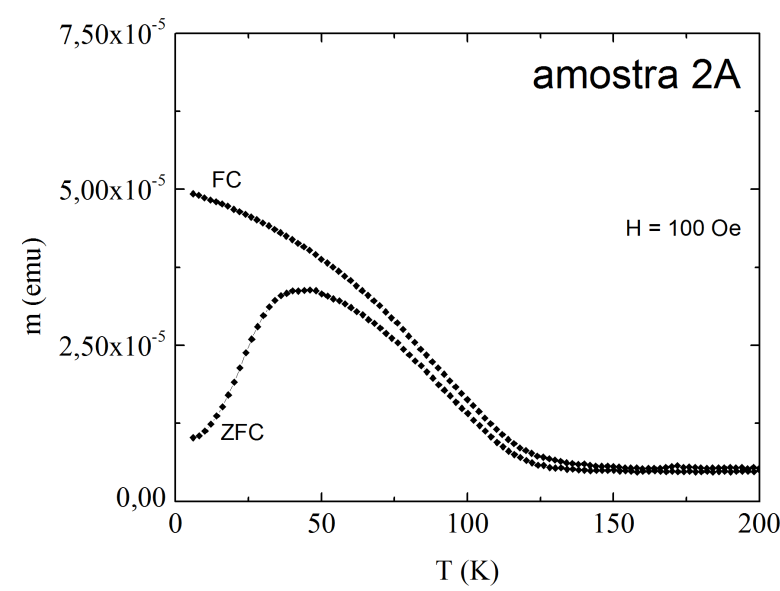

(a)

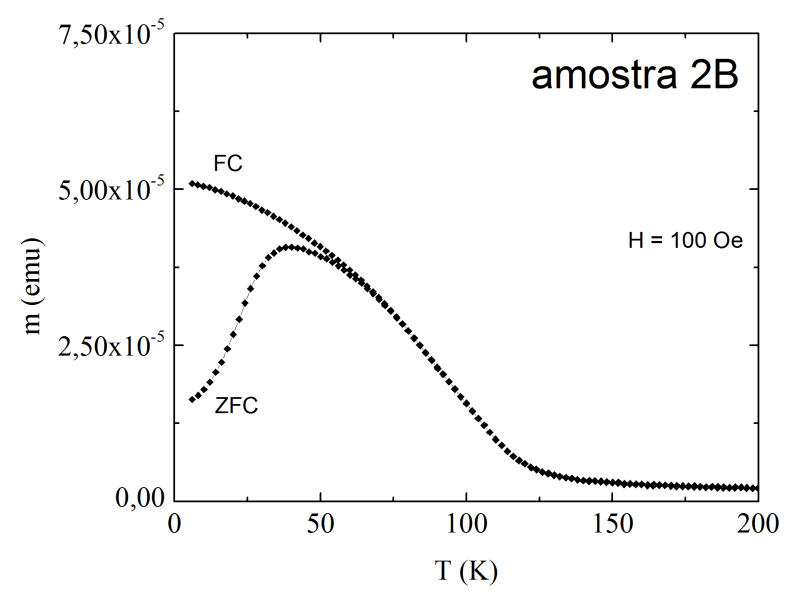

(b)

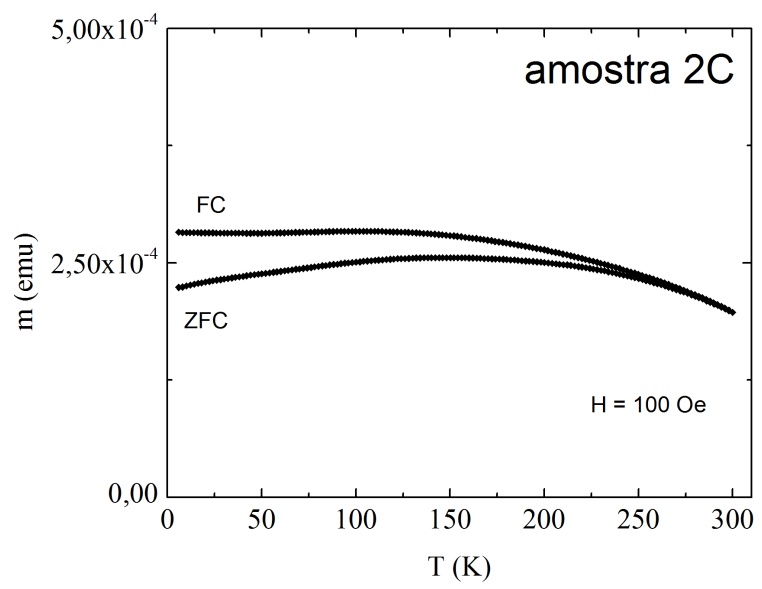

(c)

Figura 3.11: Curvas ZFC/FC das bicamadas $\mathrm{Ni}_{x} \mathrm{Cu}_{1-x} / \mathrm{FeMn} / \mathrm{Cu}$ com $\mathrm{x}=50$ (a), $\mathrm{x}=70$ (b) e $\mathrm{x}=90(\mathrm{c})$.

A separação das curvas na figura 3.11a indica grande distribuição de coercividades para a amostra $2 \mathrm{~A}$, que pode apresentar alguma irreversibilidade mesmo acima da temperatura de bloqueio estimada em 40K. Já as curvas na figura 3.11b se unem logo após o máximo da ZFC, indicando reversibilidade para a magnetização da bicamada 2B logo acima dos 40K. A bicamada 2C ainda permanece com magnetização irreversível acima $\operatorname{dos} 220 \mathrm{~K}$. 
Com curvas de magnetização em função do campo magnético em diferentes temperaturas, a variação de $\mathrm{H}_{C}$ e $\mathrm{H}_{E B}$ com a temperatura pode ser observada.

A coercividade da bicamada $2 \mathrm{~A}$ cai drasticamente antes dos $30 \mathrm{~K}$ e permanece baixa depois dos 70K, antes do que mostra a figura 3.11a. A bicamada $2 \mathrm{~B}$ é bem fiel ao que indica a figura $3.11 \mathrm{~b}$, com a coercividade caindo antes dos 50K. No entanto, aparece um leve aumento em $\mathrm{H}_{C}$ e $\mathrm{H}_{E B}$ após os $100 \mathrm{~K}$, com mais intensidade do que o que também apareceu em algumas amostras com NiO. Provavelmente relacionado com a diminuição do momento magnético da amostra[66], apesar da figura 3.11b indicar paramagnetismo nessa região.

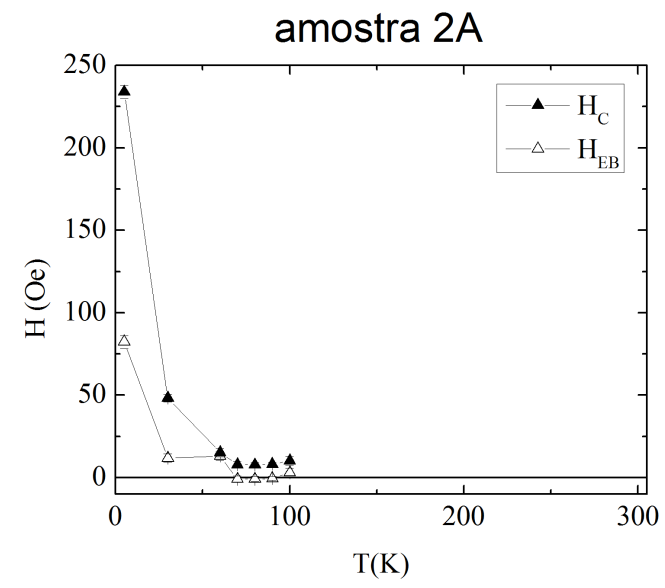

(a)

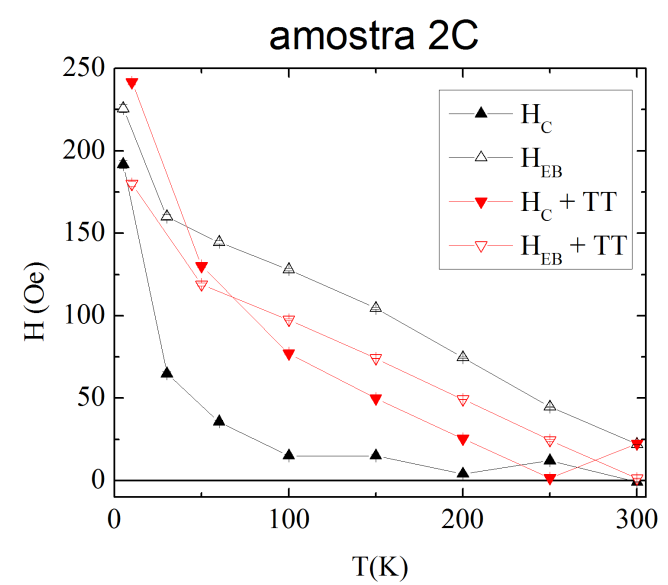

(c)

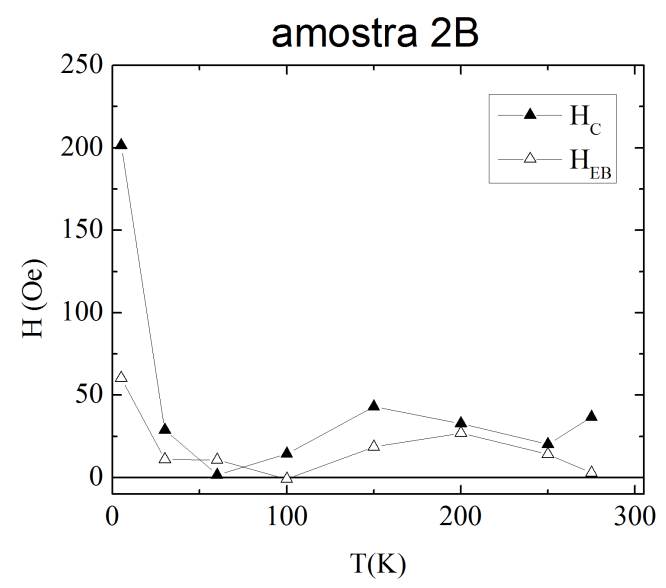

(b)

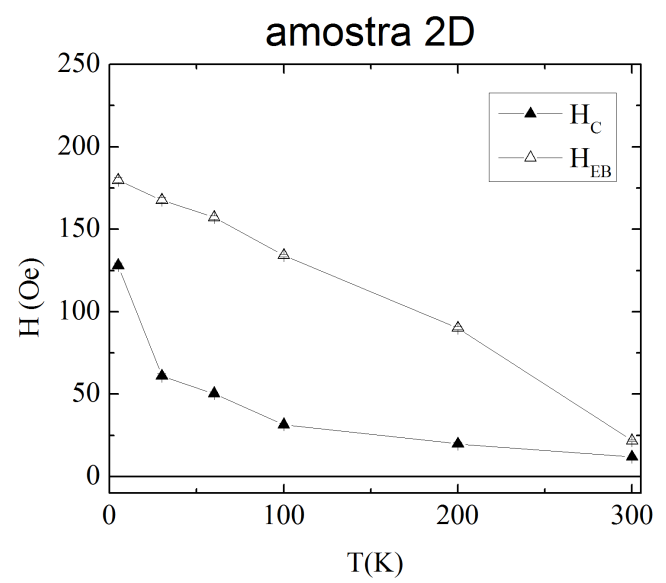

(d)

Figura 3.12: $\mathrm{H}_{C}$ e $\mathrm{H}_{E B}$ em função da temperatura para bicamadas $\mathrm{Ni}_{x} \mathrm{Cu}_{1-x} / \mathrm{FeMn} / \mathrm{Cu}: \mathrm{x}=50$ (a), $x=70$ (b),$x=90$ (c) e $x=100$ (d). A cor vermelha dos dados em (c) se refere a uma tentativa de tratamento térmico da amostra dentro do SQUID após as medidas usuais, como descrito na seção 2.4 . 
A bicamada 2C manteve magnetização irreversível ao menos até os 200K, concordando com a figura 3.11c, enquanto a bicamada 2D apresentou $\mathrm{H}_{C}$ e $\mathrm{H}_{E B}$ não-nulos até os $300 \mathrm{~K}$.

Nas temperaturas mas baixas, o incremento de cobre na liga aumentou a coercividade das bicamadas: quase 240 Oe em 2A, em torno de 200 Oe para 2B e 2C, 130 Oe para $2 \mathrm{D}$ em $5 \mathrm{~K}$. No entanto, os valores de $\mathrm{H}_{C}$ caem mais rapidamente com a temperatura para as ligas ricas em cobre: a 100K, 2A já apresenta menos de 20 Oe, 2B e 2C têm em torno de 20 Oe, Ni ainda acima de 30 Oe.

Na figura 3.13, curvas de magnetização em temperatura ambiente realizadas no VSM revelam a anisotropia unidirecional das amostras mesmo sem um tratamento térmico para induzi-la. É provável que os ímas do magnetron sputtering tenham induzido alguma anisotropia residual durante a deposição.

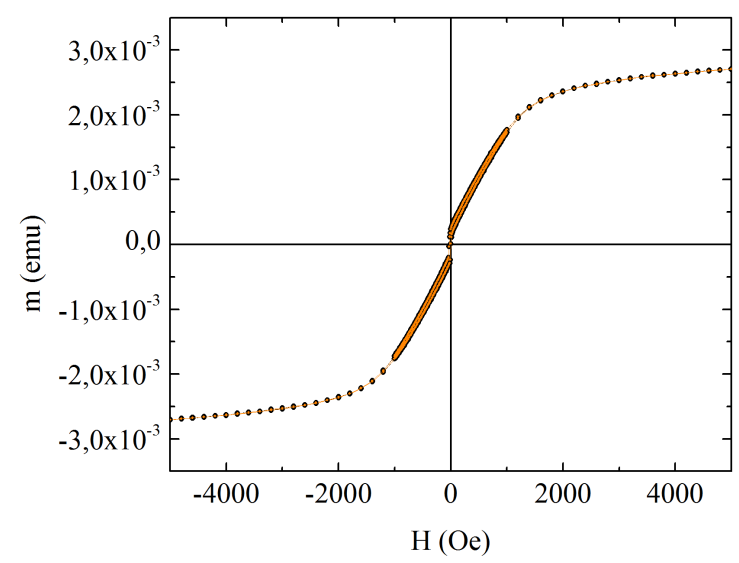

(a)

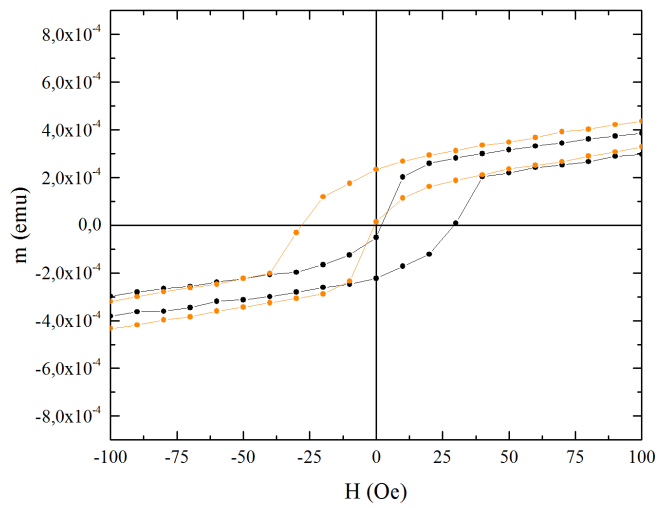

(b)

Figura 3.13: Ciclos de histerese da bicamada 2C. A medida orientada em 0 graus (cor laranja) corresponde aproximadamente ao maior valor de $\mathrm{H}_{E B}$ (associado ao eixo mais longo das amostras retangulares). Medida em 180 graus (rotacionada no plano do filme) em preto. À direita, detalhe para mostrar a histerese. 
Além das medidas nas posições observadas na figura 3.13, foram realizadas medidas em intervalos de $10^{\circ}$ completando a volta de $360^{\circ}$ no plano do filme, possibilitando observar a variação dos campos coercivo e de exchange bias em função da direção do campo magnético aplicado.

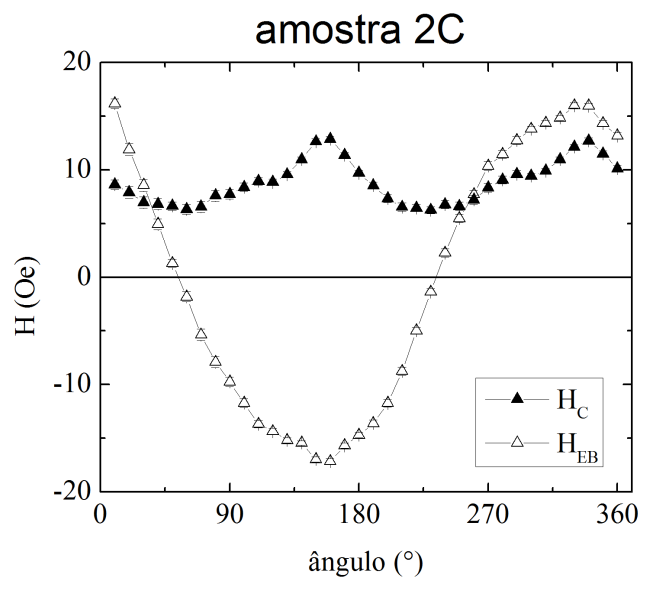

(a)

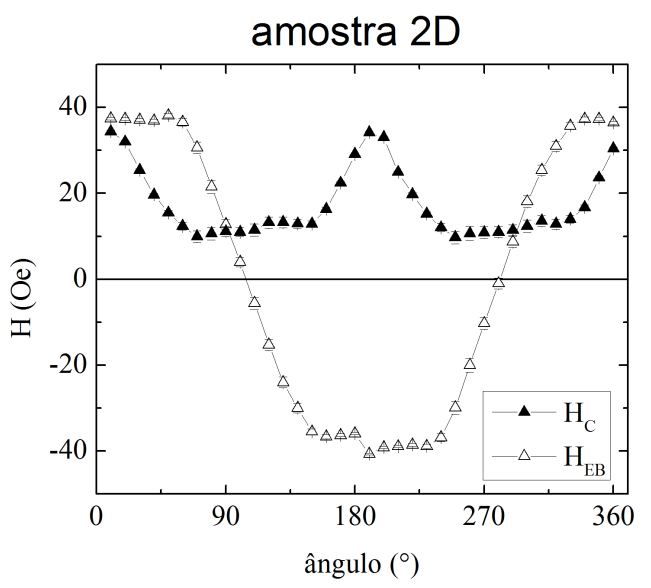

(b)

Figura 3.14: $\mathrm{H}_{C}$ e $\mathrm{H}_{E B}$ em função da direção do campo aplicado em relação a uma direção específica para bicamadas 2C (a) e 2D (b). 0 graus corresponde aproximadamente ao maior valor de $\mathrm{H}_{E B}$ (associado ao eixo mais longo das amostras retangulares). Ciclos extremamente ruidosos dificultam muito os ajustes das derivadas na outras amostras do grupo.

A figura 3.14 mostra que tanto a coercividade quanto o exchange bias caem pela metade entre $\mathrm{Ni} / \mathrm{FeMn} / \mathrm{Cu}$ e $\mathrm{Ni}_{90} \mathrm{Cu}_{10} / \mathrm{FeMn} / \mathrm{Cu}$, o que está de acordo com as medidas no SQUID para temperaturas mais altas. Lembrando que as propriedades magnéticas do níquel são "diluídas" com a adição de cobre, esse resultado era esperado. 
O mesmo método para a obtenção das curvas ZFC/FC das bicamadas anteriores foi aplicado para as bicamadas do grupo 3, resultando na figura 3.15.

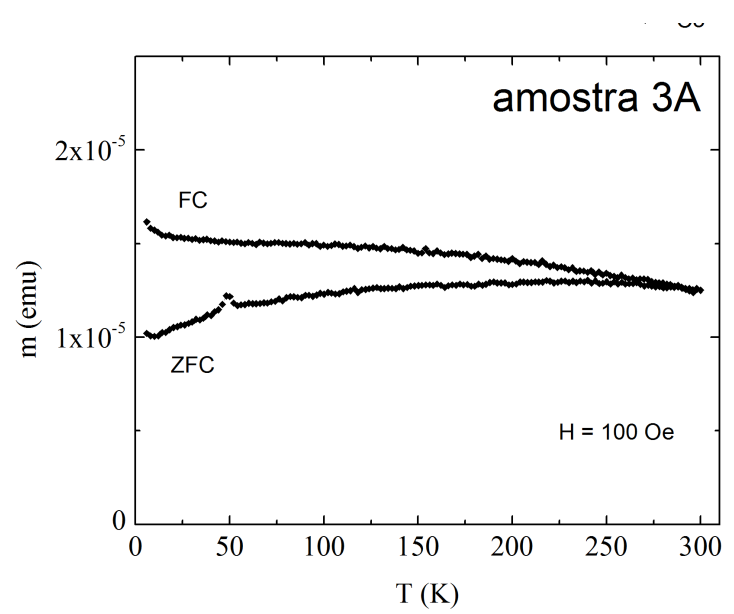

(a)

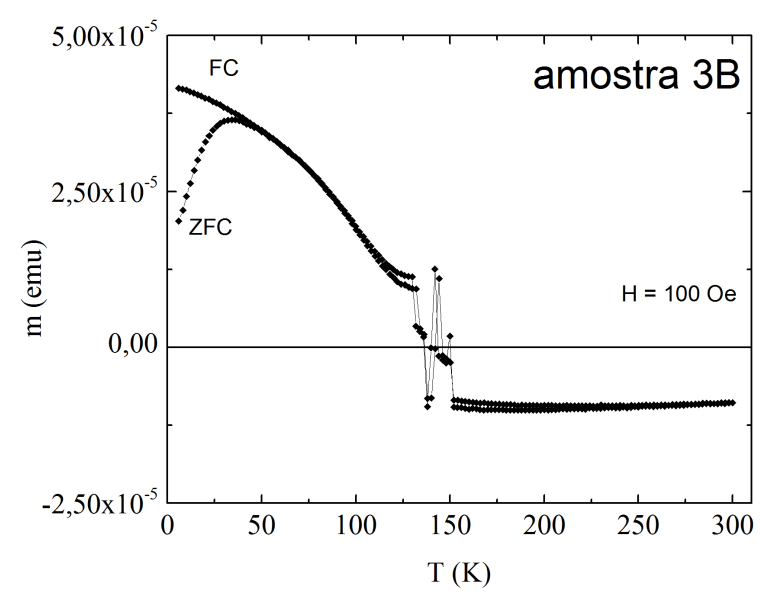

(b)

Figura 3.15: Curvas ZFC/FC das bicamadas $\mathrm{Ni}_{x} \mathrm{Cu}_{1-x} / \mathrm{IrMn} / \mathrm{Cu}$ com $\mathrm{x}=50$ (a) e $\mathrm{x}=70$ (b).

Uma larga distribuição de coercividades é observada para a bicamada 3A, que aparenta ter uma temperatura de bloqueio acima dos 200K. A magnetização da bicamada 3B se torna reversível após os 30K, mas a região entre $125 \mathrm{~K}$ e $300 \mathrm{~K}$ aparece com um momento magnético negativo.

Novamente, curvas de magnetização em função do campo magnético em diferentes temperaturas foram realizadas para observar a variação de $\mathrm{H}_{C}$ e $\mathrm{H}_{E B}$ com a temperatura, resultando na figura 3.16 . 


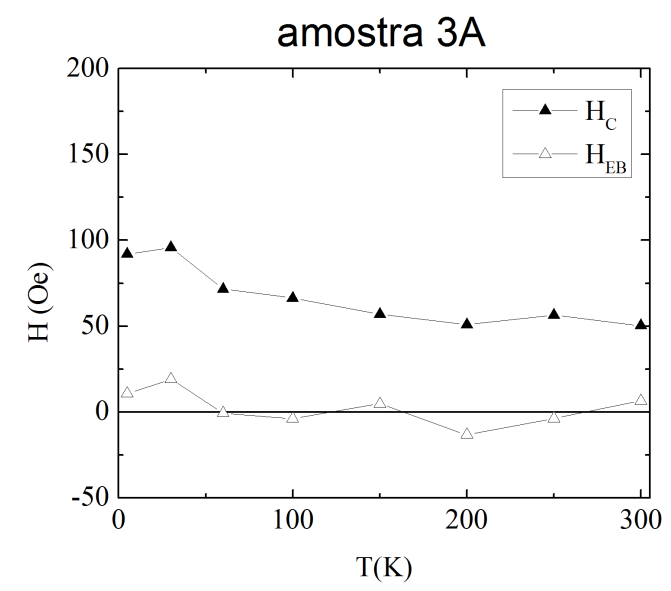

(a)

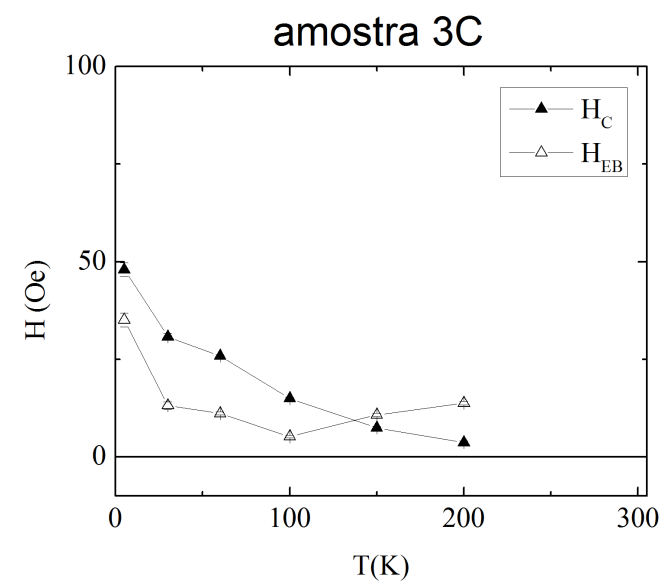

(c)

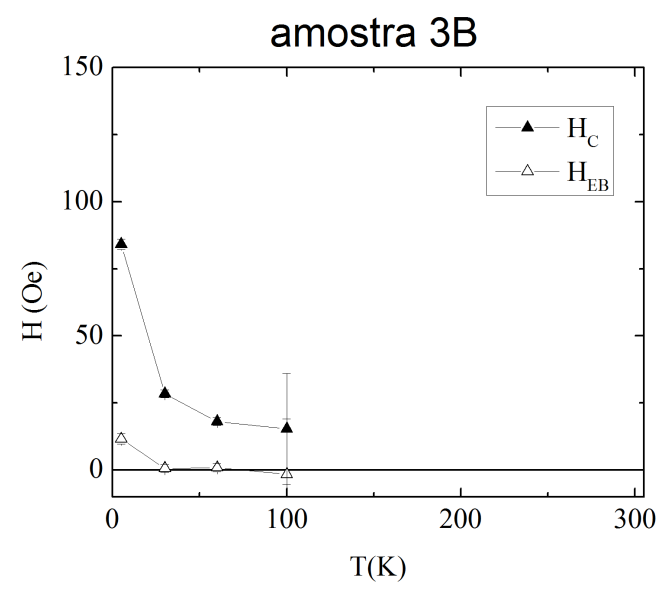

(b)

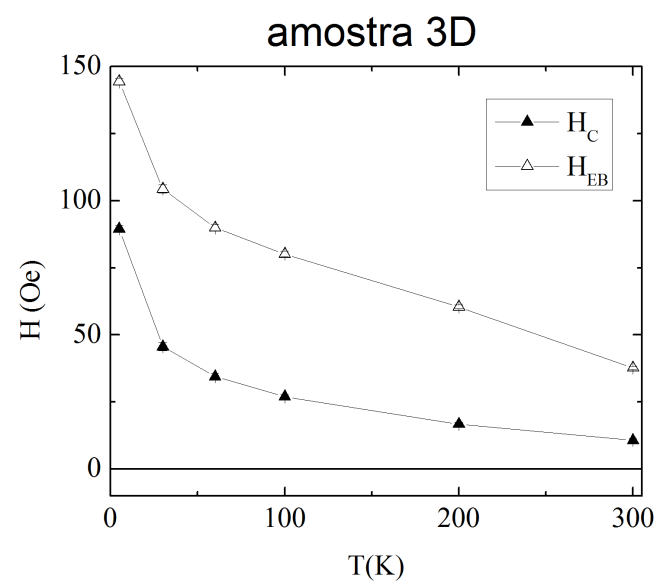

(d)

Figura 3.16: $\mathrm{H}_{C}$ e $\mathrm{H}_{E B}$ em função da temperatura para bicamadas $\mathrm{Ni}_{x} \mathrm{Cu}_{1-x} / \mathrm{IrMn} / \mathrm{Cu}: \mathrm{x}=50$ (a), $x=70$ (b), $x=90$ (c) e $x=100$ (d).

As figuras 3.16a e 3.16b seguem aproximadamente o que mostram as figuras 3.15a e 3.15b, respectivamente. A bicamada 3A permaneceu com coercividade em toda a faixa de temperaturas, enquanto a bicamada 3B se tornou paramagnética após os 100K. $3 \mathrm{C}$ possui um mínimo de $\mathrm{H}_{E B}$ em $100 \mathrm{~K}$, enquanto $3 \mathrm{D}$ possui $\mathrm{H}_{C}$ e $\mathrm{H}_{E B}$ estritamente positivo e decrescente, como o esperado (e encontrado em Ni/FeMn).

A possibilidade de acoplamento perpendicular ao plano do filme em bicamadas com IrMn foi investigada na bicamada $\mathrm{Ni} / \mathrm{IrMn} / \mathrm{Cu}$ em $5 \mathrm{~K}$, mas um $\mathrm{H}_{E B}$ praticamente nulo (considerando a incerteza devido à instabilidade) encerrou as tentativas por esse lado. 
Assim como nas bicamadas do grupo 2, as amostras do grupo 3 com mais cobre apresentaram maior coercividade na temperatura mais baixa: 90 Oe, 80 Oe e 50 Oe para $\mathrm{x}=50,70$ e 90 respectivamente. Os valores mais baixos tanto para $\mathrm{H}_{C}$ quanto para $\mathrm{H}_{E B}$ (comparados aos com FeMn) podem ser devidos a baixa textura $\left\{\begin{array}{lll}1 & 1 & 1\end{array}\right\}$ obtida. Apesar desse pico ter sido o mais intenso, o $\left\{\begin{array}{lll}2 & 0 & 0\end{array}\right\}$ não é desprezível.

A amostra com níquel puro fugiu desse padrão, apresentando maior coercividade (como esperado). Voltando à figura $3.5 \mathrm{~d}$, a camada de $\mathrm{Ni}$ é a única em que o pico $\operatorname{IrMn}(200)$ é menos intenso que o $\mathrm{NiCu}(200)$ (apenas $\mathrm{Ni}$ neste caso). Isso significa que o IrMn adquiriu uma textura $\left\{\begin{array}{lll}1 & 1 & 1\end{array}\right\}$ mais presente quando depositado sobre o níquel puro, resultando em uma interface com maior interação de troca para esta amostra.

Em medidas no SQUID, quanto mais cobre há na camada $\mathrm{Ni}_{x} \mathrm{Cu}_{1-x}$, mais relevante é o regime superparamagnético da liga que o enfraquecimento da anisotropia do AFM para a queda nas coercividades de cada bicamada, visto principalmente nas curvas $\mathrm{ZFC} / \mathrm{FC}$.

Utilizando o VSM, curvas de magnetização em temperatura ambiente para direções diferentes mostram anisotropia unidirecional. Assim como no caso do grupo 2, tal anisotropia deve ter sido induzida pelos ímas do sputtering durante a deposição. 
Novamente, as curvas de magnetização em diferentes direções foram realizadas no VSM, revelando a dependência dos campos coercivo e de exchange bias em função da orientação do campo magnético aplicado.

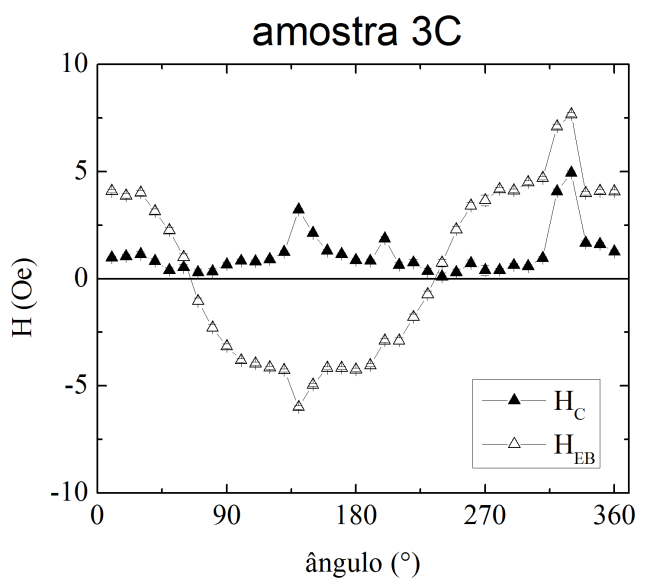

(a)

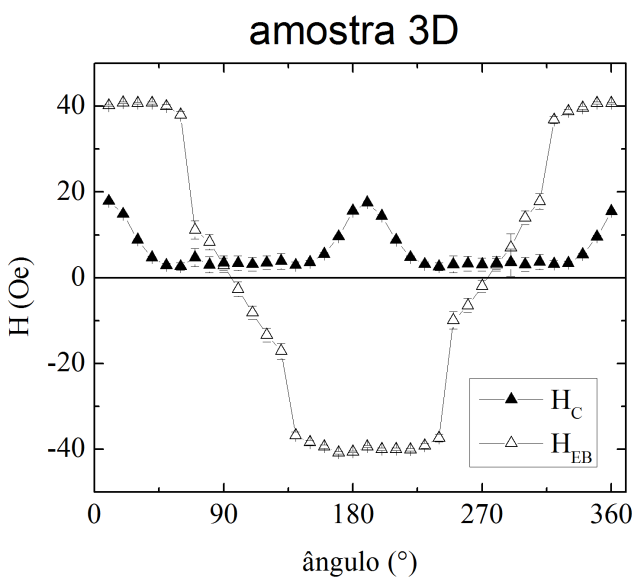

(b)

Figura 3.17: $\mathrm{H}_{C}$ e $\mathrm{H}_{E B}$ em função da direção do campo aplicado em relação a uma direção específica para bicamadas $\mathrm{Ni}_{x} \mathrm{Cu}_{1-x} / \mathrm{IrMn} / \mathrm{Cu} .0$ graus corresponde aproximadamente ao maior valor de $\mathrm{H}_{E B}$ (associado ao eixo mais longo das amostras retangulares). Ciclos extremamente ruidosos dificultam muito os ajustes das derivadas nas outras amostras.

Pela figura 3.17 , a coercividade cai em $75 \%$ ao comparar $\mathrm{Ni}$ com $\mathrm{Ni}_{90} \mathrm{Cu}_{10}$. No entanto, o exchange bias cai mais drasticamente. Os resultados estão de acordo com as medidas em temperaturas mais altas no SQUID, sendo que o VSM foi capaz de medir a bicamada 3C. 
Manipulando a equação 1.3 temos:

$$
J_{\text {int }}=\frac{H_{E B} m_{F M}}{S}
$$

com $m_{F M}$ sendo o momento magnético da camada ferromagnética saturada e $S$ a área do filme.

Desse modo, para as medidas no SQUID temos as seguintes constantes de interação (assumindo que cada filme possui a mesma área de seu respectivo substrato, medida com paquímetro):

Tabela 3.3: Constantes de troca das bicamadas a 5K. Algumas amostras* possuem incerteza apenas na área, já que o ajuste nas derivadas das curvas MxH não foi possível (nesses casos, $\mathrm{H}_{E B}$ foi estimado graficamente).

\begin{tabular}{|c|c|}
\hline amostra & $\mathrm{J}\left(\mathrm{erg} / \mathrm{cm}^{2}\right)$ a $5 \mathrm{~K}$ \\
\hline \hline 2A & $0,0119 \pm 0,0008$ \\
\hline 2B & $0,0085 \pm 0,0004^{*}$ \\
\hline 2C & $0,152 \pm 0,007$ \\
\hline 2D & $0,133 \pm 0,006$ \\
\hline \hline 3A & $0,0048 \pm 0,0002^{*}$ \\
\hline 3B & $0,0016 \pm 0,0003$ \\
\hline 3C & $0,0218 \pm 0,0014$ \\
\hline 3D & $0,151 \pm 0,009$ \\
\hline
\end{tabular}

As bicamadas 2C e 3D são as que possuem o maior valor para constante de troca. Exceto pelas bicamadas com níquel puro, todas as bicamadas com FeMn apresentaram um valor de J maior do que as bicamadas com IrMn.

Partindo de níquel puro, a bicamada com IrMn possui a maior constante de troca, mas decai mais rapidamente com o acréscimo de cobre. Em ordem crescente da quantidade de cobre, as bicamadas do grupo 3 começam com uma constante $13 \%$ maior que a bicamada 2D, mas cai rapidamente para apenas $14 \%, 19 \%$ e $40 \%$ do valor das constantes de $2 \mathrm{C}, 2 \mathrm{~B}$ e $2 \mathrm{~A}$ respectivamente. 
Utilizando a equação 3.2 nas posições em que $\mathrm{H}_{E B}$ é máximo para as medidas no VSM, é possível calcular $\mathrm{J}_{\text {int }}$ em temperatura ambiente:

Tabela 3.4: Constantes de troca das bicamadas em temperatura ambiente, via VSM.

\begin{tabular}{|c|c|}
\hline amostra & $\mathrm{J}\left(\mathrm{erg} / \mathrm{cm}^{2}\right)$ \\
\hline \hline 2C & $0,077 \pm 0,009$ \\
\hline 2D & $0,032 \pm 0,004$ \\
\hline \hline 3C & $0,028 \pm 0,003$ \\
\hline 3D & $0,096 \pm 0,005$ \\
\hline
\end{tabular}

Comparando as tabelas 3.3 e 3.4, as amostras do grupo 3 conseguiram manter uma maior fração da interação à temperatura ambiente. Chama a atenção o desempenho das amostras com cobre nessas condições: enquanto $\mathrm{J}_{\text {int }}(\mathrm{VSM})$ de $2 \mathrm{D}$ e $3 \mathrm{D}$ equivalem a $24 \%$ e $64 \%$ de $\mathrm{J}_{\text {int }}(5 \mathrm{~K}), 2 \mathrm{C}$ manteve $51 \%$ do valor e $\mathrm{J}_{\text {int }}(\mathrm{VSM})$ de $3 \mathrm{C}$ é $27 \%$ maior que $\mathrm{J}_{\text {int }}(5 \mathrm{~K})$.

Os resultados para o FeMn estão compatíveis com os encontrados por de Pires et al[74], que depositou utilizando epitaxia por feixe molecular, semente de cobre para o FeMn, tratamento térmico e medidas por efeito Kerr magneto-óptico. Seus ferromagnetos foram ligas NiFe, e sua maior constante de troca $\left(0,031 \mathrm{erg} / \mathrm{cm}^{2}\right.$ para bicamadas com $\mathrm{Ni}$ puro) é preticamente igual à mesma composição utilizada aqui, mas menor que o de $\mathrm{Ni}_{90} \mathrm{Cu}_{10} / \mathrm{FeMn}$. Esse fato mostra a importância da camada sobre a qual o FeMn é depositado. 
O maior resultado de $\mathrm{J}_{\text {int }}(\mathrm{VSM})$ encontrado aqui utilizando IrMn é metade do valor encontrado por Fuke et al[14], onde CoFe foi o ferromagneto utilizado com deposição sob campo aplicado e sobre semente de tântalo. Esse foi o maior valor de $\mathrm{J}_{\text {int }}$ já encontrado em bicamadas, mostrando a importância da indução de anisotropia e da textura cristalina do ferromagneto usado.

Em ambas as temperaturas neste estudo, a constante de troca encontrada para a amostra $2 \mathrm{C}$ foi maior que a encontrada para $2 \mathrm{D}$, contrariando a tendência do resto das amostras de uma diminuição de $\mathrm{J}_{\text {int }}$ com o aumento de cobre na camada $\mathrm{Ni}_{x} \mathrm{Cu}_{1-x}$ nos sistemas. Ainda menos esperado foi o resultado para $\mathrm{J}_{\text {int }}(5 \mathrm{~K})$, onde o valor para 2C alcançou o de 3D. Lembrando que o IrMn costuma apresentar constantes de troca maiores que o FeMn, também não foi esperado que a maioria das bicamadas do grupo 3 apresentassem $\mathrm{J}_{\text {int }}$ menor do que as constantes das bicamadas do grupo 2 correspondentes. 


\subsubsection{Multicamadas}

Curvas de magnetização em função do campo magnético das multicamadas do grupo 2 para diferentes temperaturas (figuras 3.18a e 3.18c) permitem obter o comportamento de $\mathrm{H}_{C}$ e $\mathrm{H}_{E B}$ em função da temperatura (figuras $3.18 \mathrm{~b}$ e $3.18 \mathrm{~d}$ ).

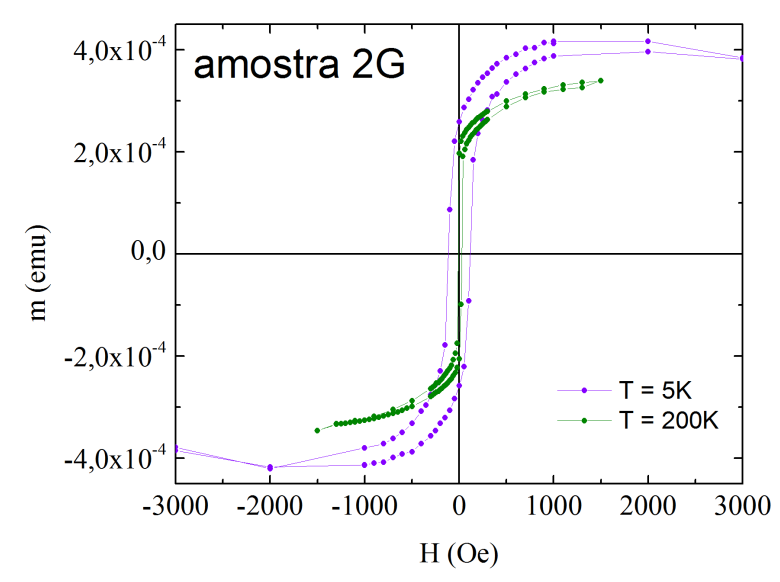

(a)

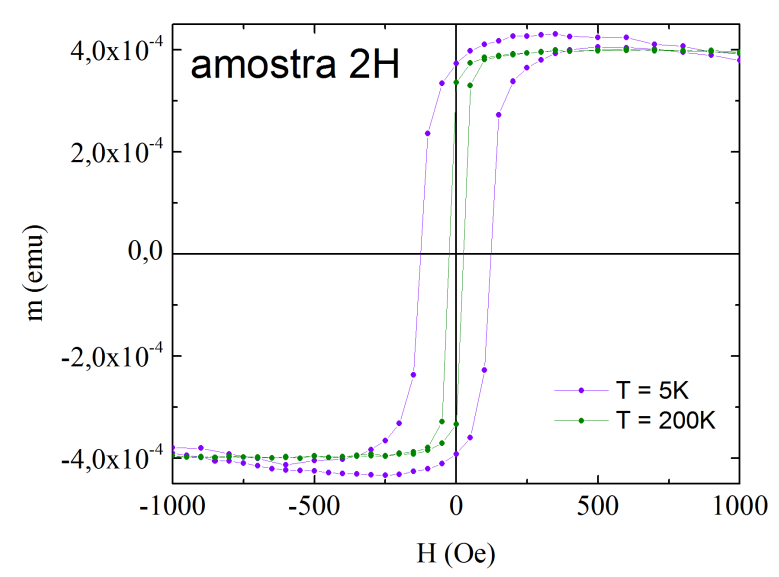

(c)

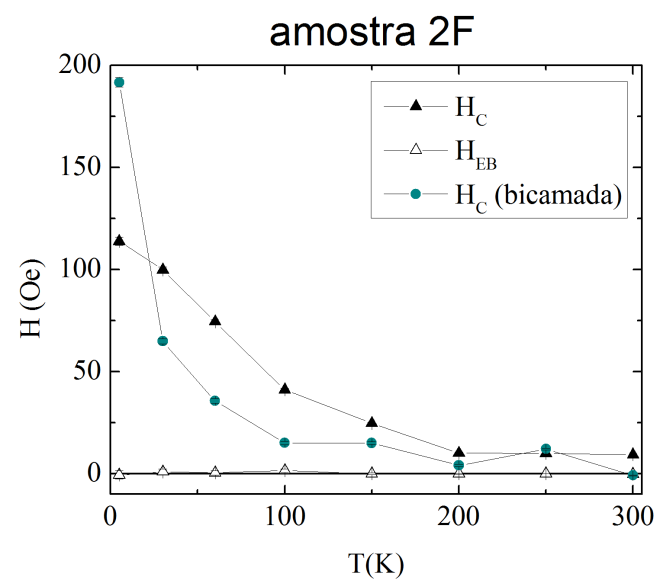

(b)

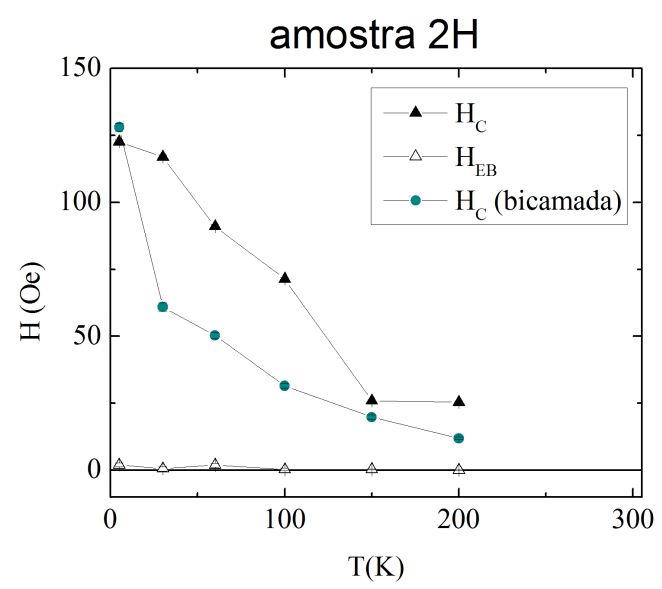

(d)

Figura 3.18: Medidas no SQUID para as multicamadas do grupo 2. Nos gráficos da direita, foram incluídas as medidas $\mathrm{H}_{C} \mathrm{x} \mathrm{T}$ das bicamadas correspondentes. 
As multicamadas do grupo 2 apresentaram apenas um ciclo de histerese simples como a figura 1.3a, em vez do ciclo esperado para uma válvula de spin como o da figura 1.5. Nesse caso, a coercividade em $100 \mathrm{~K}$ ficou $173 \%(\mathrm{x}=90)$ e $127 \%(\mathrm{x}=100)$ maior se comparadas às respectivas bicamadas, comparando as figuras $3.18 \mathrm{~b}$ com $3.12 \mathrm{c}$ e $3.18 \mathrm{~d}$ com $3.12 \mathrm{~d}$.

Talvez a camada de cobre não tenha separado efetivamente o FeMn e a camada que deveria ser livre. De fato, foi observado que esse tipo de acoplamento ainda persiste com alguma profundidade além da interface imediata.[73] Nesse caso, o acoplamento em ambas as interfaces enfraquece a anisotropia antiferromagnética, impossibilitando o exchange bias (como se a camada ferromagnética em uma bicamada fosse espessa demais). $\mathrm{Ou}$ ainda, pode haver acoplamento das camadas ferromagnéticas entre si, aumentando a espessura efetiva da camada FM e destruindo o exchange bias. No entanto, em ambos os casos ainda existiria interação de troca com o antiferromagneto: toda a anisotropia do FeMn que "prenderia" a magnetização do $\mathrm{NiCu}$ (e formaria o $\mathrm{H}_{E B}$ ) consegue apenas "arrastar" a inversão dos spins (aumentando o $\mathrm{H}_{C}$ em relação às bicamadas).

Girando a amostra no plano do filme para cada curva de magnetização no VSM em temperatura ambiente, é confirmado na figura 3.19 que não há anisotropia unidirecional.

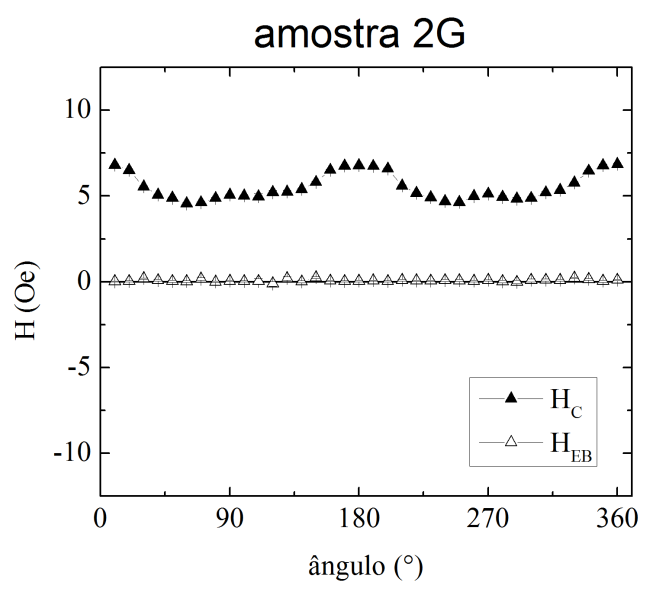

(a)

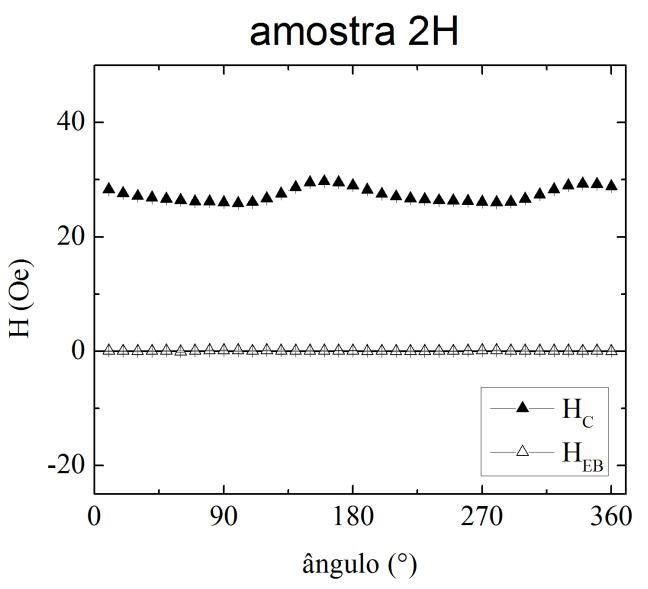

(b)

Figura 3.19: $\mathrm{H}_{C}$ e $\mathrm{H}_{E B}$ em função da direção do campo aplicado em relação a uma direção específica para multicamadas $2 \mathrm{G}$ (a) e $2 \mathrm{H}$ (b). 0 graus corresponde aproximadamente ao maior valor de $\mathrm{H}_{E B}$ (associado ao eixo mais longo das amostras retangulares). 
Como visto no SQUID, as multicamadas se comportam como bicamadas por causa do provável acoplamento entre a camada que deveria ser livre com a a outra camada. $\mathrm{O}$ acoplamento AFM/FM ainda influencia na coercividade mesmo sem exchange bias, e presença de cobre na camada $\mathrm{Ni}_{x} \mathrm{Cu}_{1-x}$ diminui a coercividade em $75 \%$.

Curvas de magnetização das multicamadas $\mathrm{Ni}_{70} \mathrm{Cu}_{30} / \mathrm{IrMn} / \mathrm{Cu} / \mathrm{Ni}_{x} \mathrm{Cu}_{1-x} / \mathrm{Cu}$ em diferentes temperaturas mostram a variação de $\mathrm{H}_{C}$ e $\mathrm{H}_{E B}$ com $\mathrm{T}$ na figura 3.20.

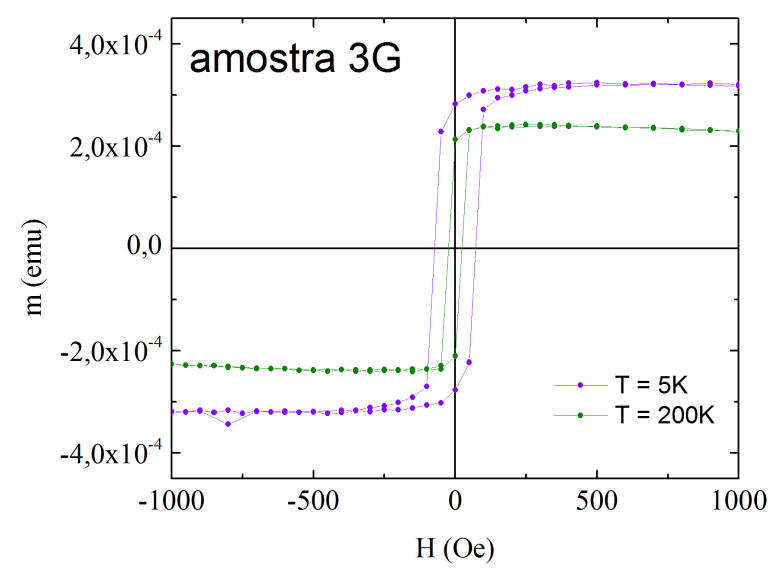

(a)

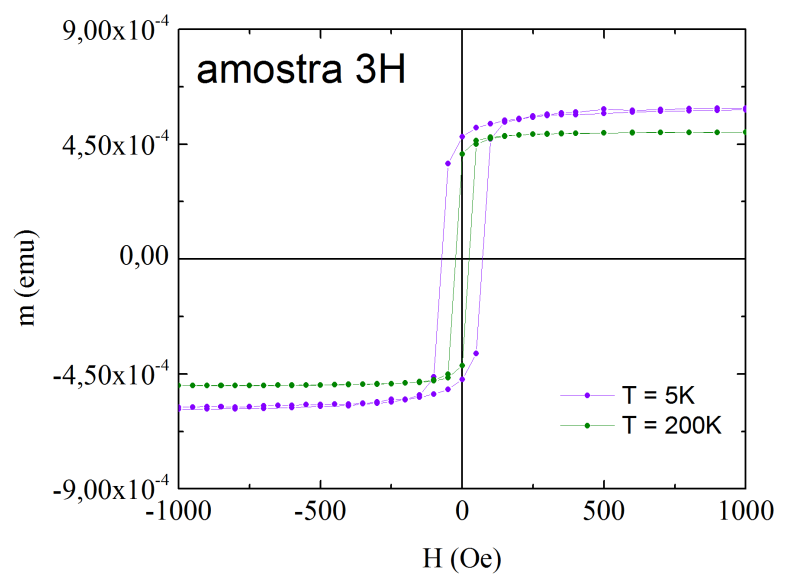

(c)

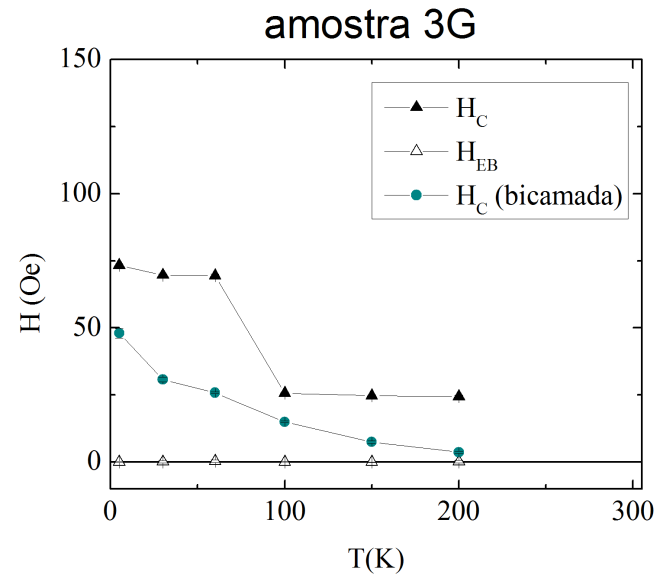

(b)

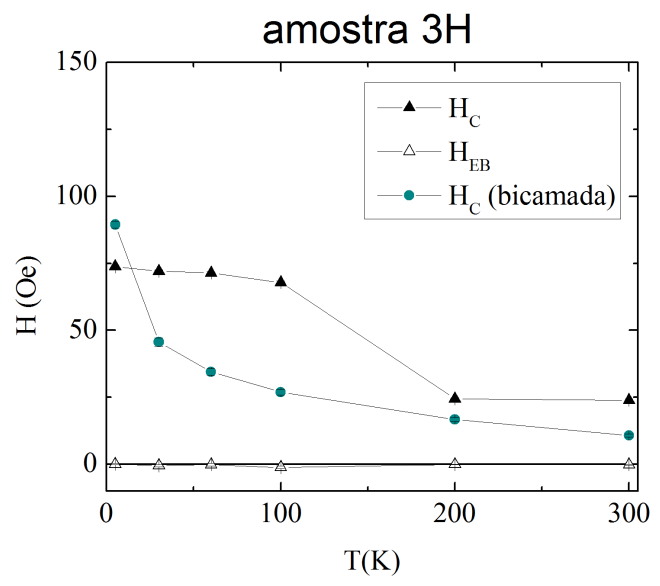

(d)

Figura 3.20: Medidas no SQUID para as multicamadas do grupo 3. Nos gráficos da direita, foram incluídas as medidas $\mathrm{H}_{C} \mathrm{x} \mathrm{T}$ das bicamadas correspondentes.

Do mesmo modo que as multicamadas do grupo 2, o grupo 3 também apresenta ciclos de histerese simples para a magnetização. Comparando as figuras 3.20b com 3.16c e $3.20 \mathrm{~d}$ com $3.16 \mathrm{~d}$, nota-se um aumento da coercividade das multicamadas a $100 \mathrm{~K}$ de $37 \%, 72 \%$ e $127 \%$ em relação às bicamadas na ordem crescente de níquel. 
Por fim, as medidas de magnetização em temperatura ambiente utilizando o VSM variando a orientação nos $360^{\circ}$ do plano do filme confirmam a ausência de anisotropia unidirecional, como mostra a figura 3.21.

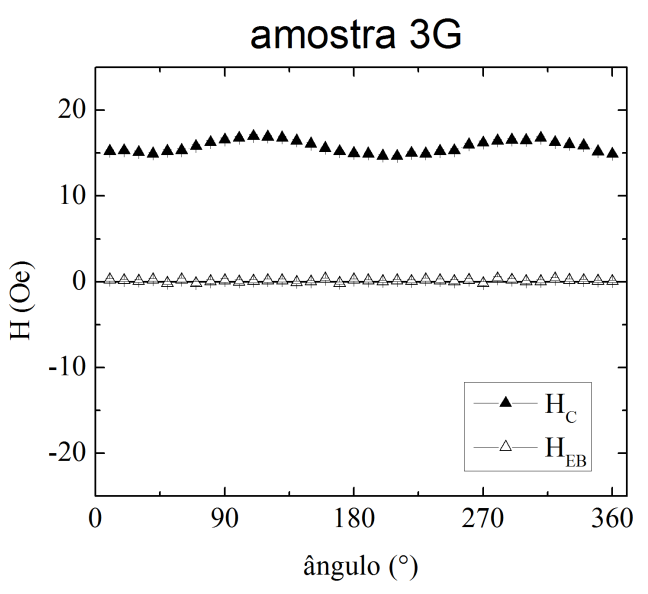

(a)

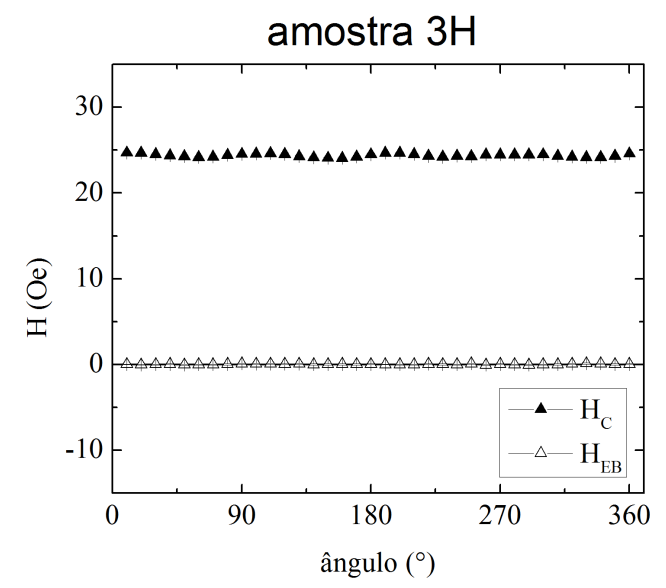

(b)

Figura 3.21: $\mathrm{H}_{C}$ e $\mathrm{H}_{E B}$ em função da direção do campo aplicado em relação a uma direção específica para multicamadas 3G (a) e 3H (b). 0 graus corresponde aproximadamente ao maior valor de $\mathrm{H}_{E B}$ (associado ao eixo mais longo das amostras retangulares).

Do mesmo modo que as medidas no SQUID e para as multicamadas do grupo 2, a magnetização das multicamadas do grupo 3 se apresentou como ciclos de histerese simples: sem exchange bias mas com coercividade mais alta que as válvulas correspondentes. A queda da coercividade com a presença de cobre na camada $\mathrm{Ni}_{x} \mathrm{Cu}_{1-x}$ entre $\mathrm{x}=100$ e $\mathrm{x}=90$ foi de $40 \%$. 


\subsubsection{Exchange Bias Duplo}

Voltando às bicamadas, a curva de $\mathrm{H}_{E B}$ da figura $3.17 \mathrm{~b}$ parece descontínua. Aquilo ocorreu devido a uma peculiaridade de suas curvas de magnetização, demonstrados na figura 3.22 a seguir:

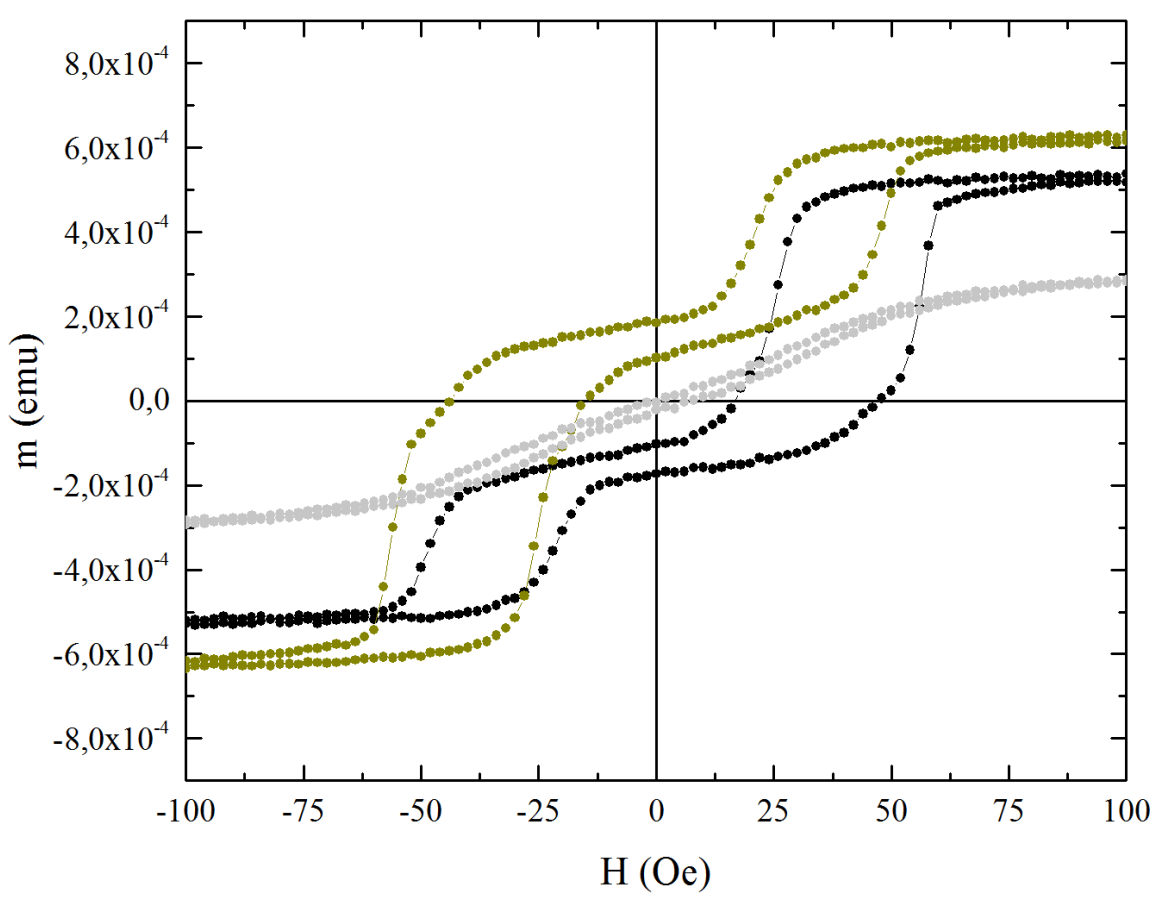

Figura 3.22: Anisotropia das curvas de magnetização para a bicamada Ni/IrMn $\left(\theta=0^{\circ} \mathrm{em}\right.$ bege, $180^{\circ}$ em preto, $90^{\circ} \mathrm{em}$ cinza).

Tal fenômeno já foi visto para bicamadas com IrMn sem tratamento térmico[52], onde múltiplos grãos da camada ferromagnética se acoplam a um grão da camada antiferromagnética adotando diferentes orientações (paralela ou antiparalela).

Apesar de todas as amostras apresentarem grãos de IrMn maiores que os grãos de $\mathrm{NiCu}$, a bicamada $\mathrm{Ni} / \mathrm{IrMn}$ apresenta o menor tamanho de grão para a camada FM, o que está de acordo com a explicação proposta.[51]

Neste caso, os valores de $\mathrm{H}_{C}$ e $\mathrm{H}_{E B}$ apresentados na figura $3.16 \mathrm{~d}$ se referem ao semi-ciclo de maior magnetização, enquanto os ajustes da figura 3.17b foram obtidos com apenas um pico das derivadas (o que acaba escolhendo a maior magnetização em ângulos 
próximos a $0^{\circ}$ e $180^{\circ}$ e adota posições mais intermediárias quando em torno de $90^{\circ}$ e $270^{\circ}$ ).

Ao contrário da curva esperado de uma válvula de spin, com o ciclo associado a uma das camadas mais centralizada em relação ao eixo H e com o outro mais largo e deslocado, esta amostra apresenta semi-ciclos com praticamente o mesmo deslocamento e coercividade. Em outras palavras, a figura 3.22 se assemelha mais à figura 1.17 do que à figura 1.5, confirmando o fato da amostra se tratar realmente de uma bicamada com acoplamento anômalo. 


\section{Capítulo 4}

\section{Conclusão}

\subsection{Discussão}

Ligas de níquel-cobre são consideradas materiais fracamente ferromagnéticos. Ainda que apresentem magnetização espontânea, o momento magnético médio por átomo é relativamente baixo (menor que o $0,6 \mu_{B}$ do níquel puro). Esta e outras propriedades ferromagnéticas (temperatura de Curie, coercividade, etc) diminuem com a quantidade de cobre na liga.

No presente trabalho, foram estudados diversos grupos de amostras para comparar os diferentes materiais em sistemas de bicamadas e multicamadas com ferromagnetos de temperatura de Curie menor que a temperatura de Neél dos antiferromagnetos. Os antiferromagnetos utilizados foram $\mathrm{NiO}$, FeMn e $\operatorname{Ir}_{19} \mathrm{Mn}_{81}$ (composição nominal dos alvos comerciais). Os ferromagnetos utilizados foram ligas de $\mathrm{Ni}_{x} \mathrm{Cu}_{1-x}$ com $\mathrm{x}$ variando entre 10 e 90 (para o NiO) ou entre 70 e 100 (para FeMn e IrMn). As curvas ZFC/FC das bicamadas com FeMn mostram comportamentos bem diferentes para as estequiometrias das camadas FM, com temperaturas de bloqueio entre $45 \mathrm{~K}$ e $50 \mathrm{~K}$ para as mair ricas em cobre.

Embora fatores como a sobreposição de tantos picos nos espectros de RBS e o baixo número de contagens nos difratogramas de raios-x tenham dificultado as análises, há alguns aspectos que inspiram confiança no sucesso das deposições: os picos de XRD relativos à $\mathrm{NiCu}$ se deslocam para ângulos maiores de maneira aproximadamente linear com a quantidade de níquel da liga. A estrutura fcc das ligas $\mathrm{NiCu}$ se mostrou suficiente para induzir o crescimento 0 das ligas FeMn e IrMn favorecendo os planos (111), com alguma variação de intensidade dependendo dos materiais.

Bicamadas com $\mathrm{T}_{C}<\mathrm{T}_{N}$ apresentam uma dependência de $\mathrm{H}_{C}$ e $\mathrm{H}_{E B}$ em relação à temperatura diferente das bicamadas convencionais $\left(\mathrm{T}_{C}>\mathrm{T}_{N}\right)$. Enquanto nessas $\mathrm{H}_{C}$ e $\mathrm{H}_{E B}$ costumam diminuir com a temperatura até $\mathrm{T}_{B} \leq \mathrm{T}_{N}$, as não-convencionais 
apresentam um pico de $\mathrm{H}_{C}$ e $\mathrm{H}_{E B}$ em uma temperatura logo abaixo de $\mathrm{T}_{C}$. Algumas das amostras estudadas, tal como visto na figura $3.12 \mathrm{~b}$ apresentam um comportamento semelhante a esse último, embora em outras seja tão sutil que se confunda com uma flutuação em torno de zero (como na figuras 3.7b).

Comparando as amostras de cada antiferromagneto, o que se observa é que as ligas com mais cobre possuem maior coercividade a baixas temperaturas. No entanto, ela cai mais rapidamente com o aumento da temperatura, fazendo com que fiquem menos coercivas do que as com mais níquel mesmo antes da temperatura ambiente ser alcançada.

A 5K, IrMn possui uma constante de troca maior que FeMn para o níquel puro, mas se torna bem menor à medida que o cobre é adicionado na liga. Ocorre o mesmo no VSM a temperatura ambiente, porém $\mathrm{J}_{\text {int }}$ do IrMn decai mais lentamente. O valor da constante de troca do FeMn é até maior na bicamada $\mathrm{Ni}_{90} \mathrm{Cu}_{10}$. Não são comportamentos muito esperados, mas os difratogramas nas figuras $3.5 \mathrm{~d}$ e principalmente $3.5 \mathrm{c}$ podem explicar isso: há sobreposição dos picos (111) do $\mathrm{FeMn}$ e $\mathrm{NiCu}$, principalmente para as ligas com mais cobre. Isso indica uma estrutura cristalina muito parecida para os dois materiais nessa direção, o que favorece a textura (111) para o FeMn, em contraste com o que ocorre com o IrMn (já que os átomos de irídio possuem um raio bem maior que o de ferro, manganês, níquel e cobre). No entanto, aqueles picos podem ser distingüidos no caso de níquel puro, indicando maior disparidade entre os parâmetros de rede para este caso, não favorecendo tanto o FeMn como nos casos com cobre. Desse modo, o níquel puro evidencia as propriedades dos antiferromagnetos de um modo mais independente do "buffer", fazendo com que a $\mathrm{J}_{\text {int }}$ do IrMn fique maior que a do FeMn, como seria esperado.

O NiO não se mostrou muito adequado para estes estudos. Com baixas constantes de troca e de anisotropia, o exchange bias e aumento de coercividade promovido pelo material em bicamadas é baixo (às vezes de difícil identificação), além de uma deposição mais complicada e demorada em RF sputtering por ser um óxido e demandar espessuras maiores.

Mesmo sem indução (voluntária) de anisotropia unidirecional, ela esteve presente em grande parte das bicamadas. As tentativas de usar o forno não tiveram êxito. É provável que a pressão utilizada na câmara não seja baixa o suficiente, degradando as amostras que foram submetidas ao tratamento térmico. O aumento na coercividade provavelmente se deve apenas ao ordenamento cristalino decorrente do lento resfriamento. A tentatíva de utilizar o SQUID para o tratamento térmico também não foi satisfatório 
para o incremento de exchange bias, uma vez que a tentativa resultou em um incremento da coercividade com redução de exchange bias.

Nas multicamadas, não foi identificado exchange bias, mas a coercividade se comportou como em uma amostra com anisotropia unidirecional em quase todos os casos, além de ter aumentado em comparação com cada bicamada correspondente em temperaturas acima de 5K. O motivo pode ser a interação entre as camadas ferromagnéticas, tornando o sistema efetivamente em uma bicamada com espessura ferromagnética aumentada, o que destrói o eschange bias mas não cancela a interação de troca na interface (que ainda aumenta o campo coercivo).

\subsection{Perspectivas}

É de grande importância verificar certas hipóteses feitas a respeito de alguns resultados obtidos neste trabalho.

Mudar a ordem de deposição das válvulas de spin para evitar o acoplamento da camada livre com o antiferromagneto seria o passo mais importante. Os parâmetros de deposição parecem adequados (apesar da análise complicada dos espectros RBS), possibilitando uma comparação direta a respeito da ordem das camadas.

Rever o método da indução de anisotropia unidirecional também é necessário. É possível utilizar um porta-amostra com ímã permanente para induzir a anisotropia ainda durante a deposição. Além disso, seria interessante tentar o tratamento térmico pós-deposição sob uma atmosfera inerte. Tais tentativas podem ser feitas nas amostras atuais, possibilitando outra comparação direta de procedimentos.

Após identificar os fatores de maior interesse, o estudo deve ser expandido com medidas de magnetorresistência e diagramas FORC ("curvas de inversão de primeira ordem", na sigla em inglês). 


\section{Referências Bibliográficas}

[1] J. M. D. Coey - Magnetism and Magnetic Materials, Cambridge University Press, Cambridge (2010) p. 19

[2] M. N. Baibich, J. M. Broto, A. Fert, F. Nguyen Van Dau, F. Petroff, P. Eitenne, G. Creuzet, A. Friederich, J. Chazelas - Physical Review Letters 61 (1988) 2472

[3] P. Grünberg, R. Schreiber, Y. Pang, M. B. Brodsky, H. Sowers - Physical Review Letters 57 (1986) 2442

[4] W. H. Meiklejohn, C. P. Bean - Physical Review 102 (1956) 1413

[5] W. H. Meiklejohn, C. P. Bean - Physical Review 105 (1957) 904

[6] A. P. Malozemoff - Physical Review B 35 (1987) 3679

[7] B. Dieny, V. S. Speriosu, S. S. P. Parkin, B. A. Gurney, D. R. Wilhoit, D. Mauri Physical Review B 43 (1991) 1297

[8] R. Schad, C. D. Potter, P. Beliën, G. Verbanck, V. V. Moshchalkov, Y. Bruynseraede - Applied Physics Letters 64 (1994) 3500

[9] I.R. McFadyen, E.E. Fullerton, M.J. Carey - MRS Bulletin 31 (2006) 379

[10] M. Julliere - Physics Letters A 54 (1975) 225

[11] B. Dieny, J. P. Gavigan, J. P. Rebouilla - Journal of Physics: Condensed Matter 2 (1990) 159

[12] M.-M. Chen, C. Tsang, N. Gharsallah - IEEE Transactions on Magnetics 29 (1993) 4077

[13] S. L. Burkett, S. Kora, J. L. Bresowar, J. C. Lusth, B. H. Pirkle, M. R. Parker Journal of Applied Physics 81 (1997) 4912

[14] H. N. Fuke, K. Saito, Y. Kamiguchi, H. Iwasaki, M. Sahashi - Journal of Applied Physics 81 (1997) 4004 
[15] T. B. Massalski, H. Okamoto - Binary Alloy Phase Diagrams vol 2, ASM International, Materials Park OH (1992) p. 1724-1725

[16] S. L. Cohen, M. A. Russak, J. M. Baker, T. R. McGuire, G. J. Scilla, S. M. Rossnagel - Journal of Vacuum Science \& Technology A 6 (1988) 918

[17] C. Tsang, N. Heiman, K. Lee - Journal of Applied Physics 52 (1981) 2471

[18] T. C. Schulthess, W. H. Butler, G. M. Stocks, S. Maat, G. J. Mankey - Journal of Applied Physics 85 (1999) 4842

[19] W. Kuch, L. I. Chelaru, F. Offi, J. Wang, M. Kotsugi, J. Kirschner - Physical Review Letters 92 (2004) 017201-1

[20] S. J. Kennedy, T. J. Hicks - Journal of Physics F: Metal Physics 17 (1987) 1599

[21] G. M. Stocks, W. A. Shelton, T. C. Schulthess, B. Újfalussy, W. H. Butler, A. Canning - Journal of Applied Physics 91 (2002) 7355

[22] R. Jungblut, R. Coehoorn, M. T. Johnson, J. aan de Stegge, A. Reinders - Journal of Applied Physics 75 (1994) 6659

[23] R. D. Hempstead, S. Krongelb, D. A. Thompson - IEEE Transactions on Magnetics 14 (1978) 521

[24] G. Choe, S. Gupta - Applied Physics Letters 70 (1997) 1766

[25] G. Wang, T. Yeh, C.-L. Lin, J. M. Sivertsen, J. H. Judy - IEEE Transactions on Magnetics 32 (1996) 4660

[26] T. Chatterji - Neutron Scattering from Magnetic Materials, Elsevier B.V., Grenoble (2005) p. 31-34

[27] W. L. Roth, G. A. Slack - Journal of Applied Physics 31 (1960) S352

[28] N. Ohshima, M. Nakada, Y. Tsukamoto - Japanese Journal of Applied Physics 35 (1996) L1585

[29] C.-H. Lai, H. Matsuyama, R. L. White, T. C. Anthony, G. G. Bush - Journal of Applied Physics 79 (1996) 6389

[30] A. Schron, C. Rodl, F. Bechstedt - Physical Review B 86 (2012) 115134 
[31] K. Watanabe, S. Tadokoro, T. Kawabe, M. Fuyama, H. Fukui, S. Narishige - Journal of The Magnetics Society of Japan 18 (1994) 355

[32] Y. Hamakawa, H. Hoshiya, T. Kawabe, Y. Suzuki, R. Arai, K. Nakamoto, M. Fuyama, Y. Sugita - IEEE Transactions on Magnetics 32 (1996) 149

[33] W. H. Meiklejohn - Journal of Applied Physics 33 (1962) 1328

[34] D.-H. Han, J.-G. Zhu, J. H. Judy, J. M. Sivertsen - Journal of Applied Physics 81 (1997) 340

[35] S. Soeya, S. Nakamura, T. Iamgawa, S. Narishige, Journal of Applied Physics 77 (1995) 5838

[36] C. Schlenker, Physica Status Solidi (b) 28 (1968) 507

[37] C.-H. Lai, T. C. Anthony, E. Iwamura, R. L. White - IEEE Transactions on Magnetics 32 (1996) 3419

[38] S. Soeya, T. Imagawa, K. Mitsuoka, S. Narishige - Journal of Applied Physics 76 (1994) 5356

[39] M. J. Carey, A. E. Berkowitz - Applied Physics Letters 60 (1992) 3060

[40] C.-H. Lai, W. E. Bailey, R. L. White, T. C. Anthony - Journal of Applied Physics 81 (1997) 4990

[41] H. D. Chopra, B. J. Hockey, P. J. Chen, R. D. McMichael, W. F. Egelhoff, Jr. Journal of Applied Physics 81 (1997) 4017

[42] S. Soeya, M. Fuyama, S. Tadokoro, T. Imagawa - Journal of Applied Physics 79 (1996) 1604

[43] K. Hoshino, R. Nakatani, H. Hoshiya, Y. Sugita - Japanese Journal of Applied Physics 35 (1996) 607

[44] H. Okamoto - Journal of Phase Equilibria 17 (1996) 60

[45] G. Anderson, Y. Huai, L. Miloslawsky - Journal of Applied Physics 87 (2000) 6989

[46] R. Nakatani, H. Hoshiya, K. Hoshino, Y. Sugita - Journal of Magnetism and Magnetic Materials 173 (1997) 321 
[47] S. Nicolodi, L.G. Pereira, J.E. Schmidt, L.C.C.M. Nagamine, A.D.C. Viegas, C. Deranlot, F. Petroff, J. Geshev - Physica B 384 (2006) 141

[48] T. Umemoto, A. Maeda, S. Takahashi, T. Tanuma, M. Kume - Japanese Journal of Applied Physics 36 (1997) 6746

[49] J. R. Childress, M. J. Carey, R. J. Wilson, N. Smith, C. Tsang, M. K. Ho, K. Carey, S. A. MacDonald, L. M. Ingall, B. A. Gurney - IEEE Transactions on Magnetics 37 (2001) 1745

[50] M. J. Carey, N. Smith, B. A. Gurney, J. R. Childress, T. Lin - Journal of Applied Physics 89 (2001) 6579

[51] I. V. Roschin, O. Petracic, R. Morales, Z. P. Li, X. Batlle, I. K. Schuller - Europhysics Letters 71 (2005) 297

[52] S. Anandakumar, V. S. Rani, S. Oh, C. G. Kim - Thin Solid Films 519 (2010) 1020

[53] R. M. Bozorth - Phisical Review Letters 1 (1951) 362

[54] P. W. Anderson, H. Suhi - Phisical Review 116 (1959) 898

[55] C. Rossel - Il Nuovo Cimento D 2 (1983) 1834

[56] A. I. Buzdin, L. N. Bulaevskil, S. V. Panyuko - JETP Letters 35 (1982) 178

[57] A. I. Buzdin - Reviews of Modern Physics 77 (2005) 935

[58] P. Nash - Phase Diagrams of Binary Nickel Alloys, ASM International, Materials Park OH (1991) p. 88 e 85-97

[59] E. Y. Nekhendzi, N. P. Kharitonov - Measurement Techniques 5 (1962) 31

[60] - K. L. Chopra, S. K. Bahl, M. R. Randlett - Journal of Applied Physics 39 (1968) 1525

[61] D. C. Jiles, T. T. Chang, D. R. Hougen, R. Ranjan - Journal of Applied Physics 64 (1988) 3620

[62] N. F. Mott - Proceedings of the Royal Society London A 153 (1936) 699

[63] P. P. Craig, W. I. Goldburg, T. A. Kitchens, J. I. Budnick - Phisical Review Letters 19 (1967) 1334 
[64] G. Iannone, D. Zola, A. Angrisani Armenio, M. Polichetti, C. Attanasio - Physical Review B 75 (2007) 064409

[65] F. C. Zumsteg, R. D. Parks - Phisical Review Letters 24 (1970) 520

[66] X. W. Wu, C. L. Chien - Physical Review Letters 81 (1998) 2795

[67] K. D. Sossmeier, L. G. Pereira, J. E. Schmidt, J. Geshev - Journal of Applied Physics 109 (2011) 083938

[68] M. G. Blamire, M. Ali, C.W. Leung, C. H. Marrows, B. J. Hickey - Physical Review Letters 98 (2007) 217202

[69] https://en.wikipedia.org/wiki/File:Bragg_diffraction_2.svg (acesso em Junho de 2015)

[70] W. P. Davey - Physical Review 25 (1925) 753

[71] G. Choe, S. Gupta - IEEE Transactions on Magnetics 33 (1997) 3691

[72] T. Lin, C. Tsang, R. E. Fontana, J. K. Howard - IEEE Transactions on Magnetics 31 (1995) 2585

[73] J. Geshev, S. Nicolodi, L. G. Pereira, L. C. C. M. Nagamine, J. E. Schmidt, C. Deranlot, F. Petroff, R. L. Rodríguez-Suárez, A. Azevedo - Physical Review B 75 (2007) 214402

[74] M. J. M. Pires, R. B. de Oliveira Jr, M. D. Martins, J. D. Ardisson, W. A. A. Macedo - Journal of Physics and Chemistry of Solids 68 (2007) 2398 